\title{
Current trends towards the synthesis of bioactive heterocycles and natural products using 1,3-dipolar cycloadditions (1,3-DC) with azomethine ylides
}

\author{
H. Ali Döndasa,* \\ María de Gracia Retamosab \\ José M. Sansanoc \\ a Mersin University, Faculty of Pharmacy. Yenisehir Campus \\ 33169 Yenisehir, Mersin (Turkey). \\ ${ }^{\mathrm{b}}$ Instituto de Investigaciones Químicas (CSIC-US) and Centro de \\ Innovación en Química Avanzada (ORFEO-CINQA) Avda. \\ Américo Vespucio, 49,41092 Sevilla (Spain). \\ c Departamento de Química Orgánica, Instituto de Síntesis \\ Orgánica (ISO) and Centro de Innovación en Química Avanzada \\ (ORFEO-CINQA), University of Alicante-03080 Alicante (Spain). \\ * indicates the main/corresponding author. \\ yakdas25@mersin.edu.tr
}

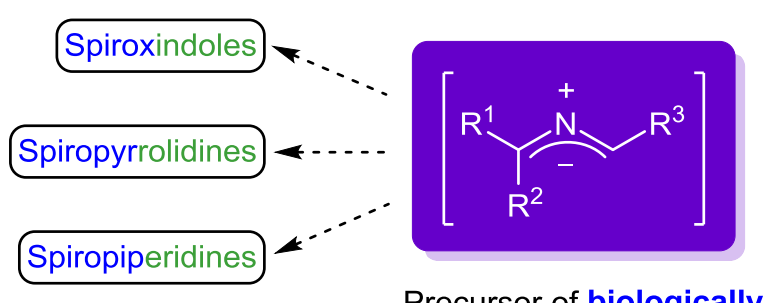

Precursor of biologically active compounds and

natural products

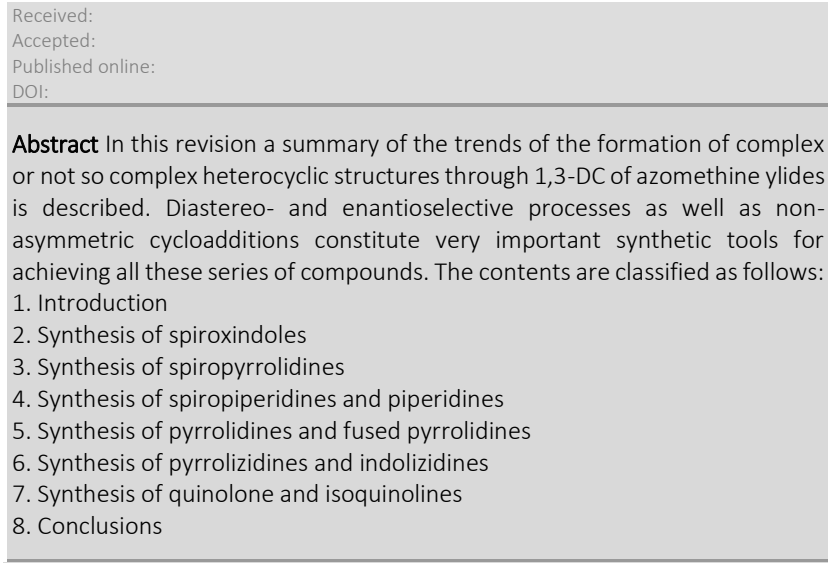

Key words Azomethine ylide dipolar cycloaddition - natural products bioactivity - heterocycles

\section{Introduction}

Biomimetic studies and biosynthetic theories strongly support that general $[3+2]$ cycloadditions $^{1}$ take place frequently in nature. $^{2}$ In this line, azomethine ylides are useful synthetic intermediates to access complex molecules, and in consequence, their precursors are valuable building blocks in the elaboration of structurally diverse biologically important heterocycles and natural products. The main utility of these dipolar intermediates is as component of 1,3-dipolar cycloaddition (1,3-DC) together with electrophilic alkenes. Inter- and intramolecular versions of these types of 1,3-DCs provide a potentially flexible and versatile entry into the complex molecular framework with a pyrrolidine core. These cycloadditions reach a special dimension when the catalytic enantioselective process is successfully implemented. In this way, up to four contiguous stereogenic centers can be unambiguously generated in just one single step.

There are many excellent reports and reviews in the literature about the generation, and applications concerning 1,3-DCs with azomethine ylides but this field is in continuous expansion. ${ }^{3}$ In this review the literature from 2015 through 2016 was covered organizing the research in terms of biologically important heterocycles and natural product from cascade 1,3-DC of azomethine ylide to the most simple cycloaddition [the application of this strategy to the generation of new materials or polymers is not covered in this review].

\section{Synthesis of spirooxindoles}

Spirooxindole skeleton has an important biological role in bioorganic and medicinal chemistry as well as in the drug discovery programs. ${ }^{4}$ Synthesis of novel potentially bioactive spirooxindoles has been reviewed in a recent paper and the work related to spirooxindolepyrrolidines was also detailed. ${ }^{5}$ However, in this review some very recent publications have not been highlighted. Therefore, in this revision the most recent work regarding to spiroxindolepyrrolidines, obtained from a multicomponent 1,3-dipolar cycloaddition (1,3-DC) of azomethine ylides with the appropriate alkene, is reported.

The synthesis of spirooxindolepyrrolizidine derivatives $\mathbf{4}$ and 4', as well as their in vitro bioactivity against Mycobacterium tuberculosis, were reported by Askri et al. Compounds 4 and 4' were prepared from non-stabilized azomethine ylides, generated in situ from isatin derivatives 2 and L-proline 1. Subsequent 1,3DC with (E,E)-1,3-bis(arylidene)indan-2-ones 3 yielded the 
corresponding dispirooxindolepyrrolizidines in a one-pot three component domino reaction with poor diastereoselectivities (Scheme 1).6, 7 In general, in these type of cycloadditions regarding iminium-decarboxylation route, the iminium salt I formed between compounds $\mathbf{1}$ and $\mathbf{2}$ undergoes a spontaneous decarboxylation to give the intermediate azomethine ylide II, which reacts with the electrophilic alkene with total regioselection.

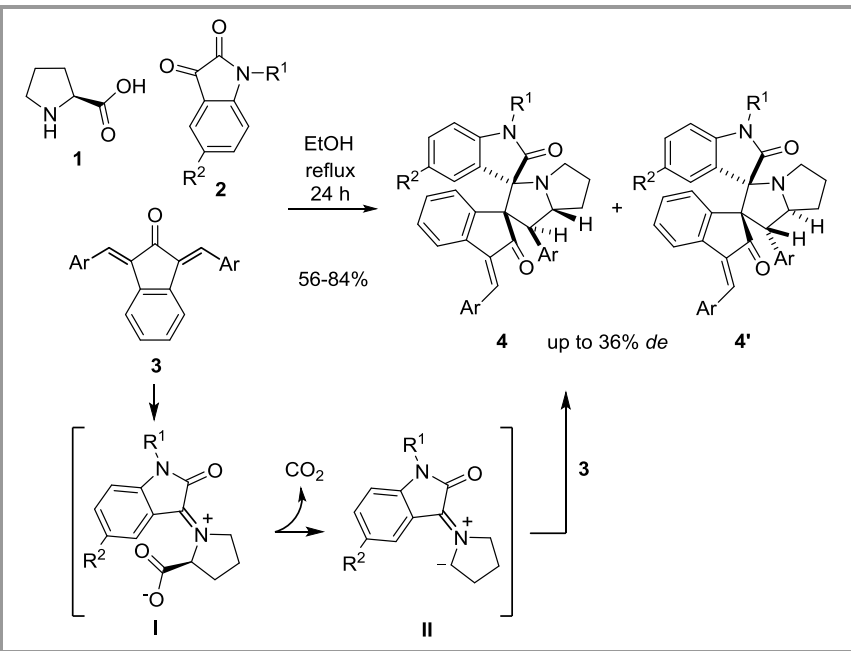

Scheme 1 Synthesis of diastereomeric mixtures of spirooxindoles 4 and $\mathbf{4}^{\prime}$

An environmentally friendly synthesis of spirooxindolopyrrolizidines 6 was reported by Tiwari et al. starting from proline $\mathbf{1}$, isatins $\mathbf{2}$, and acrylonitrile or methylacrylate in water. The reaction proceeded regioselectively in a three-component manner. Again, the in situ generation of fleeting non-stabilized azomethine ylide, and subsequent 1,3-DC reaction with these electron deficient alkenes $\mathbf{5}$ as dipolarophiles, afforded biologically active spirooxindolopyrrolizidine derivatives $\mathbf{6}$ (Scheme 2). ${ }^{8}$

A variant of this green process was the 1,3-DC run with a MoritaBaylis-Hillman (MBH) adduct 7 (Scheme 2), derived from pyridine-4-carboxaldehyde and lauryl acrylate, giving similar spirocycloadducts in good yields but employing toluene instead of water. ${ }^{9}$

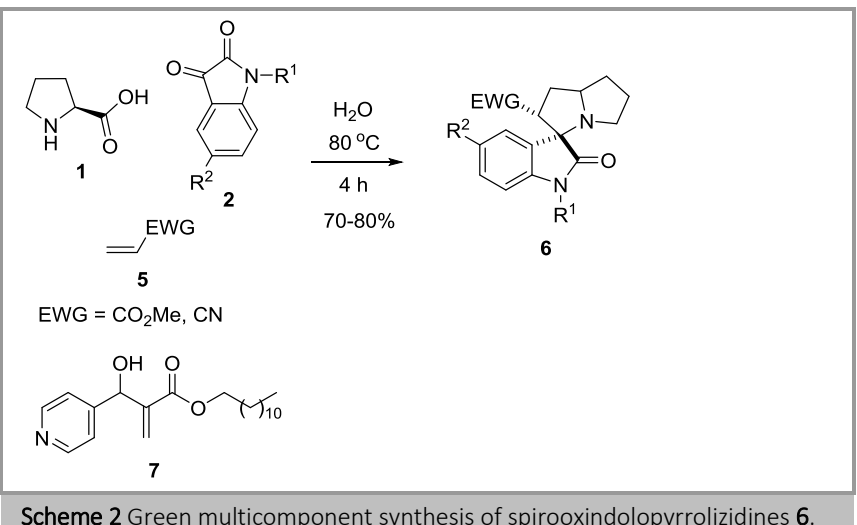

Scheme 2 Green multicomponent synthesis of spirooxindolopyrrolizidines 6 .
Potentially bioactive spiroheterocycles 10, containing both spirooxindole and pyrrolizidine core structures, were enantioselectively prepared by Taghizadeh and co-workers. The 1,3-DC was carried out in the presence of $\mathrm{Cu}(\mathrm{OTf})_{2}$. bis(arylmethyleneamine) $\mathbf{9}$ chiral complex, ethanol, proline 1, isatins 2, and acrylic dipolarophiles 8 under mild conditions (Scheme 3).10

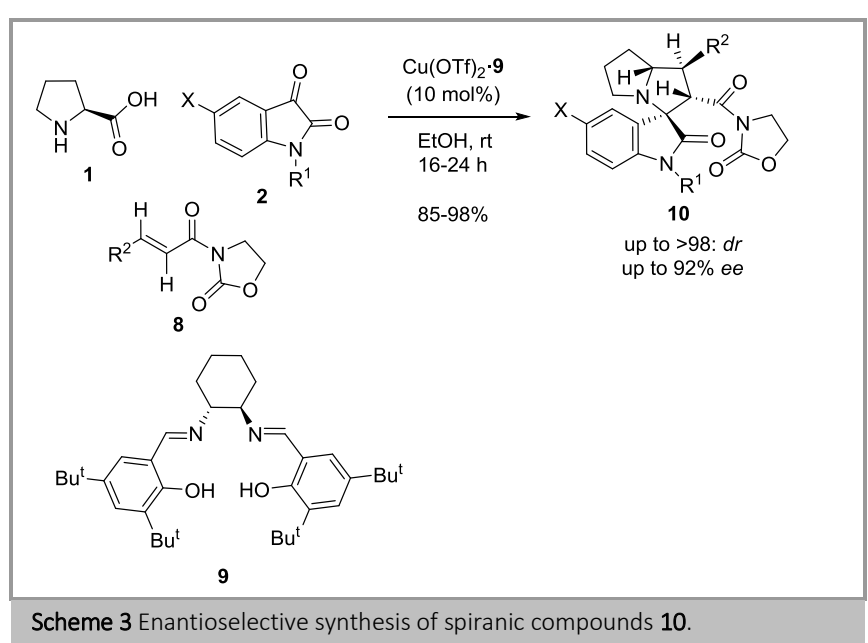

Highly activated tetraethyl vinylidene-1,2-(bis)phosphonate $\mathbf{1 1}$ was allowed to react with isatins 2 and various amino acids (proline 1, sarcosine 13, or piperidine-2-carboxylic acid 14) in the presence of montmorillonite as catalyst. The 1,3-DC occurred in refluxing acetonitrile obtaining spirotetracyclic adducts $\mathbf{1 2}$ as a mixture of diastereoisomers in moderate to good yields (Scheme 4). ${ }^{11}$

$$
\text { Scheme 4 Preparation of spirooxindoles } 12 \text { bearing geminal bisphosphonate }
$$

Alkylidene oxazolones $\mathbf{1 5}$ were selected as dipolarophiles to synthesize biologically important spirooxindole frameworks 16. Diverse isatins 2 and a variety of amino acids such as glycine $\mathbf{1 7}$, sarcosine 13, L-proline 1, or thiazolidine-4-carboxylic acid 18, afforded, in a one-pot tricomponent process, regio- and diastereoselective 1,3-DCs (Scheme 5). Biological evaluation of 
compounds 16 against several cancer cell-lines revealed that some of them possessed antitumor activity. ${ }^{12}$

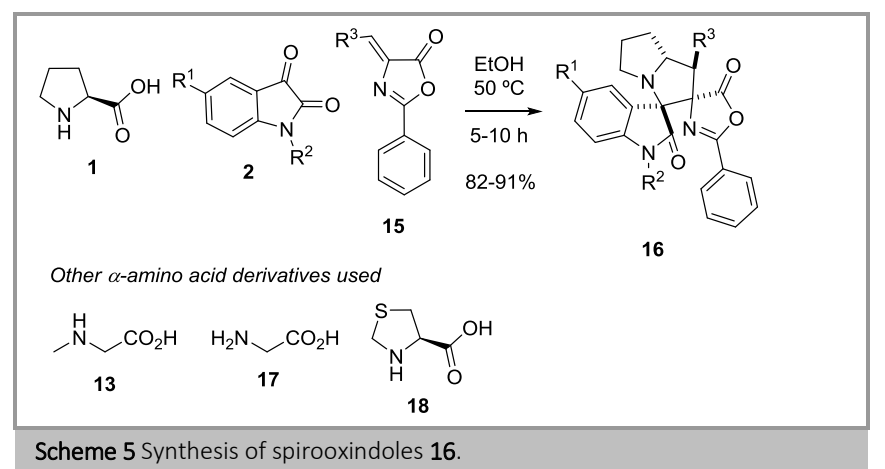

A range of potentially bioactive substituted dispiropyrrolidines/-imidazolidines $\mathbf{2 3}$ were prepared in the presence of copper(I) thiophene-2-carboxylate (CuTC) catalyst in refluxing 1,2-dichloroethane (1,2-DCE). Here, the in situ generated imine III reacted with the copper(I)-carbene (obtained by decomposition of diazocompound 21) giving a fleeting aziridine, which evolved thermally to azomethine ylide IV (Scheme 3). The reaction proceeded chemo-, regio-, and diastereoselectively in very good yields. The complexity of the resulting products $\mathbf{2 3}$ is obvious because two of the four generated stereogenic centers are quaternary carbons (Scheme 6). ${ }^{13}$

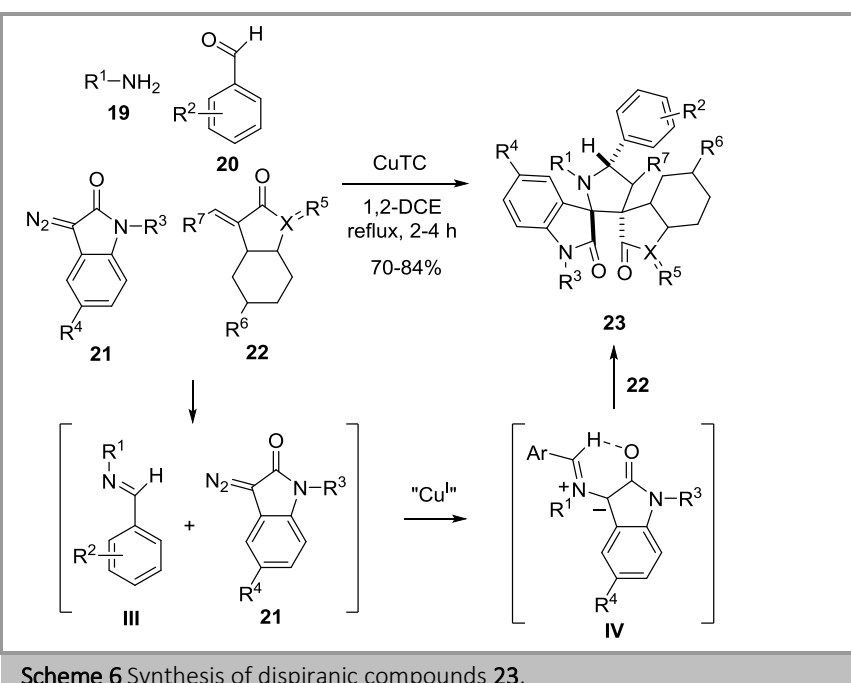

Spirooxindolepyrrolidines $25(\mathrm{n}=1)$ and an example of spirooxindolepiperidine $\mathbf{2 5}(\mathrm{n}=2)$ fused to nitrochromanes were prepared from isatin 2 and proline 1 or pipecolic acid $\mathbf{1 4}$ as azomethine ylide sources. The 1,3-DC occurred in refluxing ethanol (Scheme 7), and proceeded with total control of the diastereoselectivity. ${ }^{14}$

A similar cycloaddition with electrophilic alkenes 26, instead of using nitroalkene 24, was performed. The cycloaddition proceeded chemo-, stereo- and regioselectively throughout the styrene moiety. ${ }^{15}$ In other contribution, (2-nitrovinyl)imidazoles 27 (Scheme 7) were allowed to react under similar reaction conditions producing a 95:5 ratio of the corresponding spirocycloadducts. ${ }^{16}$

Trihalomethyl-substituted nitroethylenes 28 (Scheme 7) were selected as dipolarophiles to prepare a variety of biologically active spirooxoindolepyrrolidines, which may be of interest for medicinal chemistry. ${ }^{17}$

Analogously, new designed glycol-3-nitrochromenes $\mathbf{2 9}$ and $\mathbf{3 0}$ (Scherme 7), derived from glyco- $\beta$-nitroalkenes and salicylaldehyde, were tested as dipolarophiles in refluxing acetonitrile to give the corresponding biologically active sugarbearing spirooxindole cycloadducts as single diastereoisomers in good yields. ${ }^{18}$

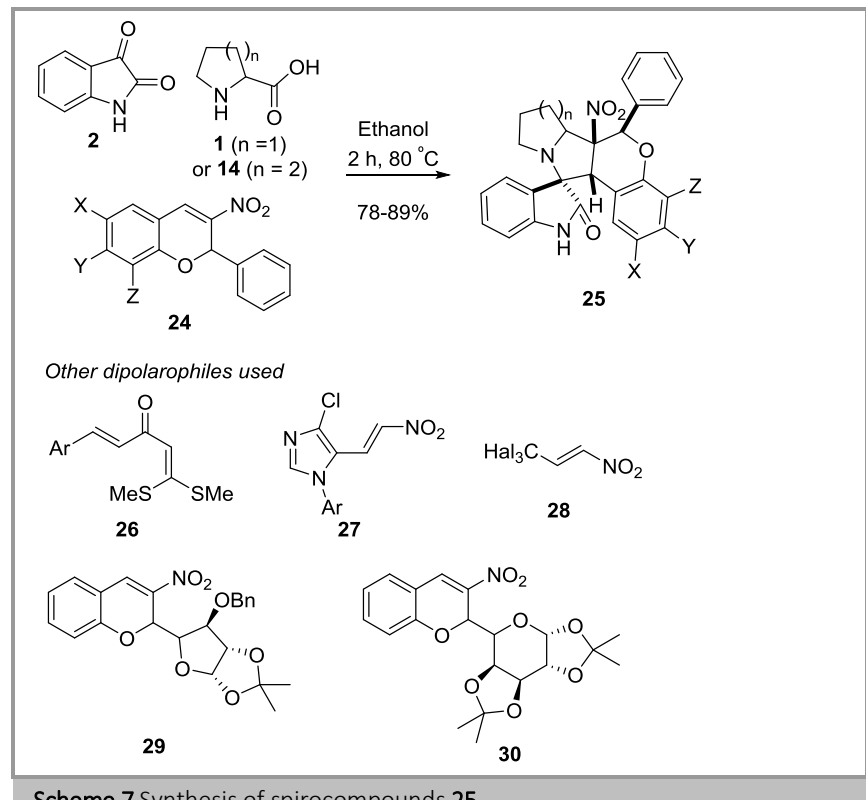

Scheme 7 Synthesis of spirocompounds 25 .

Spirooxindoles 32, bearing quinoline, pyrrolidine, pyrrolothiazole and indolizine ring system hetereocycles, were prepared by Kumar et al. from, sarcosine 13, isatin 2 and potential bioactive dipolarophiles 31, derived from pyrazolo[3,4b]quinolone, such as it is shown in Scheme 8. The ecofriendly reaction was achieved via in situ generated azomethine ylide and stereoselective 1,3-DC in a three-component sequential atom economy processes. ${ }^{19}$ This protocol was extended to another components such as, thiazolidine-4-carboxylic acid $\mathbf{1 8}$ and piperidine-2-carboxylic acid 14, together with acenaphthenequinone $\mathbf{3 3}$, to access potential bioactive diverse spiro-tethered pyrazolo quinoline heterocycles 34-37 (Scheme 8). 

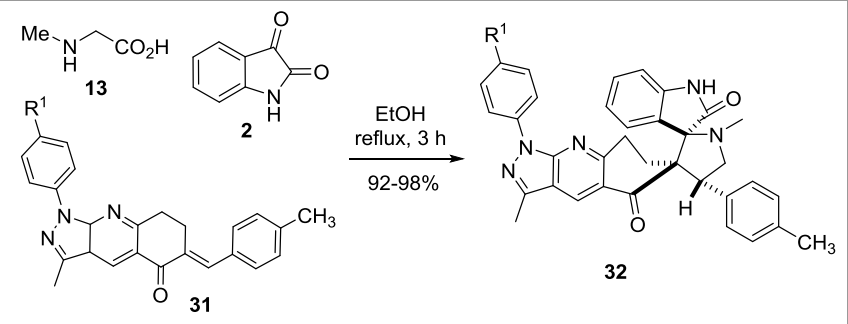

Other $\alpha$-amino acid derivatives used

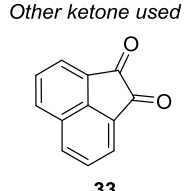

Several polycyclic compounds isolated using this methodology $\mathrm{R}^{1}$
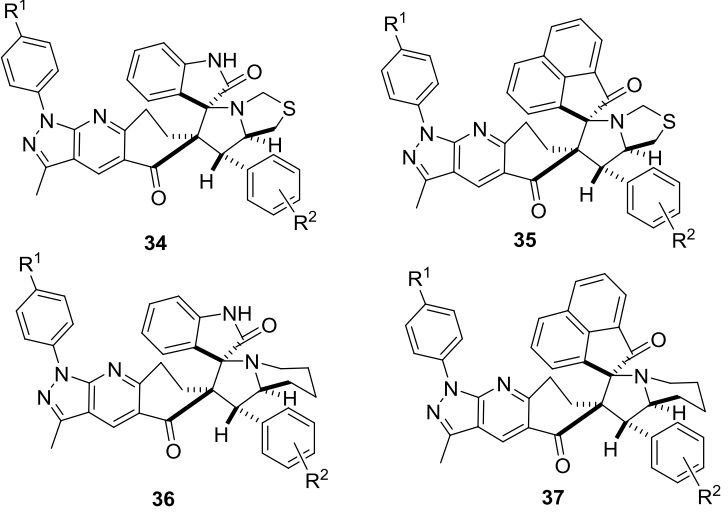

Scheme 8 Synthesis of spiroxindoles $32,34-37$, from pyrazolo[3,4-b]quinolone 31.

From symmetric dipolarophiles $\mathbf{3 8}$, sarcosine $\mathbf{1 3}$, and isatin derivatives $\mathbf{2}$, a series of dispirooxindoles $\mathbf{3 9}$ were obtained in high diastereoselections. They showed higher potency, against the HeLa (cervical) tumor cell line, than reference cisplatin derivatives (Scheme 9). ${ }^{20,21}$ In addition, it was discovered that these molecules exhibited antitumor activity against hepatocellular cancer (HEPG2) cell line, ${ }^{22}$ breast cancer (MCF7, T-47D) and colon cancer (HCT116). ${ }^{23}$

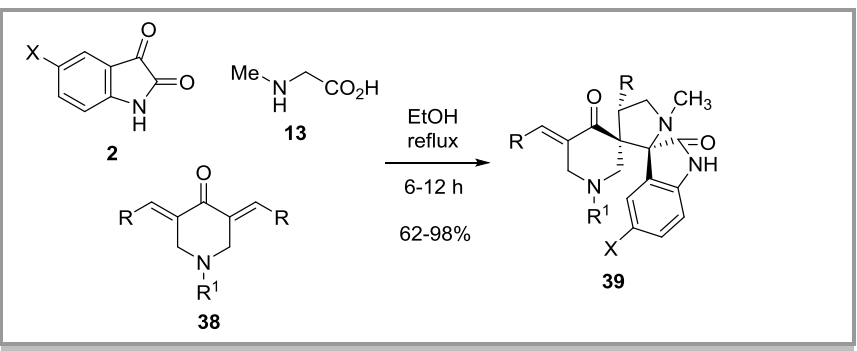

Scheme 9 Generation of dispiroxindoles 39.

Synthesis of sugar-containing spirocyclic pyrrolidine derivatives 41 were reported by Raghunathan et al. Here, $\alpha$-aminoacids, ketones and electrophilic olefin $\mathbf{4 0}$ incorporating a sugar moiety were allowed to react via 1,3-DC (Scheme 10). Proline 1, sarcosine 13, tetrahydroisoquinolinic acid $\mathbf{4 2}$ or pipecolinic acid 14 and acenaphthoquinone 33 , isatin 2 , or indenoquinoxalinone
43 were employed in this cascade protocol to access a variety of biologically important spiroheterocyclic compounds $\mathbf{4 1}$ as single diastereoisomers. ${ }^{24}$ Regio- and diastereo-selective 1,3-DC also afforded dispirooxindolopyrrolidines in a similar way, but employing 3-arylmethylidene-5-phenyl-3H-furan-2-ones $\mathbf{4 4},{ }^{25}$ or 3,5-diarylmethylenespiro[indole-30,2- [1,3]thiazolane]20(1H)-4-diones $\mathbf{4 5}$ as dipolarophiles (Scheme 10). ${ }^{26}$

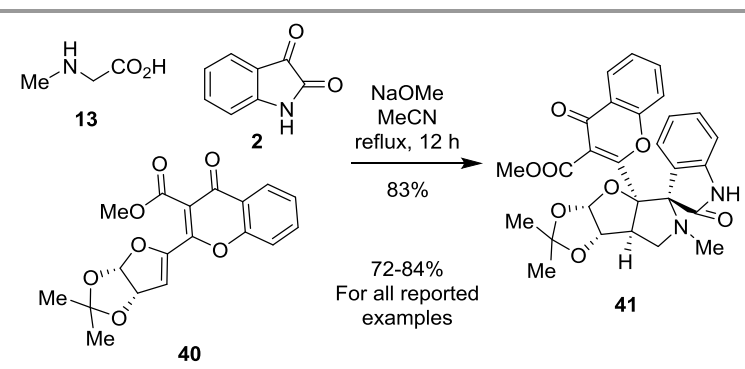

Other $\alpha$-amino acid derivative used

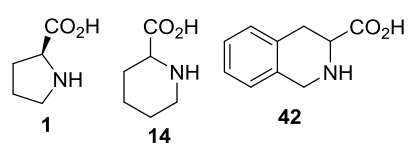

Other ketone used

Other dipolarophiles used<smiles>[R]C=C1C=C(c2ccccc2)OC1=O</smiles><smiles>O=C1/C(=C/[Al])SC2(C(=O)Nc3ccccc32)N1[Te]</smiles>

45

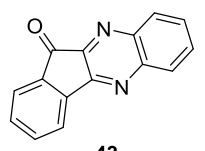

43

Scheme 10 Synthesis of sugar-containing spirocyclicpyrrolidines 41 .

Another potential bioactive dispirooxindolo derivatives $\mathbf{4 8}$ were described by Mondal and co-workers from $\mathrm{N}$-benzyl glycine $\mathbf{4 6}$ and isatins $\mathbf{2}$ or acenaphthoquinone $\mathbf{3 3}$ with andrographolide 47, isolated from A. paniculata, as dipolarophile (Scheme 11). Their cytotoxic potential and antitimural activity of these spiroheterocycles $\mathbf{4 8}$ displayed more potency against MCF-7 breast cancer cell line when comparing andrographolide $\mathbf{4 7}$ itself. 27

This promising activity, confirmed by biological tests, moved to the authors to elaborate new semisynthetic antitumor spirooxindole frameworks from acenaphthoquinone $\mathbf{3 3}$ (or isatin 2 derivatives) and secondary amino acids such as sarcosine 13, and proline $1 .{ }^{28}$ 


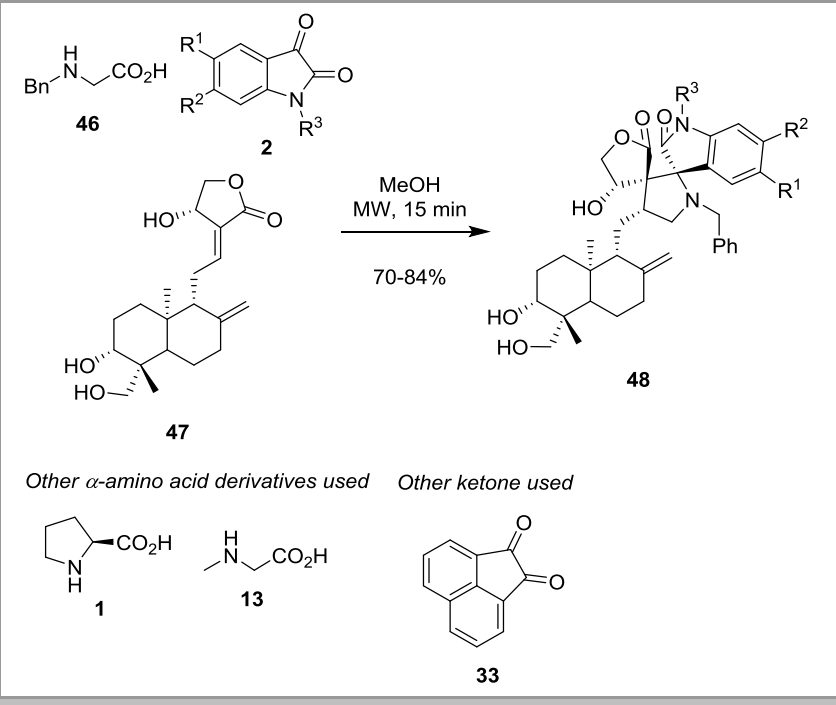

Scheme 11 Synthesis of dispiroandrographolide-type cycloadducts 48 via 1,3DC of azomethine ylides.

Dispiroxindole heterocycles 50, possessing dihydroanthracene ring system, were diastereoselectively prepared by Arumugam et al. in the presence of an ionic liquid (1-butyl-3methylimidazolium bromide [bmim]Br), isatin 2, sarcosine 13 and 10-benzylideneanthracen-9 $(10 H)$-one derivatives 49 (Scheme 12).29

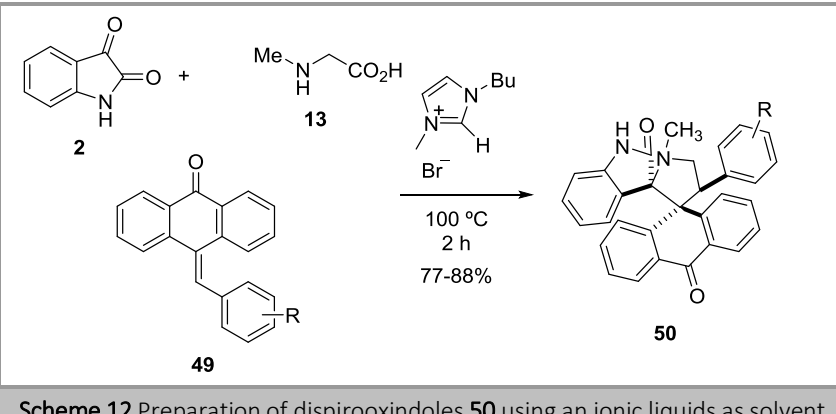

A series of spiroxindolepyrrolidines $\mathbf{5 3}$ showing potential cholinesterase inhibitory activity were prepared by Kumar et al. In ionic liquid medium the 1,3-DCs of the azomethine ylide, formed with 1,2-diketones, such as isatins $\mathbf{2}$ or acenaphthenequinone 33, and tryptophan 51, with arylmethylidene inden-1-ones $\mathbf{5 2}$, were successfully achieved. A representative example is shown in Scheme 13.30 Other dispirooxindolopyrrolidines were prepared using 1-butyl-3methylimidazolium bromide by mixing the corresponding amino acid, isatin 2, and (E)-2-oxoindolino-3-ylideneacetophenones $\mathbf{5 4 .}{ }^{31}$

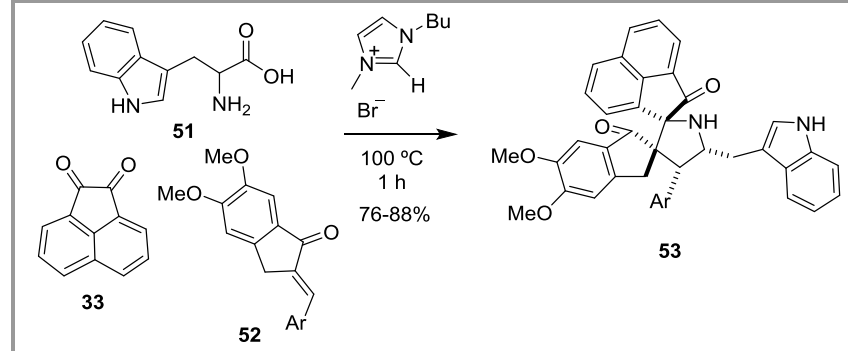

Other dipolarophiles used<smiles>[R]c1ccc(C(=O)/C=C2/C(=O)Nc3ccccc32)cc1</smiles>

Scheme 13 Potential cholinesterase inhibitors 53 obtained via 1,3-DC

Biologically important aryl-/heteroaryl-substituted functionalized spiroxindole derivatives $\mathbf{5 6}$ were obtained employing electrophilic alkenes $\mathbf{5 5}$ containing an indole unit. Apart from isatins $\mathbf{2}$ and proline $\mathbf{1}$, other components such as acenaphthoquinone 33 or ninhydrin 57, sarcosine 13 and alkenes $\mathbf{5 8}$ (bonded to a pyrrole ring) were successfully tested. In general, the chemical yields and the diastereoselections were very high (Scheme 14). ${ }^{32}$

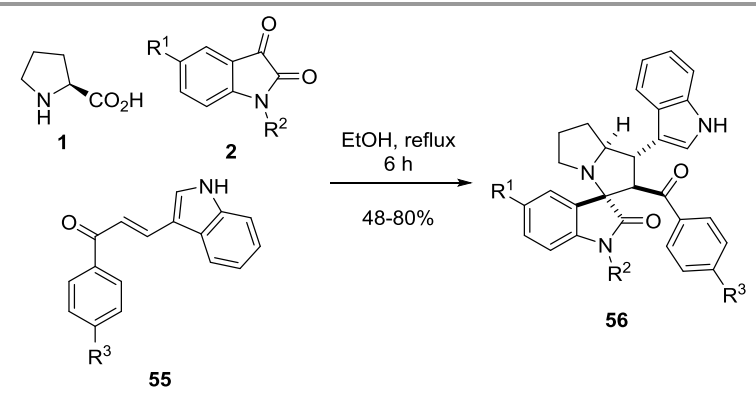

Other $\alpha$-amino acid derivative used Other dipolarophile used
$\stackrel{\mathrm{Me}}{\mathrm{H}} \underset{13}{\mathrm{~N}} \widehat{\mathrm{CO}_{2} \mathrm{H}}$

Other ketones used<smiles>O=C1C(=O)c2cccc3cccc1c23</smiles><smiles>O=C1c2ccccc2C(=O)C1(O)O</smiles>

33<smiles>[R]c1ccc(C(=O)/C=C/c2cccn2C)cc1</smiles>

Scheme 14 Sythesis of biologically important aryl-/heteroaryl-substituted cycloadducts 56 .

Spiroxindole-fused cycloadducts $\mathbf{6 0}$ and $\mathbf{6 1}$ were reported by Perumal et al. from 1,3-thiazolane-4-carboxylic acid $\mathbf{1 8}$ or sarcosine $\mathbf{1 3}$ and substituted isatins $\mathbf{2}$ as source of azomethine ylide intermediates. The 1,3-DC with benzimidazolphenylacrylonitrile $\mathbf{5 9}$ as dipolarophile occurred, in refluxing methanol, in very high yields and excellent diastereoselections (Scheme 15). This protocol, operating in a one-pot three-component manner, ${ }^{33}$ was employed in the 
reactions involving nitrile 62 (Scheme 15). The combination of 62 with isatin derivatives 2 and with the corresponding $\alpha$-amino acid $(1,13$, or 18$)$ furnished biologically important cycloadducts with very interesting activities against bacteria and fungi. ${ }^{34}$

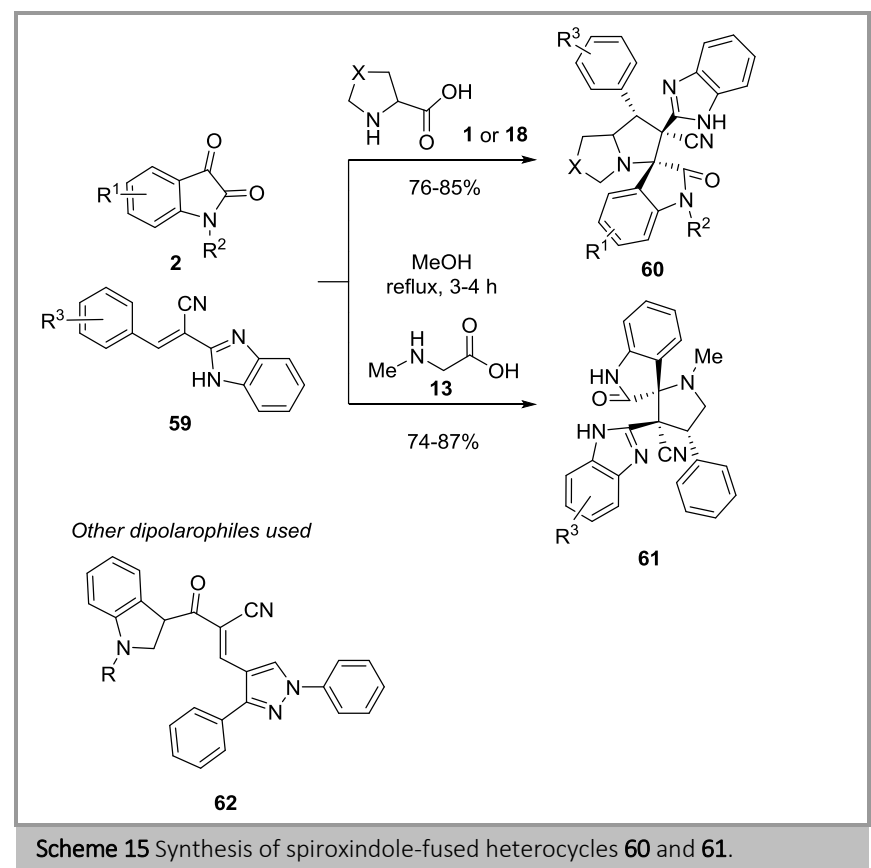

Preparation of dispiro-acenaphthylen-2-one curcuminoids 64 and 65 were described by Mondal et al. from acenaphthoquinone $\mathbf{3 3}$ and proline $\mathbf{1}$ as precursors of the corresponding azomethine ylide, together with curcumin $\mathbf{6 3}$ as dipolarophile. This attractive natural compound allowed the preparation of spirocycloadducts as 1:1 mixture of $\mathbf{6 4}$ and $\mathbf{6 5}$ in good yield after a double 1,3-DC (Scheme 16). ${ }^{35}$

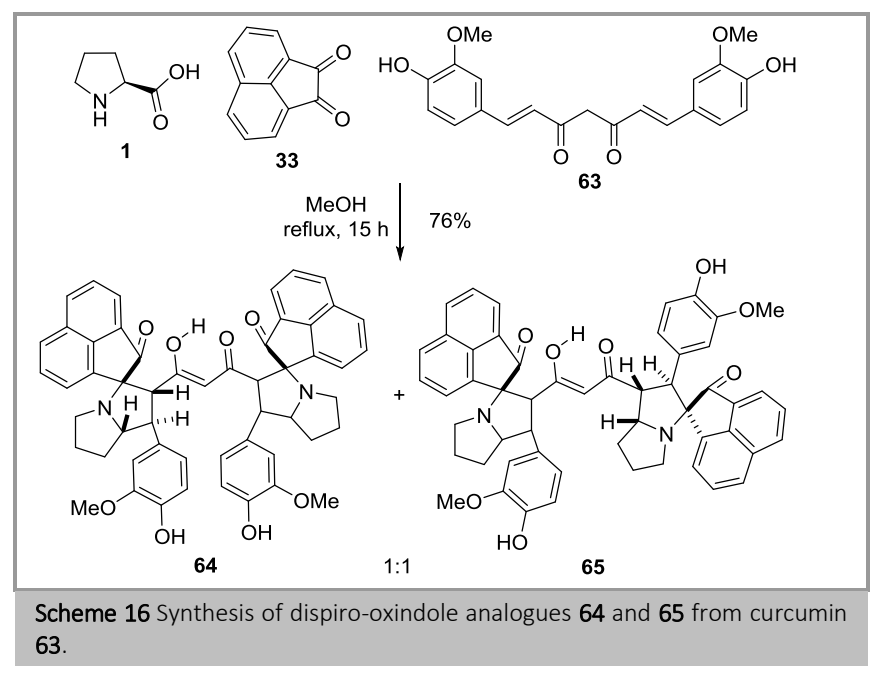

Synthesis of spirooxindolepyrrolizines $\mathbf{6 9}$, bearing a 1,2,3triazole moiety, was reported by Khurana et al. via stereo- and regioselective 1,3-DC. The in situ generated azomethine ylide $\mathbf{V}$ in glacial acetic acid triggered this one-pot four component domino strategy (Scheme 17). This cascade reaction involved the formation of the triazole derived from $N$-propargylated isatin $\mathbf{6 7}$ and aryl azides $\mathbf{6 6}$ in the presence of copper(II) sulfate. Then, the reaction with L-proline $\mathbf{1}$ or sarcosine $\mathbf{1 3}$ and decarboxylation of the resulting intermediate afforded the corresponding azomethine ylide $\mathbf{V}$, which reacted with coumarin-3-carboxylic acid 68 as dipolorophile giving the desired spirooxindoles 69 in very good yields (Scheme 17). ${ }^{36}$

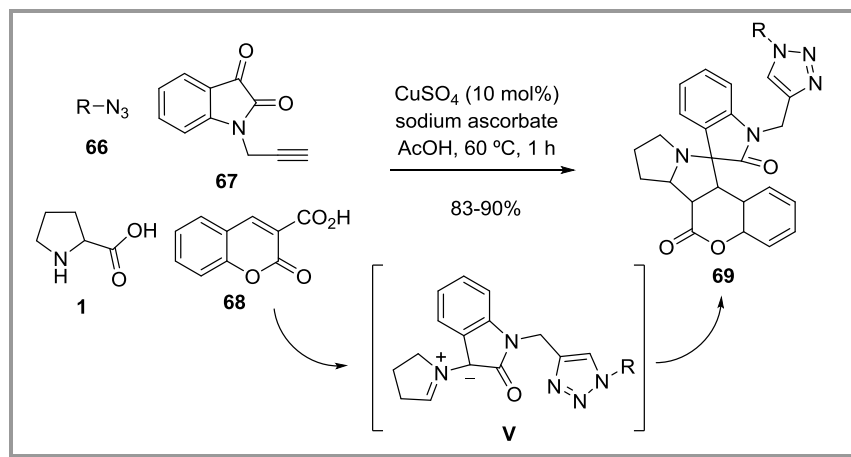

Scheme 17 Synthesis of spirooxindolepyrrolizines fused to coumarin ring heterocycles 69

Dispirooxindolepyrrolidines $\mathbf{7 1}$ were reported by Singh et al. and prepared from sarcosine 13, isatins 2 with $N$-aryl-3-benzylidenepyrrolidine-2,5-diones $\mathbf{7 0}$ as dipolarophiles. These products were diastereoselectively isolated in high yields (Scheme 18)..$^{37}$ Glycine $\mathbf{1 7}$ or sarcosine $\mathbf{1 3}$ with isatins 2,38 or even proline $\mathbf{1}$ plus acenaphthenequinone 33 or indenoquinoxaline-11-one $\mathbf{4 3}$ were also essayed in the presence of dipolarophiles $\mathbf{7 0 . 3 9}$

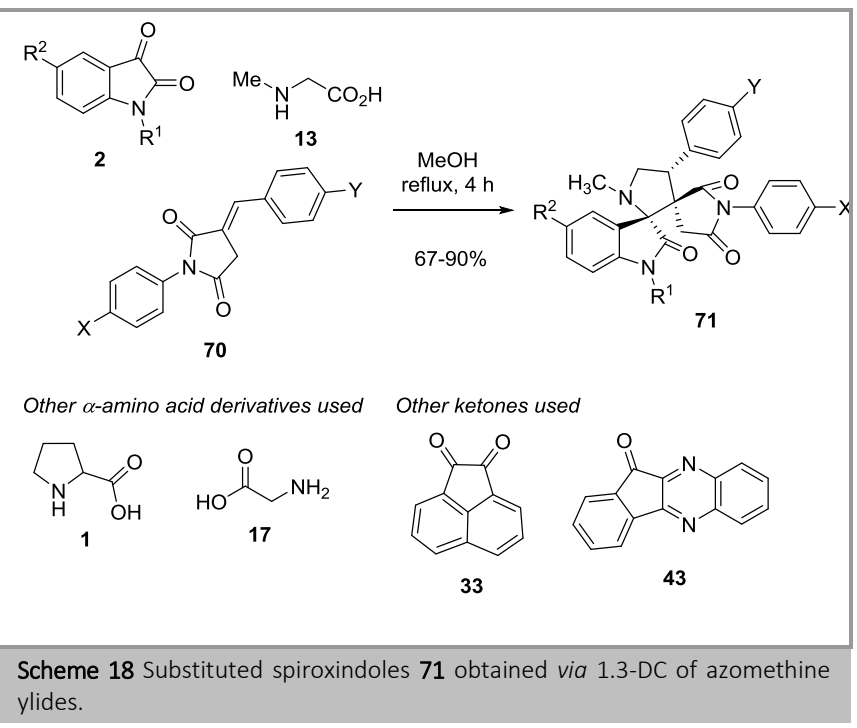

Spiro-pyrrolizidinooxindoles $\mathbf{7 3}$ and $\mathbf{7 4}$, derived from isatins $\mathbf{2}$ or acenaphthoquinone 33, respectively, bearing a withaferin-A system were isolated by Mondal and co-workers. Proline $\mathbf{1}$ was selected as precursor of the azomethine ylide, which furnished exclusively cis-fused cycloaducts $\mathbf{7 3}$ and $\mathbf{7 4}$ in a total atom- 
economic one-pot three-component manner (Scheme 19). Their bioactivities were evaluated exhibiting a very promising cytotoxicity towards various cancer cell lines. ${ }^{40}$

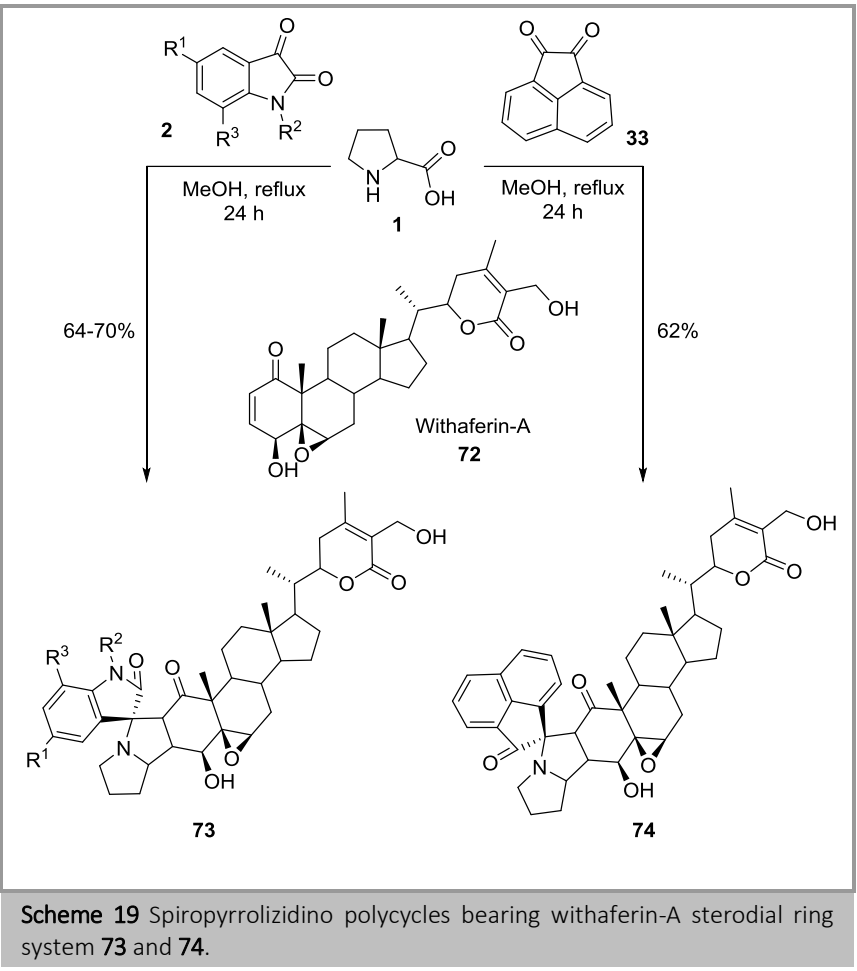

Substituted spirooxindolepyrrolizines $77\left(\mathrm{X}=\mathrm{CH}_{2}\right)$, and spirooxindolethiazoles $77(\mathrm{X}=\mathrm{S})$ were prepared from a range of secondary $\alpha$-amino acids (proline 1 or 1,3-thiazolane-4carboxylic acid 18) and dialkyl acetylenedicarboxylates $\mathbf{7 5}$ as precursors of azomethine ylides VI. Interestingly, this way of generating in situ azomethine ylides reacted with substituted methyleneoxindoles 76 through a sequential 1,3-DC (Scheme 20). This reaction protocol was also extended to the use of another $\alpha$-amino acid derivatives to yield the corresponding spiroheterocycles under thermal conditions. ${ }^{41}$

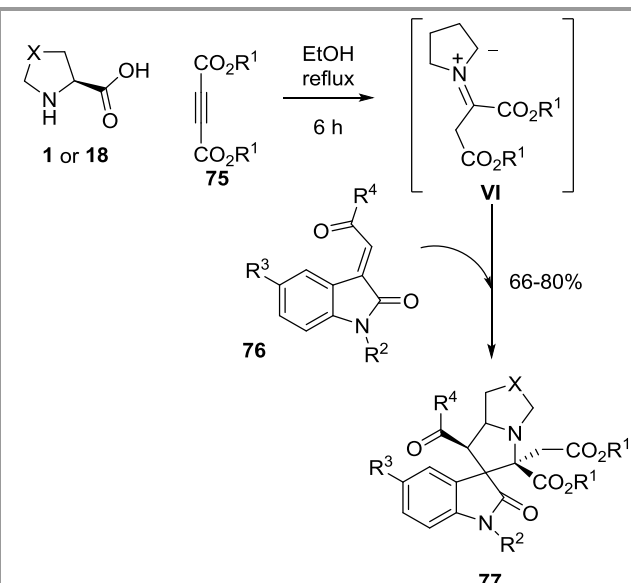

Scheme 20 Synthesis of spirooxindolepyrrolizines $77\left(\mathrm{X}=\mathrm{CH}_{2}\right)$, and spirooxindolethiazoles $77(X=S)$ from dialkyl acetylenedicarboxylates.
The unprecedented formation of dispirooxindolepyrrolizine thiazolidine-2,4-diones $\mathbf{7 9}$, contrary to the commonly observed regiochemistry, was described by Kumar et al. via one pot threecomponent 1,3-DC from isatin $\mathbf{2}$, proline $\mathbf{1}$ and $(Z)$-arylidene thiazolidine-2,4-diones $\mathbf{7 8}$. The reaction took place under refluxing methanol with total regio- and diastereoselection (Scheme 21). ${ }^{42}$ Many biological studies concerning medical applications of heterocycles $\mathbf{7 9}$ are currently in progress.

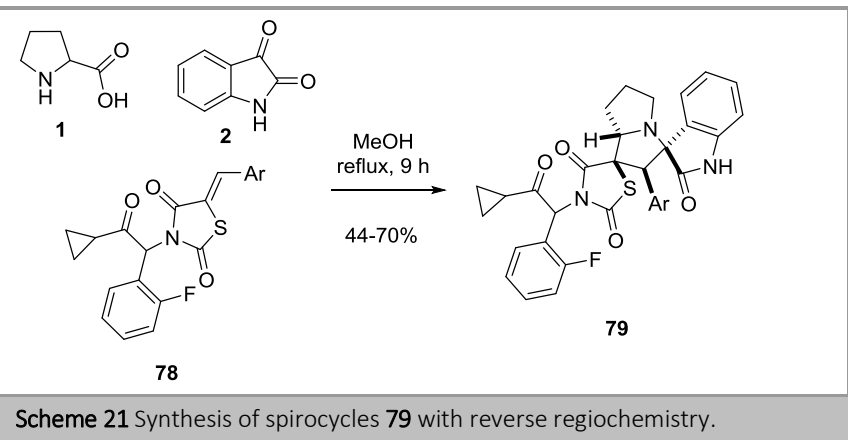

Dandia and co-workers constructed diastereoselectively various biologically important dispiropyrrolidinethiapyrrolizidine frameworks 81. Trifluoroethanol (TFE) was employed as enviromentally friendly solvent and also as catalyst due to its Bronsted acidity. Isatin derivatives $\mathbf{2}$ or azanaphthoquinone $\mathbf{8 0}$ $(\mathrm{X}=\mathrm{NH})$, benzooxazinone $\mathbf{8 0}(\mathrm{X}=0)$ derived electrophilic alkenes and sarcosine $\mathbf{1 3}$ or 1,3-thiazolidine carboxylic acid $\mathbf{1 8}$ were the components used in this study (Scheme 22). ${ }^{43}$

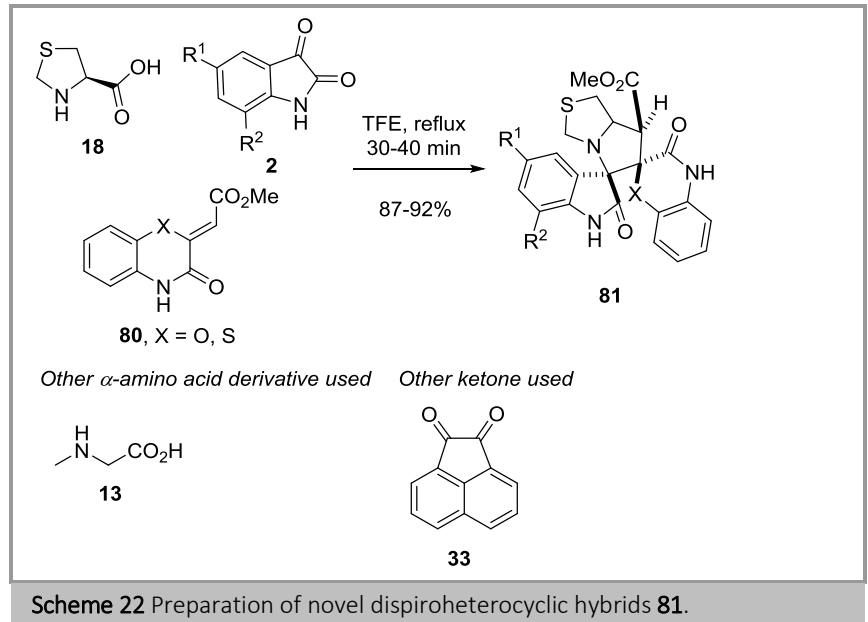

Bisspirooxindolopyrrolidines $\mathbf{8 3}$ and bisspirooxindolopyrrolizidines $\mathbf{8 4}$ were reported by Javidan et al. employing bischalcone 82 as bisdipolarophile in the 1,3-DC involving isatins $\mathbf{2}$ and secondary $\alpha$-amino acid derivatives such as proline $\mathbf{1}$ or sarcosine 15. Final cycloadducts were obtained under mild conditions in very high both chemical yields and diastereoselections (Scheme 23). ${ }^{44}$ The biological activity of selected molecules $\mathbf{8 3}$ or $\mathbf{8 4}$ are under study. 


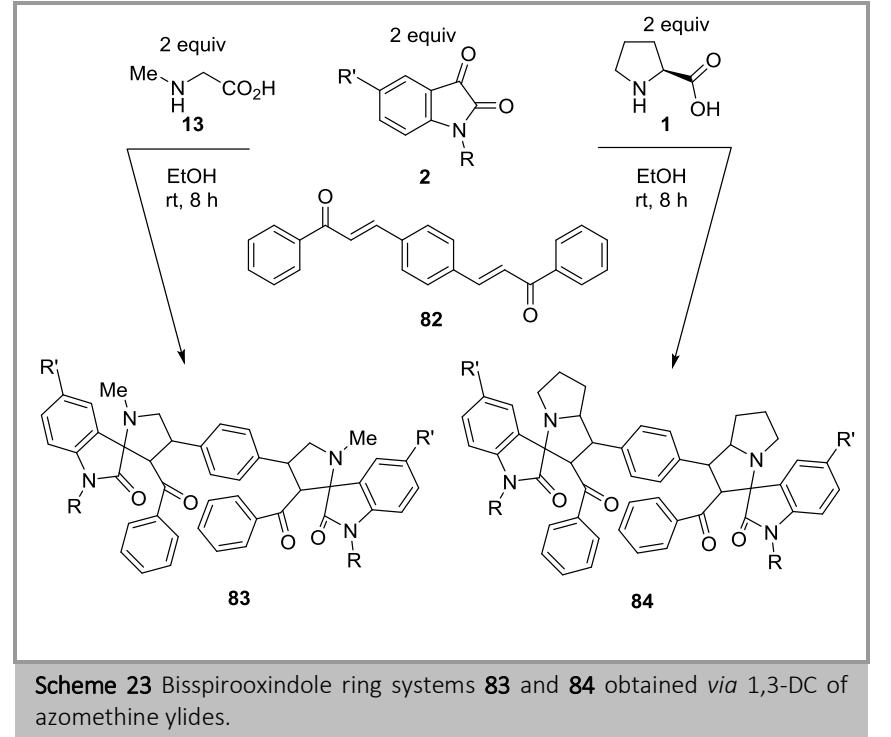

Biologically active quinolines containing both indoline and spirooxindole core structures $\mathbf{8 6}$ were designed by Mohan and co-workers. The 1,3-DC was carried out from sarcosine 13/thiazolydine-4-carboxylic acid 18 together with isatins 2/acenaphthoquinone 33/ninhydrin 57 and with designed $(E)$ 3-[(quinolin-3-yl)methylene]indolin-2-one derivatives 85 as dipolarophiles (Scheme 24). Biological evaluation of this new spiroheterocycles 86 revealed important in vitro antioxidant, antidiabetic and acetylcholinesterase (AChE) inhibitory activities. $^{45}$

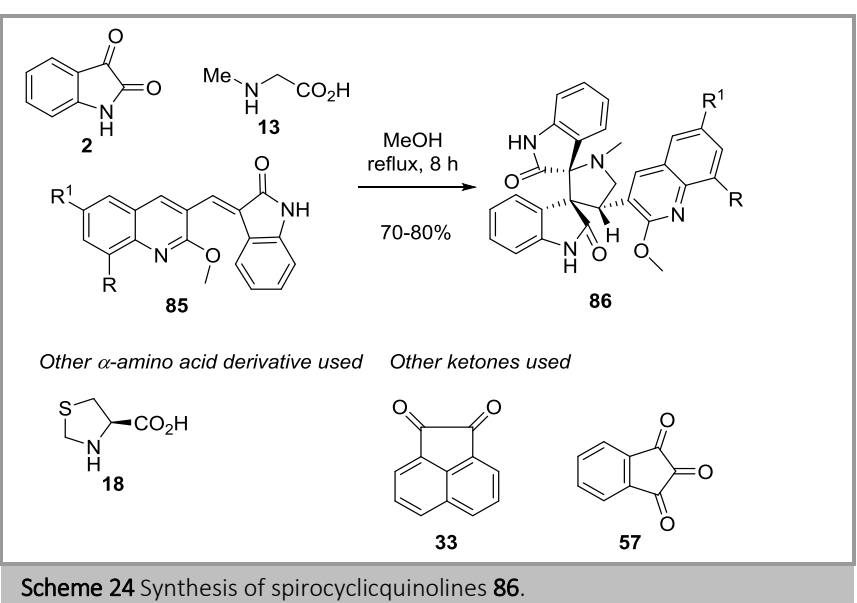

Bioactive spirooxindoles 88, incorporating a steroidal framework, were reported. Isatin $\mathbf{2}$ and sarcosine $\mathbf{1 3}$ reacted with a newly designed steroidal dipolarophile $\mathbf{8 7}$, derived from pregnenolone, through a conventional 1,3-DC under mild reaction conditions (Scheme 25). The produced spirooxindolepyrrolidines $\mathbf{8 8}$ exhibited antiproliferative activities against four human cancer cell lines including MCF-7.46

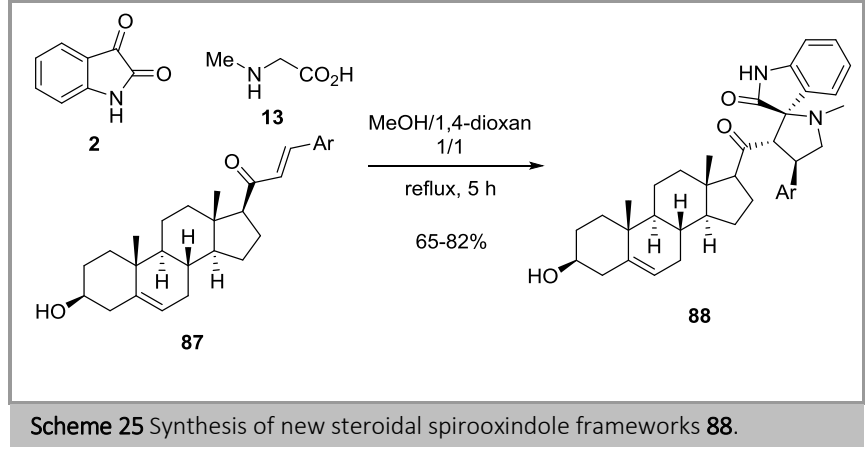

Interesting bioactive chiral enantioenriched spiroxindole derivatives 92 were prepared in the presence of a chiral ligand 91 (35 mol\%) from isatins 2, diethyl 2-aminomalonate 89 and aldimine 90. This three-component reaction occurred via asymmetric 1,3-DC between the imine 90 and the azomethine ylide. The resulting structurally congested imidazolidines 92 were isolated with good chemo-, diastereo- and enantioselections (Scheme 26). ${ }^{47}$

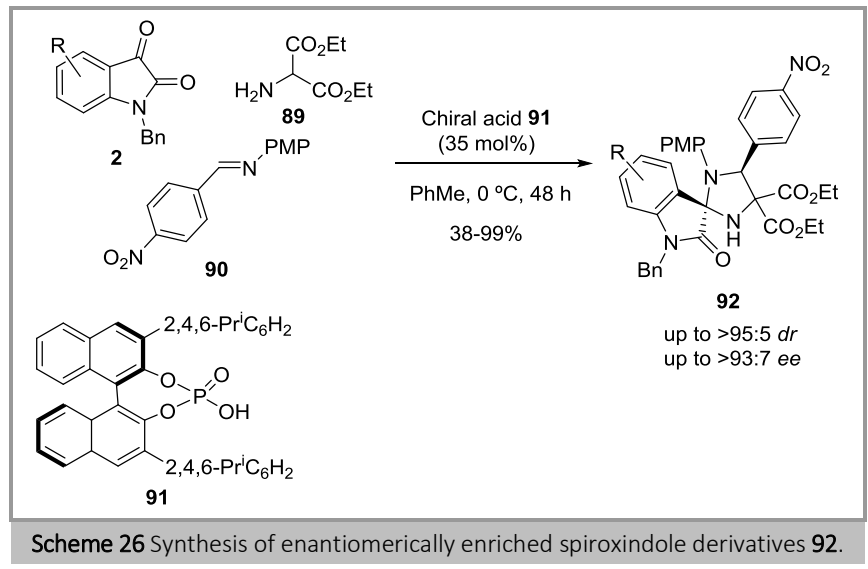

Synthesis of pentacyclic spirooxindole pyrrolidines 96 were prepared from the in situ generated tricyclic azomethine ylide derived from pyridone-annelated isatin 95 and amino acids 93 and maleimides 94 in refluxing aqueous methanol (Scheme 27). ${ }^{48}$ It is noteworthy the preference of the attack of amino group of the acids 96 towards the hydrate moiety, rather than the conjugated alkene moiety present in the two components $\mathbf{9 4}$ and 95 involving in the cycloaddition.

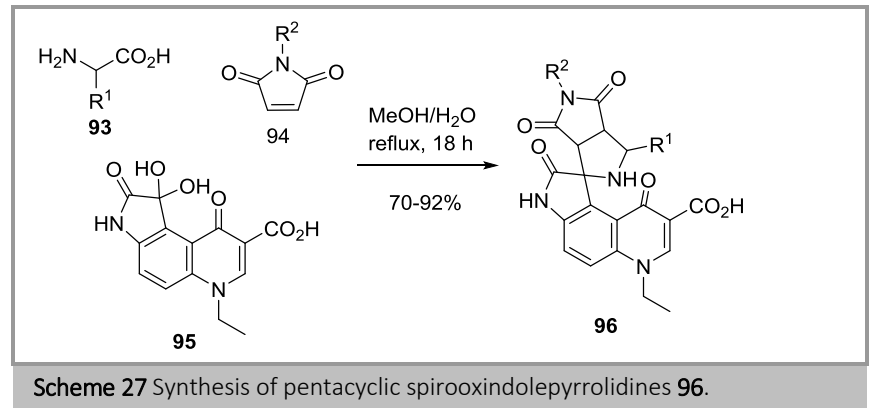


Dipolarophiles 97 were employed in the enantioselective 1,3-DC catalyzed by chiral bisphosphoric acid $\mathbf{9 8}$. The enantiomerically enriched bis-spirooxindolepyrrolidines 99 were obtained in good yields, very high diastereomeric ratios and excellent enantioselectivities in ethanol at $50{ }^{\circ} \mathrm{C}$. Isatins 2 and diethylaminomalonate $\mathbf{8 9}$ were also the precursors of the azomethine ylides (Scheme 28). ${ }^{49}$

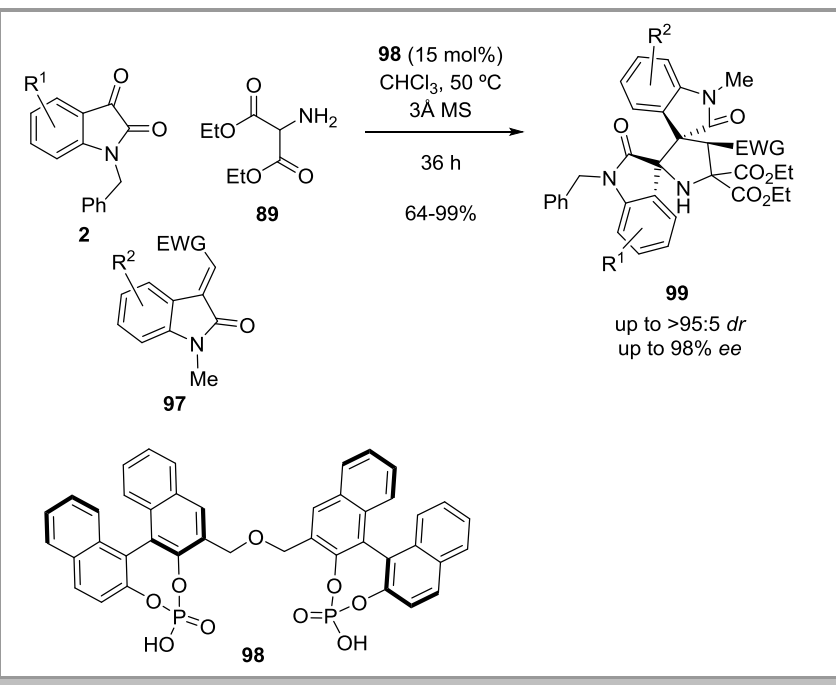

Scheme 28 Enantioselective synthesis of spirocycles 99.

Biologically important substituted spirooxindole cycloadducts 101 were obtained by Shi and co-workers in the presence of the same chiral bisphosphoric acid $\mathbf{9 8}$ as organocatalyst. This enantioselective 1,3-DC with isatins 2, diethyl aminomalonate $\mathbf{8 9}$ and alkyl 2,3-allenoates $\mathbf{1 0 0}$ as dipolarophiles, furnished enantioenriched anticancer and antimicrobial spiro[indoline3,2'-pyrrole] frameworks 101 in high diastereomeric ratios and good to excellent enantioselections (Scheme 29). ${ }^{50}$

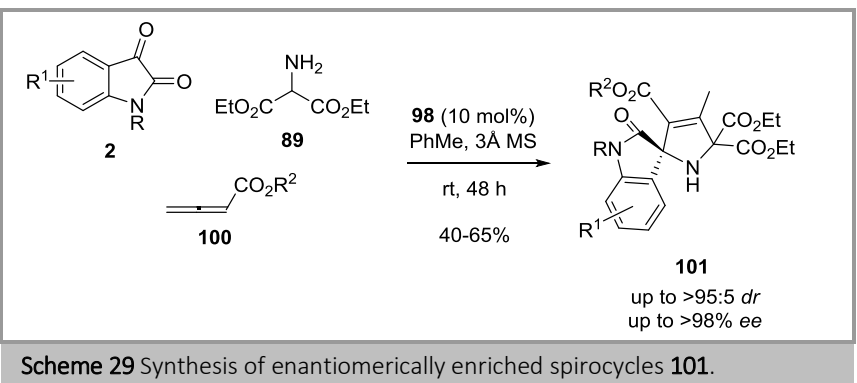

Dialkyl but-2-ynedioates $\mathbf{7 5}$ acted as dipolarophiles during the multicomponent 1,3-DC with cyclic $\alpha$-amino acids such as proline 1, 4-thiaproline $\mathbf{1 8}$, or $(2 S, 4 R)$-4-hydroxyproline 102 , with isatins 2. The resulting spirooxindolepyrrolizines 103 were isolated in good yields (Scheme 30). In addition, spiroxindoleazepines $\mathbf{1 0 4}$ were isolated as major compounds when two equivalents of electrophilic alkyne $\mathbf{7 5}$ were added together with one equiv of the rest of components. In this last example, alkynes behaved such as it was described in Scheme 20.51

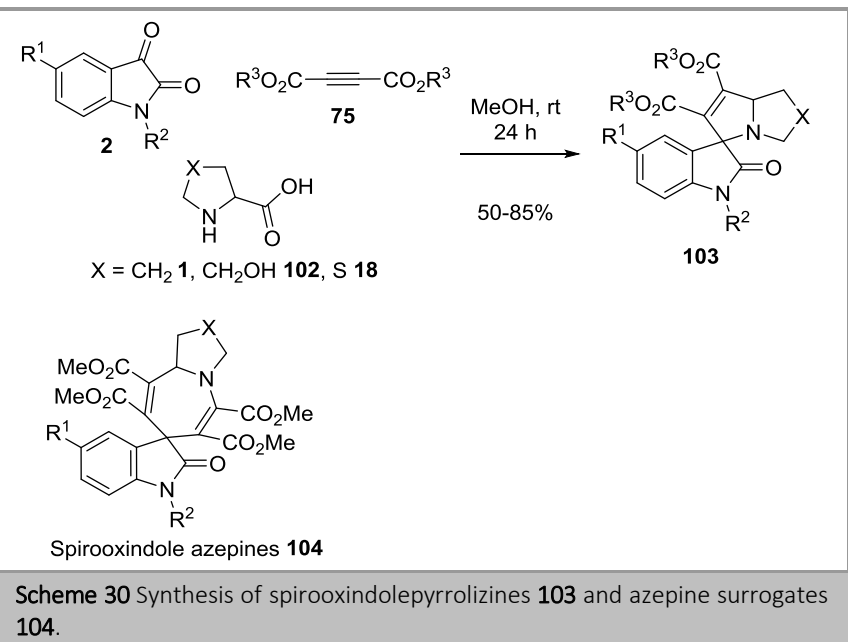

\section{Synthesis of spiropyrrolidines}

Non-asymmetric synthesis of diazaspiropyrrolidine derivatives 106, possessing a dihydroisoquinoline moiety, were prepared from isoquinolines $\mathbf{1 0 5}$ with 3 equiv of the corresponding maleimide 94 without solvent at $70 \stackrel{\circ}{\circ}$. The intermediate azomethine ylide VII was not formed as usual but through a Michael-type addition of the isoquinoline onto malimide followed by a prototropic shift (Scheme 31$) .52$

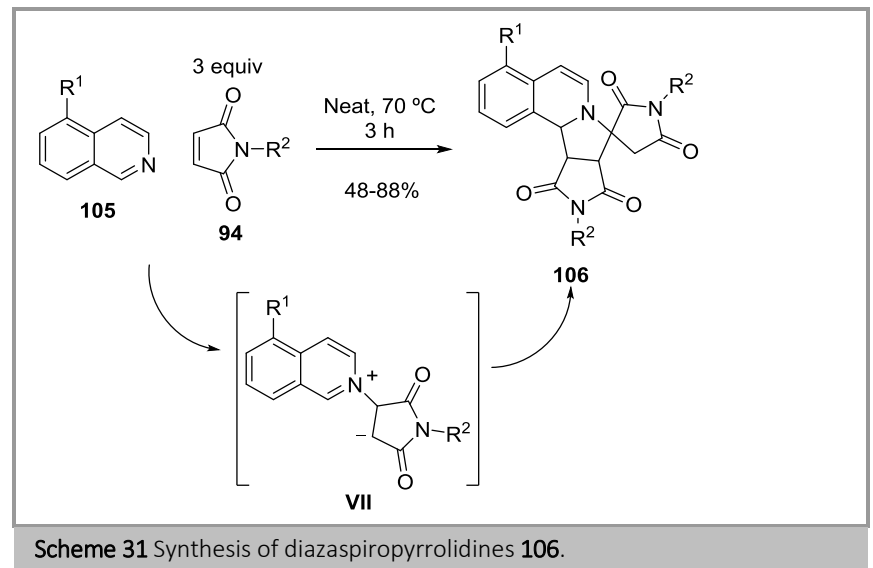

Spiroheterocycles 109, containing both pyrrolidine and indanone core structures, were synthesized from iminoesters 107 and alkylidene-1-indanone derivatives 108 as dipolarohiles in the presence of a series of imidazolium salts as catalysts. The diastereoselectivities were low but the chemical yields were excellent under mild conditions. The catalyst was efficiently recovered and reused several times without losing efficiency (Scheme 32). ${ }^{53}$ 


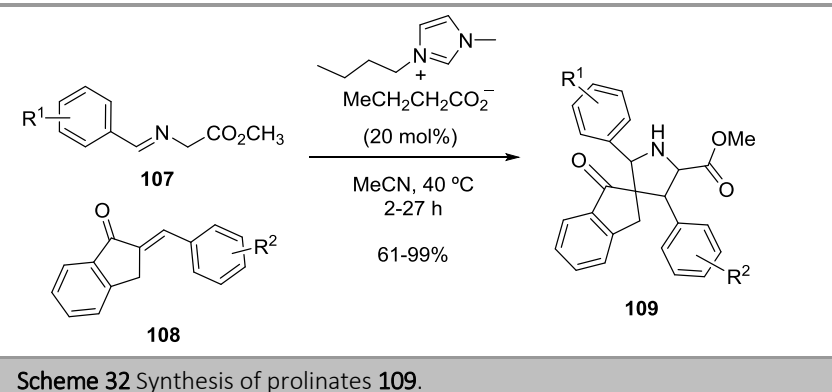

Scheme 32 Synthesis of prolinates 109

A pyrrolidine ring bearing two quaternary centers corresponding to spiranic systems $\mathbf{1 1 3}$ was also designed for the construction of natural alkaloids. Liu et al. reported a one pot five-component reaction to produce dispiroindenoquinoxalinepyrrolidines $\mathbf{1 1 3}$ from 1,3-indanedione 111, 1,2-phenylenediamine $\mathbf{1 1 0}$, ninhydrin 57, sarcosine $\mathbf{1 3}$, and aromatic aldehydes (for example 112). A plausible mechanism proposed by the authors suggested that the formation of indenoquinoxaline-11-one 43, from condensation reaction of 1,2-phenylenediamine $\mathbf{1 1 0}$ and ninhydrin 57, and subsequent reaction with sarcosine 13 and decarboxylation afforded the corresponding azomethine ylide. Then, stereoselective 1,3-DC with the dipolarophile $\mathbf{1 1 4}$ (derived from the aldehyde $\mathbf{1 1 2}$ and 111) produced the desired dispiroindenoquinoxalinepyrrolidines 113 (Scheme 33). ${ }^{54}$ Some spiropyrrolothiazoles were prepared using a similar strategy but employing different components as $(E)$ - $\beta$-nitrostyrene,, 55 or even 1,3-thiazolane-4-carboxylic acid as dipolarophiles. ${ }^{56}$

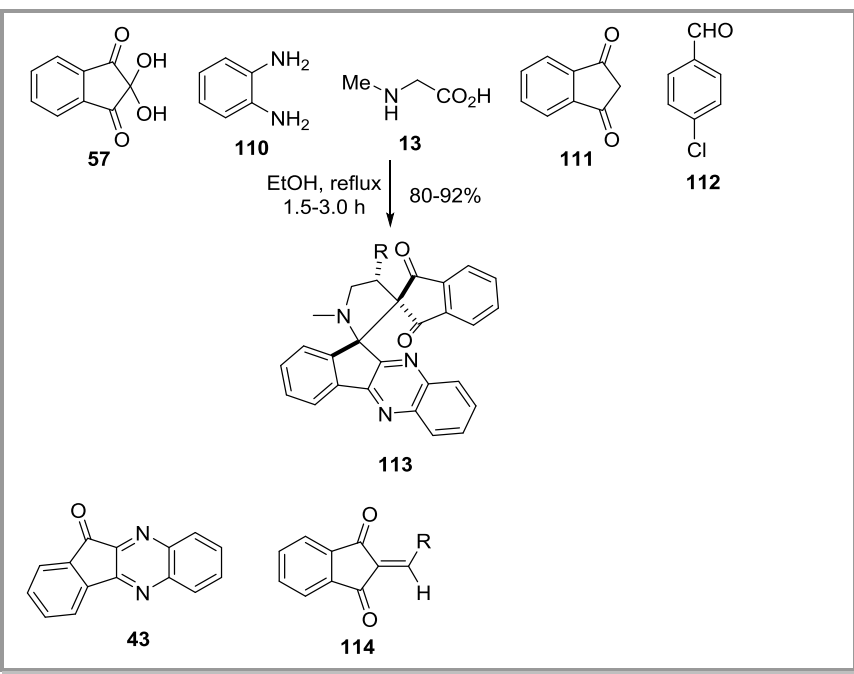

Scheme 33 Synthesis of dispiroindenoquinoxalinepyrrolidines 113 in a one-pot five-component process. good yields (scheme 34).57 This method is valuable for the synthesis of steroidal surrogates of biological significance.

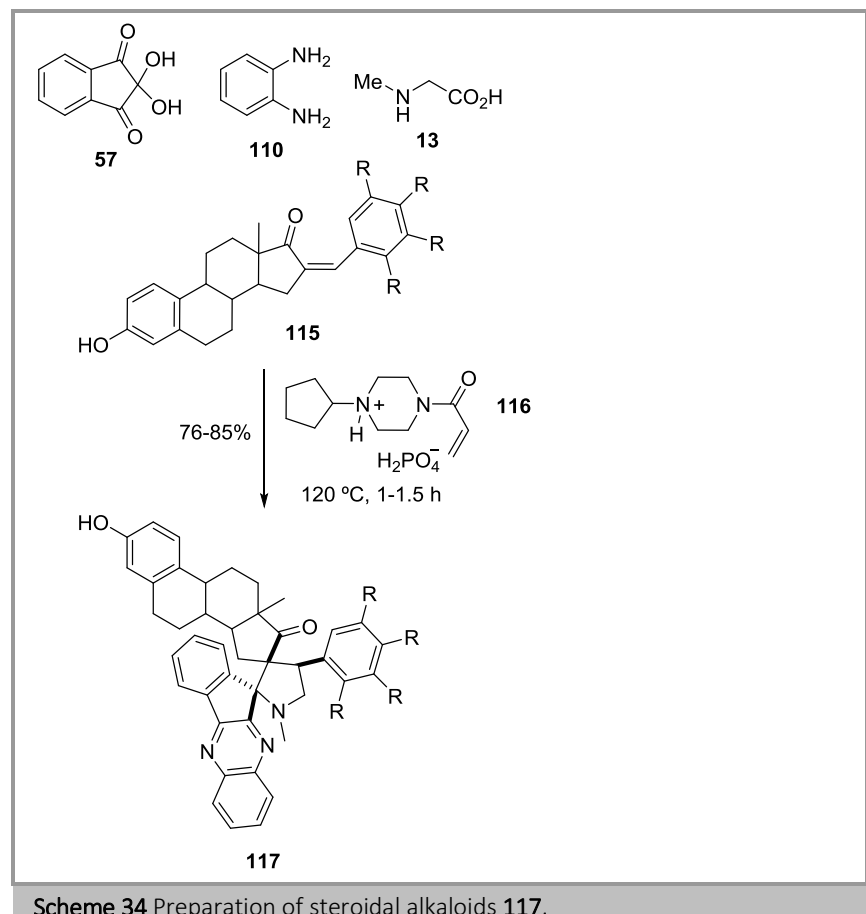

Enantioselective 1,3-DC between imino esters 107 and $\alpha$ alkylidene succinimides $\mathbf{7 0}$ were successfully achieved employing $\mathrm{Cu}(\mathrm{OAc})_{2}$ and $\mathrm{N}, \mathrm{O}$-chiral ligand 118. Structurally diverse functionalized endo-dispiropyrrolidine cycloadducts 119 were obtained in very high diastereoselection and high to excellent enantioselections (up to 97\% ee) (Scheme 35). These cycloadducts were transformed into $\mathrm{N}$ methylbispiropyrrolidines and further reduction with $\mathrm{LiAlH}_{4}$ afforded functionalized substituted spiroheterocycles $\mathbf{1 2 0}$ in good yield and up to $99 \%$ ee. This process was also applied to enantioselective 1,3-DC with 2-oxoindolin-3-ylidenes 121 as dipolarophiles giving biologically active exo-dispiropyrrolidine skeletons 122 in good yield and up to 95\% ee (Scheme 35). ${ }^{58}$
Novel steroid grafted dispiroindenoquinoxalinepyrrolidines $\mathbf{1 1 7}$ were prepared by Raghunathan et al. from ninhydrin 57, sarcosine 13, 1,2-phenylenediammine 110 and estrone derived dipolarophiles $\mathbf{1 1 5}$ in the presence of an ammonium salt $\mathbf{1 1 6}$ as catalyst. This facile one-pot four-component [3+2]-cycloaddition occurred under mild reaction conditions, easy workup, and in 


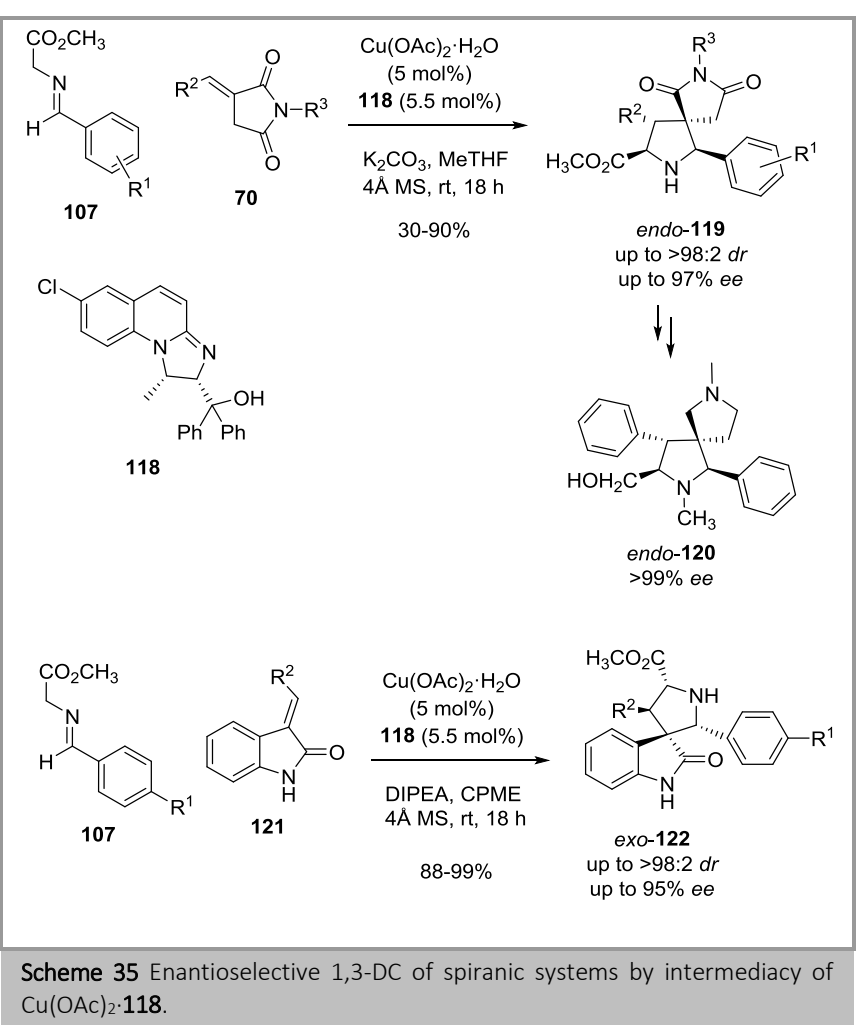

Synthesis of enantiomerically enriched diazabisspiropyrrolidines 125 and $\mathbf{1 2 6}$ was reported by Cossío and co-workers. Initially an interrupted $1,3-\mathrm{DC}$ was performed in the presence of the catalytic complex $\mathrm{Cu}(\mathrm{MeCN})_{4} \mathrm{PF}_{6} \cdot \mathbf{1 2 7}$ with the aim of obtaining the cis- or the trans- $\gamma$-lactams 123, respectively. The diastereoselective 1,3-DC was performed with these imines and nitroalkenes, vinylic sulfones, acrylates, etc., using stoichiometric amounts of AgOAc (Scheme 36). ${ }^{59}$ At this moment, this family of spiranic compounds are being evaluating as anticancer agents.

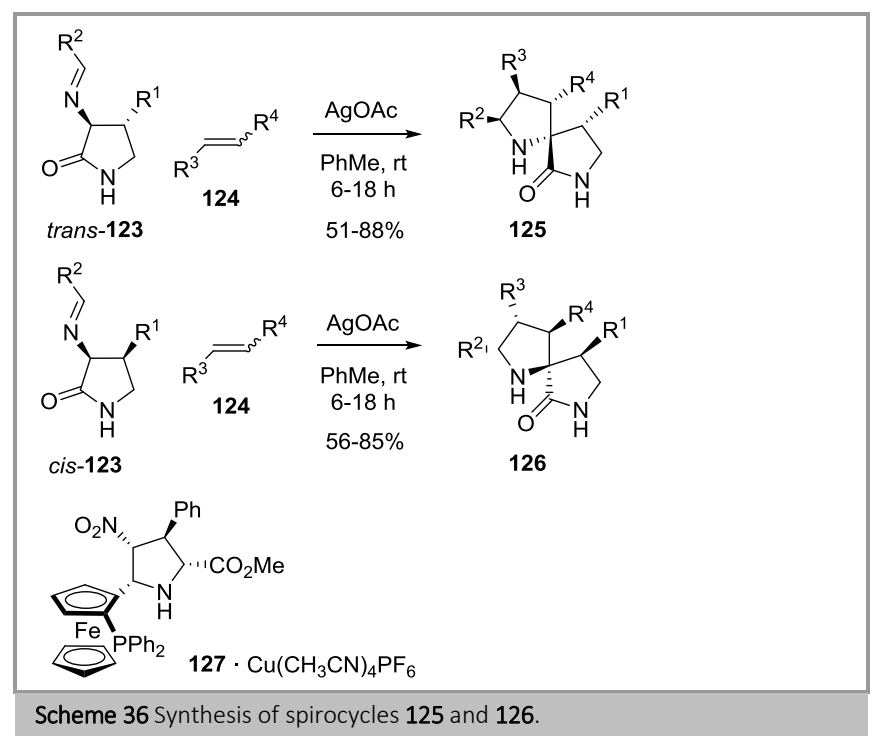

A range of chiral highly substituted spironitroprolinates 131 were reported in the presence of chiral bifunctional catalytic ligand based on $[(R, R)$-Me-DuPhos] 130 and AgF as source of chiral induction. The 1,3-DC was run with $\alpha$-imino- $\gamma$-lactones 128 and nitroalkenes 129 as dipolarophiles. ${ }^{60}$ The reaction proceeded enantio- and diastereoselectively to form up to four new chiral centers and overwhelmingly endo-spiranic cycloadducts 131 (Scheme 37).61 Biological evaluation of some of these compounds revealed promising antitumor activity.

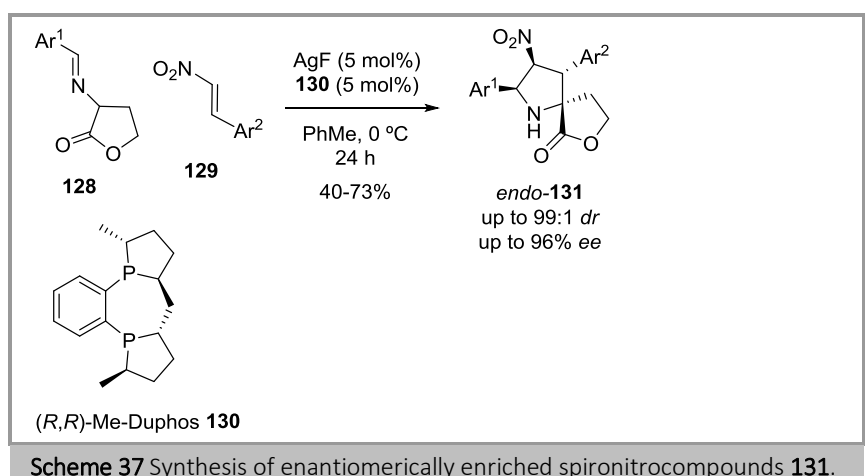

Asymmetric synthesis of biologically important tricyclic spiroheterocycles endo-134 possessing a cyclopropane unit was described. $\alpha$-Imino- $\gamma$-lactones $\mathbf{1 2 8}$ reacted with cyclopropylidene acetates $\mathbf{1 3 2}$ as dipolarophiles using $\mathrm{CuBF}_{4} \cdot \mathrm{TF}$ BiphamPhos 133 as catalyst to afford endo-spirocycloadducts 134 in good diastereoselectivities and very high enantioselectivities (Scheme 38). ${ }^{62}$

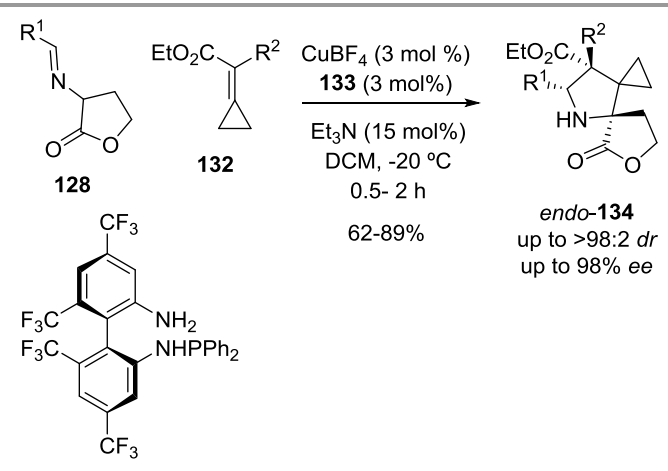

(S)-TF-Biphamphos 133

Scheme 38 Synthesis of enantiomerically enriched endo-spironitrocompounds 134.

\section{Synthesis of spiropiperidines and piperidines}

The 2,3-pyrrolidino-3,4-piperidine (4,7-diazabicyclo[4.3.0]nonane) scaffold is an integral part of the underlying structure of numerous alkaloids possessing diverse bioactivities, including anti-tumor, antibiotic, and insecticidal activity. 
Biologically active spiropiperidine derivatives $\mathbf{1 3 6}$ were reported by Guo and co-workers starting from homoserine lactone 128 and tropone $\mathbf{1 3 5}$ as dipolarophile. Here, a [6+3] cascade cycloaddition took place in the presence of $\mathrm{AgOAc} \cdot \mathrm{PPh}_{3}$ as catalyst and DBU as base. The final diastereoselectivity was very high as well as chemical yield under mild reaction condition (Scheme 39). ${ }^{63}$

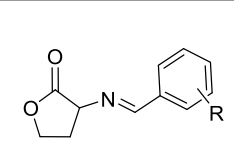

128

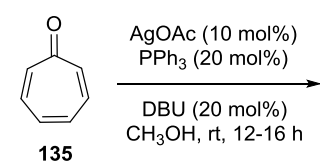

$52-76 \%$

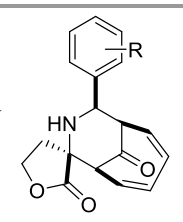

136
Scheme 39 Preparation of heterocycles 136

Potentially bioactive functionalized enantioenriched bridged piperidine derivatives 139 were designed by Wang et al. in the presence of $\mathrm{Cu}(\mathrm{MeCN}) 4 \mathrm{BF}_{4} \cdot 138$ catalytic system. The [3+6] cycloaddition with acyl heptatrienes $\mathbf{1 3 7}$ produced the corresponding exo-cycloadducts 139 with multiplication of stereocenters with excellent exo-selectivity in good yields and up to $99 \%$ ee (Scheme 40 ). ${ }^{64}$

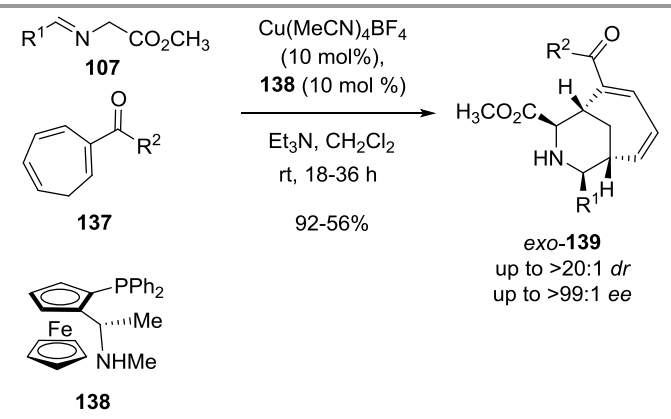

Scheme 40 Enantiomerically enriched exo-cycloadducts 139 .

A range of important substituted enantiomerically enriched pyrrolidinopiperidine derivatives $\mathbf{1 4 2}$ were synthesized by Waldmann and co-workers. The intramolecular 1,3-DC reaction of starting iminoamides $\mathbf{1 4 0}$ (generated from the corresponding $\mathrm{N}$-Boc protected amine) occurred in the presence of the chiral complex formed by $\mathrm{Cu}(\mathrm{MeCN})_{4} \mathrm{BF}_{4}$ and chiral ligand 141. Final fused bicycle 142 was obtained in good yields, excellent diastereoselections and very high diastereomeric ratio (Scheme 41). ${ }^{65}$ Once product 142 was formed, a sequential addition of $(E)$ cinnamaldehyde 143 and alkenes 124 took place yielding fully substituted fussed-pyrrolizidines $\mathbf{1 4 4}$ in good conversions (Scheme 41). The main interest of this work was the definition of the scaffolds of glycosidase inhibitors, which have been the subject of numerous investigations.

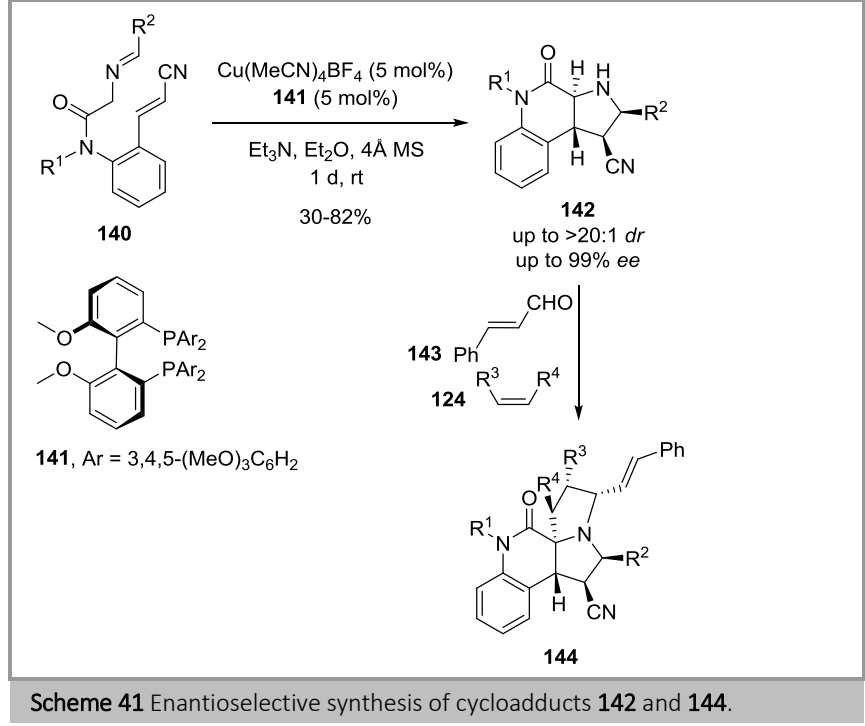

The elaboration of biologically important substituted tetrahydro$\gamma$-carbolines 147 was performed during the enantioselective [3+3] cycloaddition between imino esters 107 and 2indolylnitroethylenes $\mathbf{1 4 5}$ in the presence of $\mathrm{CuPF}_{6} \cdot \mathrm{Ph}$ Phosferrox 146 as catalytic complex. This chemo- and stereoselective [3+3] cycloaddition was produced, rather than expected 1,3-DC, in very high yields, diastereomeric ratios and enantioselectivities (Scheme 42).66 The proposed stepwise mechanism, caused by the high stability of the resulting enolate of the Michael-type addition, favored the Friedel-Crafts reaction of the nucleophilic 3-position of the indole.

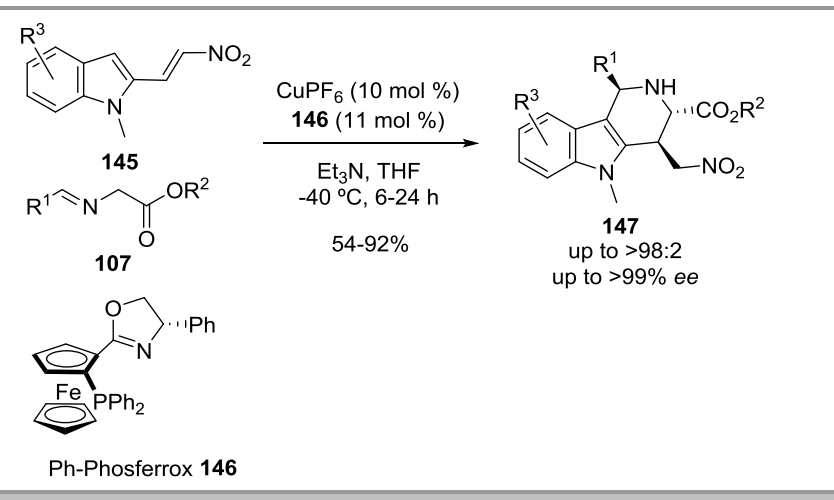

Scheme 42 Synthesis of tetrahydro- $\psi$-carbolines 147 via [3+3] cycloaddition.

\section{Synthesis of pyrrolidines and fused pyrrolidines}

Pyrrolidine ring systems possessing a chiral sugar building block 149 were reported by Thangamuthu et al. from sarcosine 13, paraformaldehyde and an electrophilic alkene bonded to a fullprotected glucopyranosyl unit 148. The cycloadduct was isolated in good yield and as only one diastereoisomer (Scheme 43). ${ }^{67}$ The biological evaluation of these compounds are currently in progress, demonstrating very promising applications. 


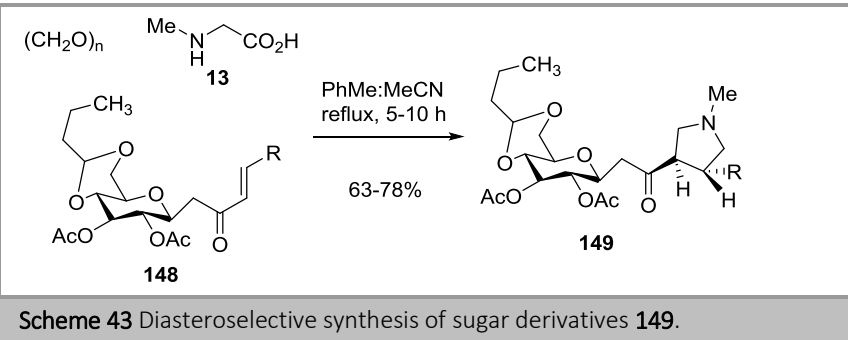

With the same aim, new pyrrolidine-containing macrocycles $\mathbf{1 5 1}$ bearing a triazole ring and a sugar (D-glucose) fragment, were prepared via intramolecular 1,3-DC of azomethine ylide. ${ }^{68}$ The 1,3-DC occurred diastereoselectively in refluxing toluene in good yields independently of the amino acid employed (scheme 44). This strategy provides opportunities for the preparation of libraries of carbohydrate grafted macrocycles with triazole spacer unit for biological screening.

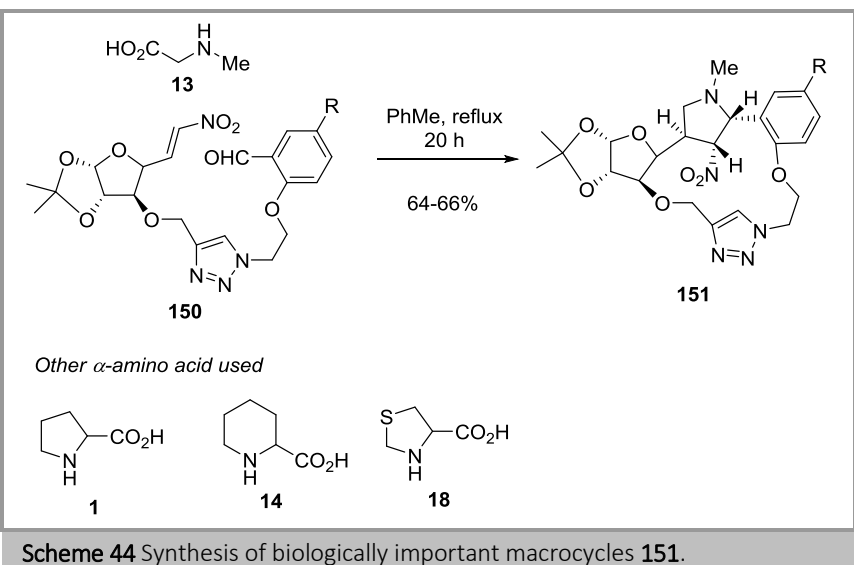

A series of polyhydroxyalkylpyrrolidines 153 and ent-153, as potential inhibitors of a $\beta$-galactofuranosidase, were described by Varela et al. employing a silver-catalyzed 1,3-DC from imino esters and $(S)$ - or $(R)$-sugar pyranone as dipolarophiles (Scheme 45). ${ }^{69}$ After a sequence of reactions comprised by hydrolysis, reductions, $N$-protection, degradative oxidations, etc., allowed the access to polyhydroxyalkylpyrrolidines 154-156, which were evaluated as inhibitors of the $\beta$-galactofuranosidase from Penicillium fellutanum.

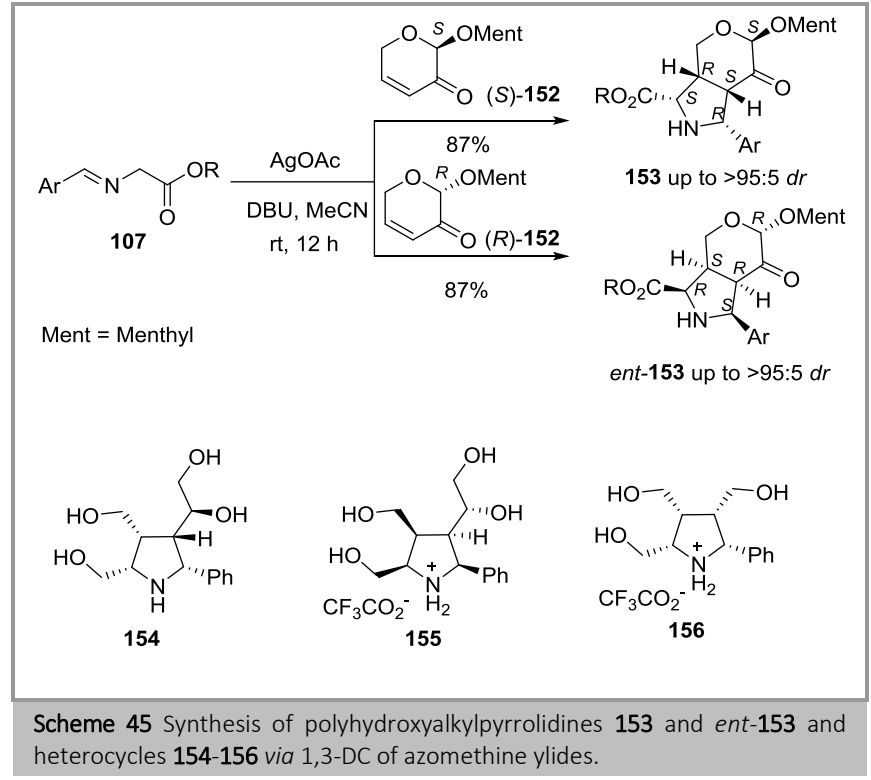

Recently, an approach to the synthesis of parkacine 159 (a lycorine-type alkaloid) was communicated. The key step of the synthesis consisted in an intramolecular 1,3-DC. Chiral hept-6yne-al derivative 157 was selected to construct the C/D ring system of a lycorine-type alkaloid parkacine. However, the cycloaddition furnished a C/D ring-closure product with opposite configurations at 7- and 7a-carbons, after comparison with the absolute configuration of the natural product (Scheme 46). ${ }^{70} \mathrm{~A}$ possible reason of this epimerization could be caused through imine-enamine tautomerization (previous to the formation of the 1,3-dipole IV) involving the stereogenic center bearing the phenyl group.

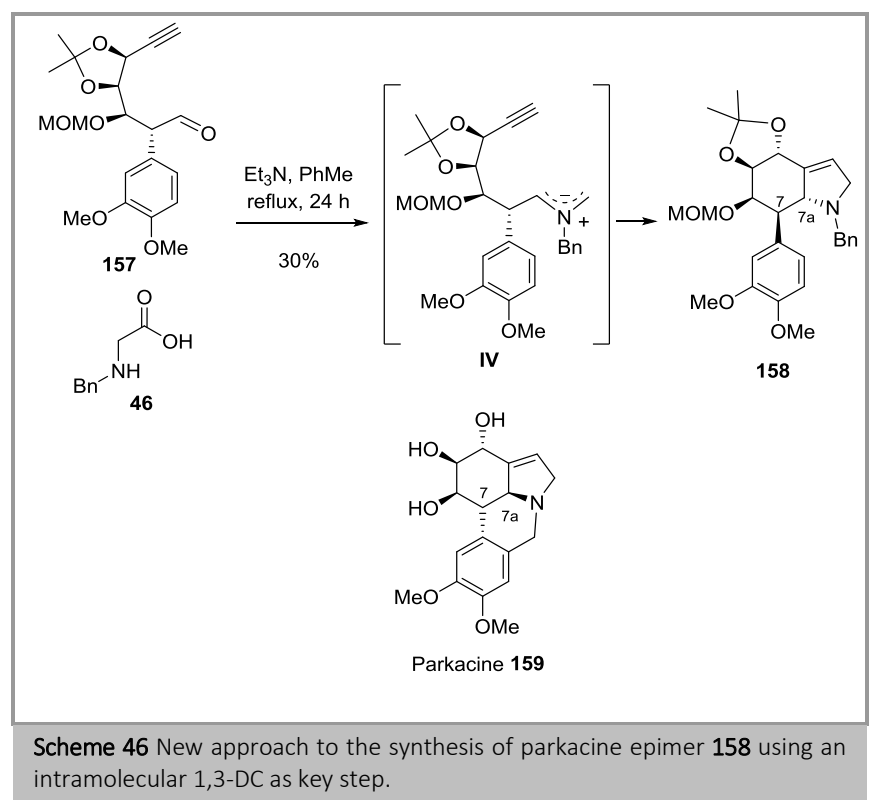

A series of functionalized $\beta$-proline dimers, trimers, etc. (eg 162 and 163), were designed from the corresponding menthyl acrylate 160 and iminoglycinate 107 through a silver-catalyzed 
1,3-DC. The repeating acylation with acryloyl chloride, followed by cyclization, allowed the extension of this process towards hexamer chiral $\beta$-peptide molecular framework 163 in good yields (Scheme 47). ${ }^{71}$ These new poly- $\beta$-prolines were generated in the two enantiomeric forms exhibiting an important antitumor activity in HRPC cells. ${ }^{72}$

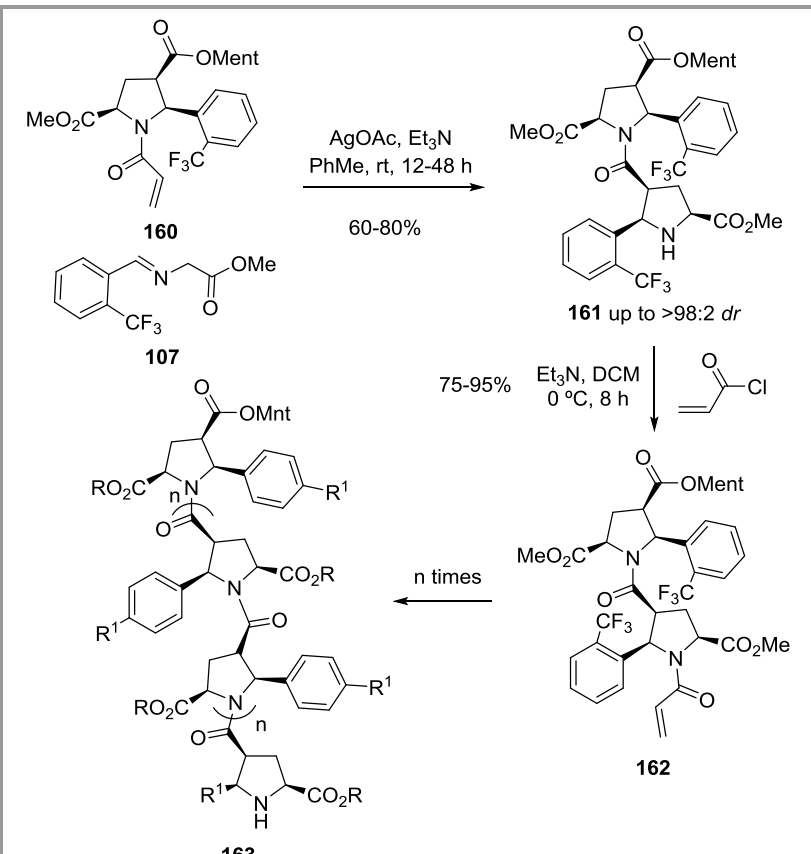

Scheme 47 Synthesis of functionalized $\beta$-proline dimers and oligomers 162 and 163.

Concerning non-asymmetric approaches, substituted pyrano[2,3-c]pyrrolidines were reported by Sosnovskikh and coworkers from sarcosine 13, formaldehyde and 4-aryl-6(trifluoromethyl)-2-pyrones $\mathbf{1 6 4}$ as dipolarophiles. The 1,3-DC produced cis-fused ring cycloadducts with high diastereoselectivity in refluxing benzene (scheme 48). ${ }^{73}$ Several applications of these compounds in medicinal chemistry are being envisaged.

Analogously, the synthesis of benzopyrano[3,4-c]pyrrolidines was described in a diastereoselective 1,3-DC between an $\propto$ iminoester 107 and coumarin in the presence of AgTFA. ${ }^{74}$

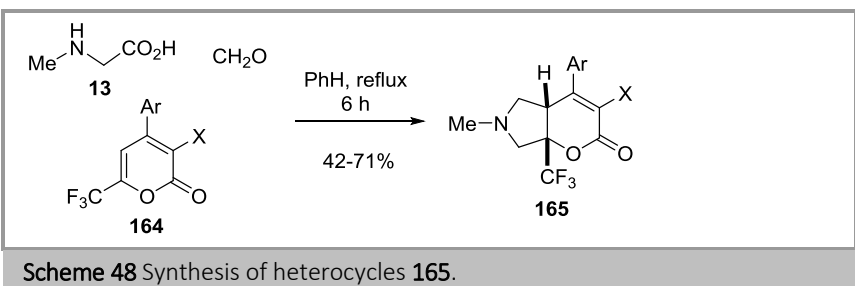

Scheme 48 Synthesis of heterocycles 165.

Hydroxypiperidones are important structures since the pharmaceutical point of view. They were prepared taking advantage of the use of aldehydes as dipolarophiles such as occurred in the 1,3-DC involving sarcosine 13, formaldehyde and an aromatic aldehyde or ketone 166. Ketal hydrolysis and lactonization from 167 afforded isolable compounds 168, which can be transformed into the corresponding substituted benzofused pyperidones 169 (Scheme 49). ${ }^{75}$

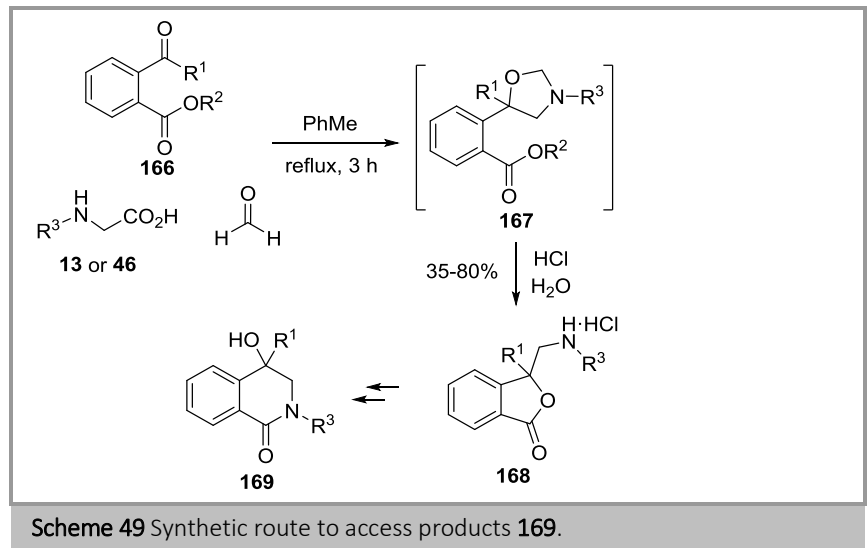

Potential biologically active benzoxazine framework alkaloids 173 were obtained through a $[3+3]$ process rather than the expected 1,3-DC. Racemic binol-derived phosphoric acid 172 acted as Brønsted acid catalyst activating the enone dipolarophile (Scheme 50). ${ }^{76}$ A modification of this procedure using $\mathrm{GaBr}_{3}$ instead of the phosphoric acid furnished cycloadducts in better yields and better periselectivities. ${ }^{77}$

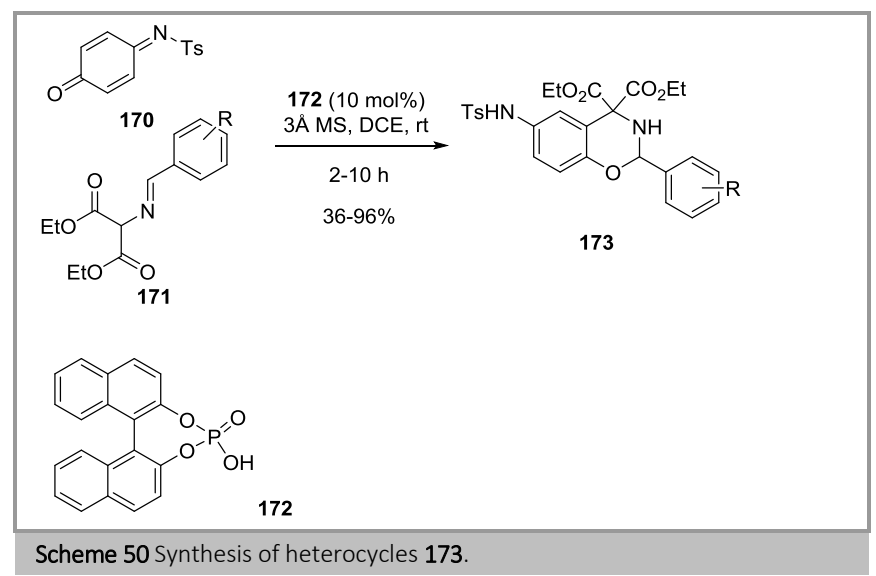

A diversity oriented synthesis (DOS) was described during the study of one-pot multicomponent cycloadditions of nonstabilized azomethine ylides (formaldehyde and $\mathrm{N}$-alkylamino acids) and 1,2-diaza-1,3-dienes $\mathbf{1 7 4}$ and $\mathbf{1 7 6}$ as dipolarophiles in toluene. It was found that the nature of the substituents in the azadiene was crucial for the cycloaddition in such a way that the presence of an electron-withdrawing group bound to the azo group favored the generation of 1,2,4-triazepines $\mathbf{1 7 7}$ through a [4+3] cycloaddition. However, a phenyl group bonded to this azo moiety furnished pyrrolidines $\mathbf{1 7 5}$ in a typical 1,3-DC in moderate to good yields (Scheme 51).78 


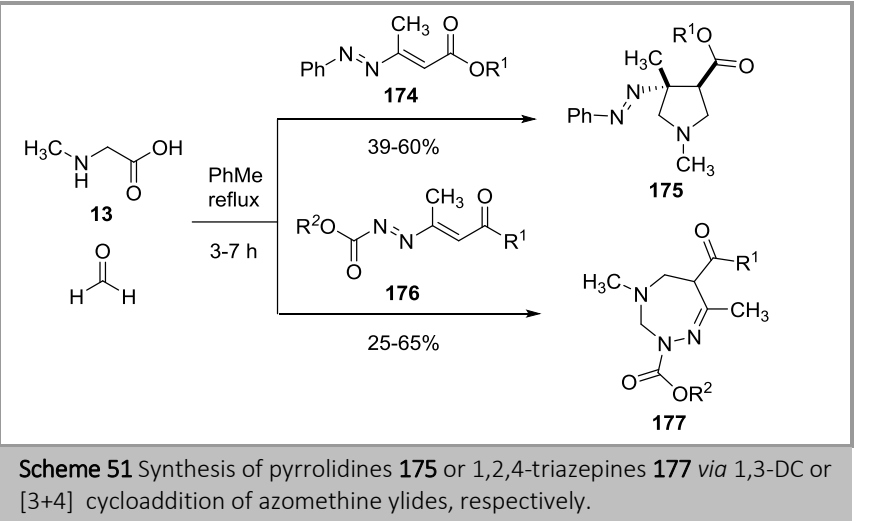

AgOAc-catalyzed [3+2] cycloaddition of the azomethine ylides derived from imino esters 107 and alkenes 178 was successfully achieved. Final pyrrolidines $\mathbf{1 7 9}$ were generated in good yields and high diastereomeric ratios under mild conditions (Scheme 52). The biological properties of these compounds are under study. ${ }^{32}$

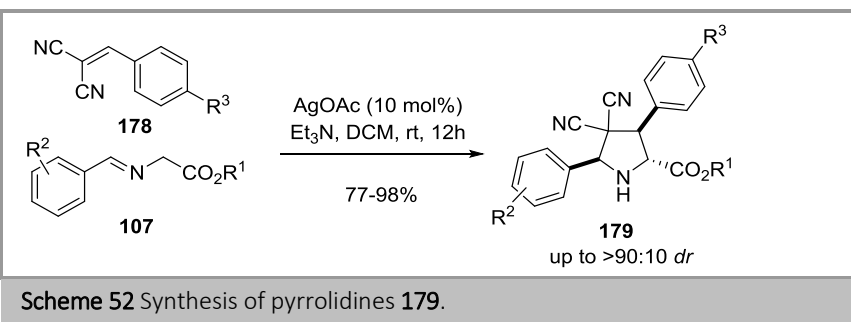

The 1,3-DC has been considered the key step in the new approach to the synthesis of fused benzodiazepines 182. This attractive family of compounds are under screening. Firstly, the thermal multicomponent 1,3-DC took place in the presence of alanine derivative 180, 2-azidebenzaldehyde 66, and maleimides 94 in short reaction times (Scheme 53). Triazolobenzodiazepine derivatives 182, obtained as unique diastereoisomers, were prepared from 181 through conventional $N$-propargylation followed by intramolecular copper-free 1,3-DC of the azido group with the alkyne residue. ${ }^{79}$

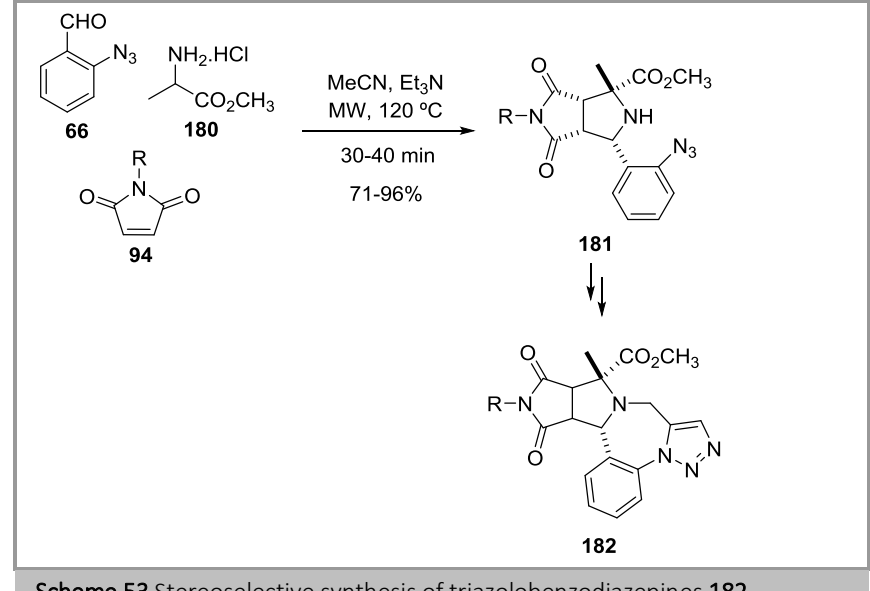

Scheme 53 Stereoselective synthesis of triazolobenzodiazepines 182

Unstabilized azomethine ylides, generated from sarcosine $\mathbf{1 3}$ and paraformaldehyde, reacted with dihetaryl system 183 to give several cycloaddition adducts depending of the solvent involved. Thus, when benzene was employed product $\mathbf{1 8 4}$ was exclusively formed in quantitative yield. However, in the case of using MeCN, hydropyrrole 185 and pyrrole 186 were obtained as mixture of products in low yields (Scheme 54).80

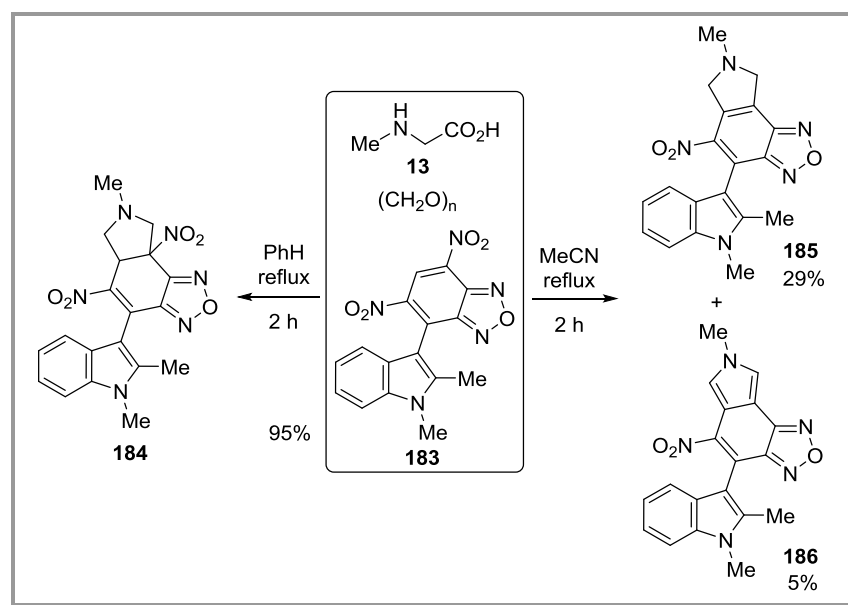

Scheme 54 Sythesis of substituted complex heterocycles 184-186

A series of substituted $\mathrm{N}$-arylpyrrolidines $\mathbf{1 8 8}$, using various electron-deficient alkenes $\mathbf{1 2 4}$ as dipolarophiles during the reaction of imino esters 107 to aryne precursors 187, were generated in good chemical yields and very high diastereoselectivities. Here, the direct attack of the imino esters to the aryne and protonation of the resulting anion occurred giving raise azomethine ylides VIII and VIII'. In addition, imidazolidines 189 were analogously obtained adding 2 equiv of imino ester 107 under mild conditions (Scheme 55). ${ }^{81}$ Both types of heterocycles were tested as antiviral agents, specifically to those emerging viral infections. 


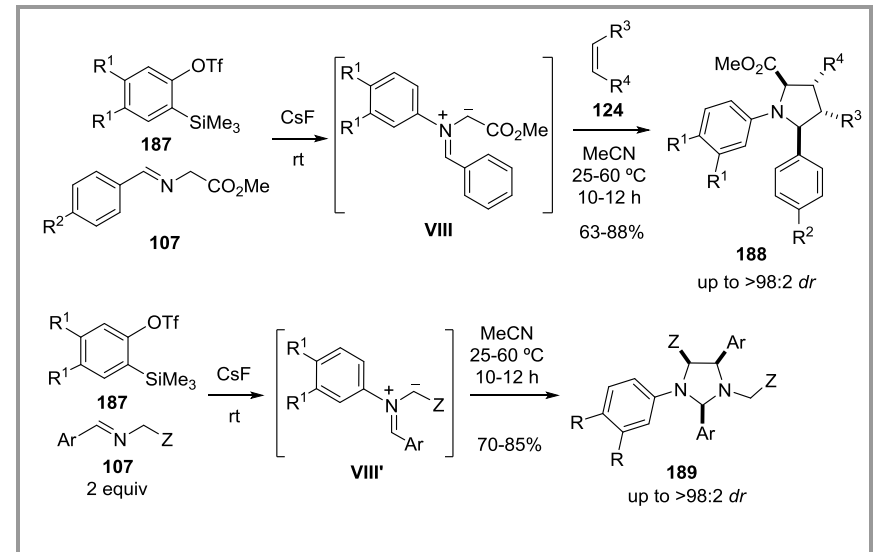

Scheme 55 Preparation of imidazolidines 189 and substituted pyrrolidines 188 from imines 107 and trimethylsilyl aryl triflates 187

An approach to the synthesis of 6-5-7 ACD azatricyclic ring system of numerous calyciphylline A-type alkaloids was successfully developed combining reagents 190 and 191. The use of $\mathrm{H}_{3} \mathrm{PO}_{4}$ as promoter in a highly donating solvent such as DMF produced the expected [3+2] cycloaddition under very mild conditions. The intramolecular 1,3-DC between a nonstabilized azomethine ylide $\mathbf{I X} \rightarrow \mathbf{I X}$, generated by desilylation of $N$ (trimethylsilyl)methyliminium salt, and an electron-poor alkene afforded calyciphylline derivative $\mathbf{1 9 2}$ as unique diastereoisomer (Scheme 56). ${ }^{82}$

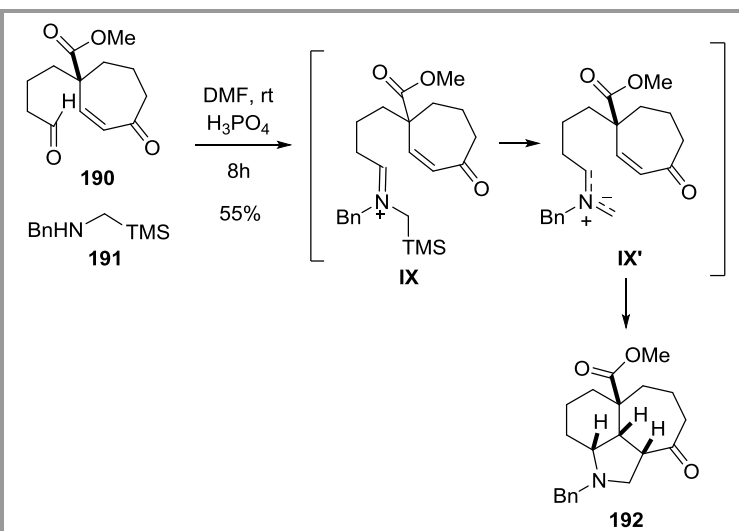

Scheme 56 Intramolecular 1,3-DC reaction to yield calyciphylline type alkaloid 192.

Bioactive compounds bearing the chromene[4,3- $b]$ pyrrolidine moiety 195 were constructed by intramolecular 1,3-DC. $\alpha$-Amino esters 194 and $O$-crotonylsalicylaldehyde 193 under MW or conventional heating afforded alkaloid chromane hetereocycles 195 in good yields via imine/[1,2]-prototropic shift route (Scheme 57). The 1,3-DC was diastereoselective in most of cases, obtaining other diastereoisomers in variable proportions. ${ }^{83}$

Similar transformations were reported by Nelson and coworkers in the search of new scaffolds for exploitation in the production of alkaloid-like libraries.84 In addition, the intramolecular 1,3-DC of allylic aminopyrimidine derivatives was also successful and afforded pyrimidine fused tricyclic systems 196 in very high yields under thermal conditions. ${ }^{85}$ As an extension of this work, the synthesis of potential bioactive functionalized fused penta/hexacyclic alkaloids were constructed by the substitution of acyclic amino esters by tetrahydroisoquinolines (Scheme 57). ${ }^{86}$

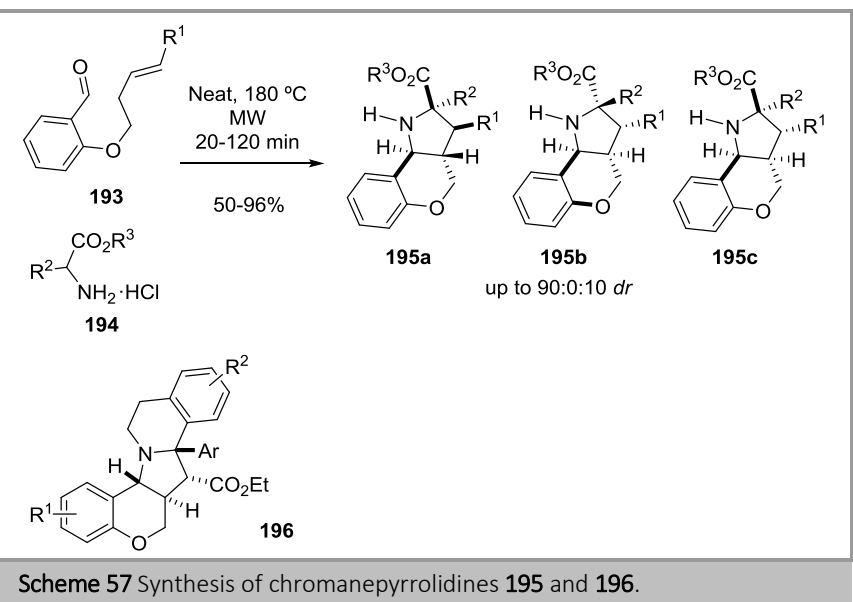

Functionalized aziridines 197 were employed as generators of azomethine ylides $\mathbf{X}$ by thermolysis in the 1,3-DC with allenes 198 bearing a tetrazol moiety. The resulting tetrazolylsubstituted pyrroles 199 or alkylidenepyrrolidines 200 resulted to be very attractive since the pharmaceutic point of view. The nature of the substituent at the terminal position of the allene affected the reaction course when a benzoyl group is bonded to the aziridine ring. However, the presence of an ester group instead (for example in aziridine $197 \mathrm{X}=\mathrm{OEt}$ ) was not so important producing exclusively pyrrolidines 201 in excellent diasteromeric ratios and high chemical yields (Scheme 58). ${ }^{87}$

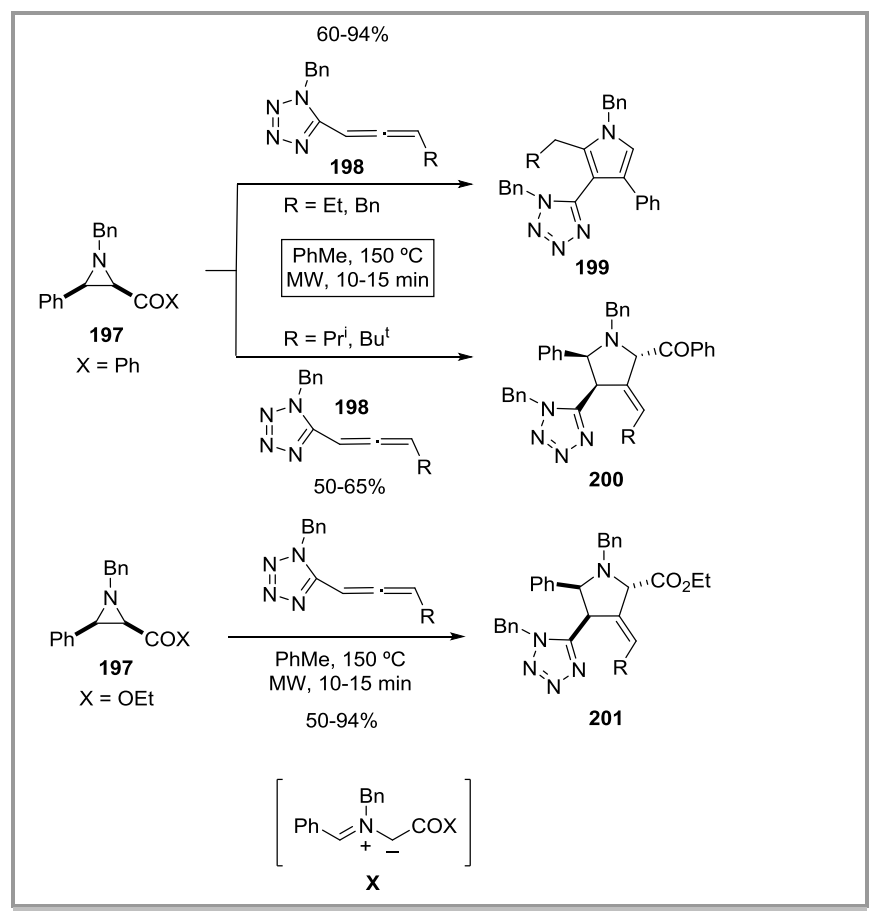

Scheme 58 DOS of pyrroles 198 and pyrrolidines 199 and 201. 
Important chromenopyrrole derivatives 203 and 205, were prepared by the generation of azomethine ylides from aziridines 202 and 204 bearing terminal alkyne/allene groups, respectively. The stereoselective intramolecular 1,3-DC took place in refluxing toluene giving only one stereoisomer in good chemical yields. The triple carbon-carbon bond led the corresponding 1,4-dihydrochromeno[4,3-b]pyrrol 203, whilst allene allowed the stereoselective synthesis of 3methylenechromano[4,3-b]pyrrole derivative 205 (Scheme 59). ${ }^{88}$ An alternative way to obtain the fused pyrrole heterocycle in good yields, consisted in a sequential one-pot 1,3-DC employing synthesis from $\mathrm{N}$-substituted-Boc-glycine-O-aryl ester, bearing this arene moiety an alkyne group at its orthoposition. ${ }^{89}$

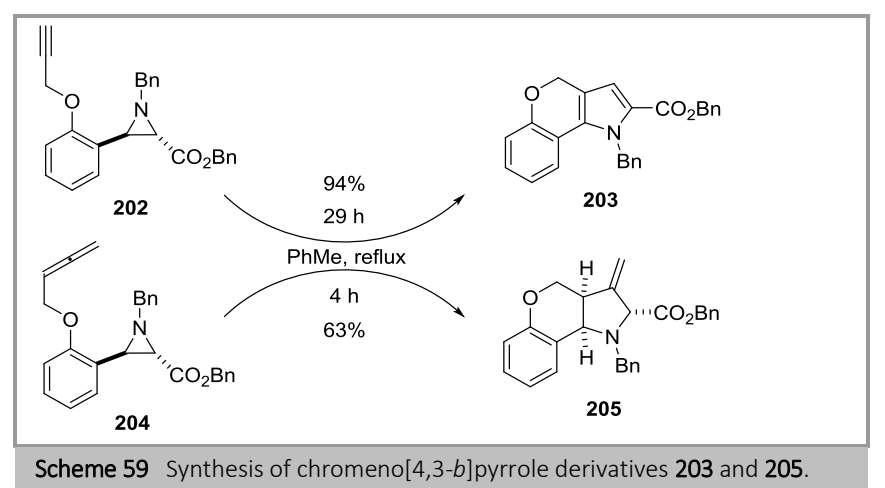

ABC Tricyclic ring system similar to that found in manzamine alkaloid framework was prepared by Coldham et al., 1,3-DC being one of the three key steps of the synthesis. The 1,3-DC was successful with only one diastereomer of $\mathbf{2 0 6}$ demonstrating the high control of the geometry of the transition state. The same aldehyde was able to afford stereodivergent products 208 or 206, in moderate to good yields, depending on the reagents involved in the generation of the azomethine ylide (Scheme 60).90

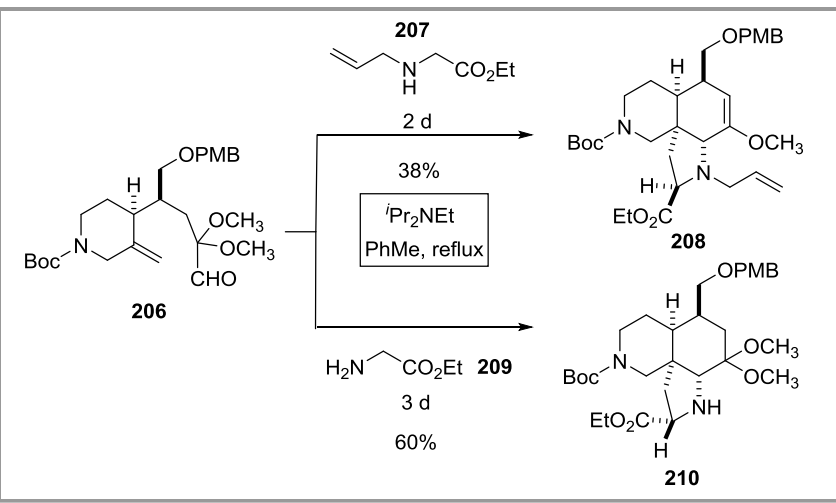

Scheme 60 Selective synthesis of tricycles 208 and 210.

An unprecedented generation of non-stabilized azomethine ylides from $N$-(trimethylsilylmethyl)amides $\mathbf{2 1 1}$ was optimized. The activation of the amide was done with triflic anhydride, then, partial reduction with 1,1,3,3-tetramethyldisiloxane (TMDS), and desilylation with cesium fluoride afforded the final intermediate ylide XIII. Operating under mild conditions, the 1,3-DC tolerated several sensitive functional groups and provided cycloadducts 212 in very good yield. The use of various dipolarophiles were successful, cis-diastereoselectivity for the substrates bearing an electron-withdrawing group being determined (Scheme 61). ${ }^{91}$

The sequence formed by and nonstabilized azomethine ylide derived from $N$-substituted glycine and formaldehyde $\rightarrow$ anthraquinone $\rightarrow$ 1,3-oxazole formation $\rightarrow$ generation of azomethine ylide $\rightarrow 1,3$-DC with electrophilic alkenes was also developed for the preparation of substituted pyrrolidines..$^{92}$

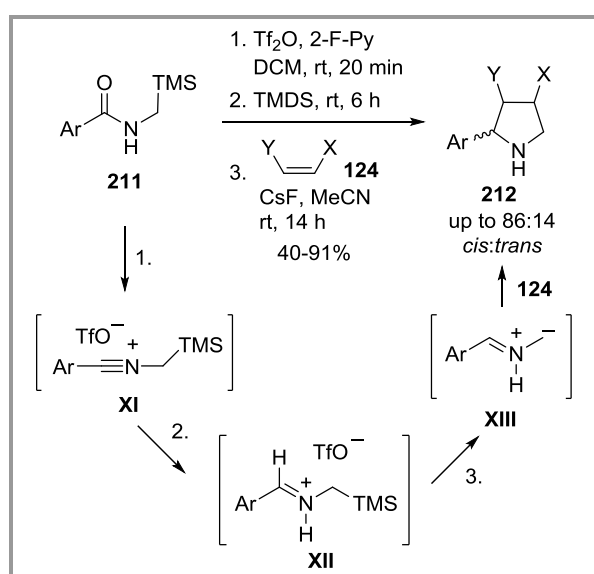

Scheme 61 1,3-DC reaction of nonstabilized azomethine ylides derived from secondary aromatic $N$-(trimethylsilylmethyl)amides 211 .

Potentially bioactive pyrroles 215 bearing a phosphonate unit at the 2-position are currently under evaluation. The preparation consisted in a simple 1,3-DC between imino phosphonates $\mathbf{2 1 3}$ and 1,3-DC with ynones $\mathbf{2 1 4}$ giving intermediate cycloadducts, which underwent a subsequent aromatization (Scheme 62). The multicomponent version was essayed but in lower chemical yield. ${ }^{93}$

Scheme 62 Synthesis of pyrroles 215 .

The stability of the pyrrol unit was the driving force to construct a novel nitrogen-doped corannulene derivative 219. The key 1,3dipolar cycloaddition of a polycyclic aromatic azomethine ylide precursor $\mathbf{2 1 7}$ with a diarylethyne $\mathbf{2 1 6}$ gave product 218, which underwent a palladium-catalyzed intramolecular cyclization to complete the synthesis. This molecule represents the first example of a corannulene derivative bearing an internal 
heteroatom, having particular and exclusive physical and biological properties (Scheme 63). ${ }^{94}$

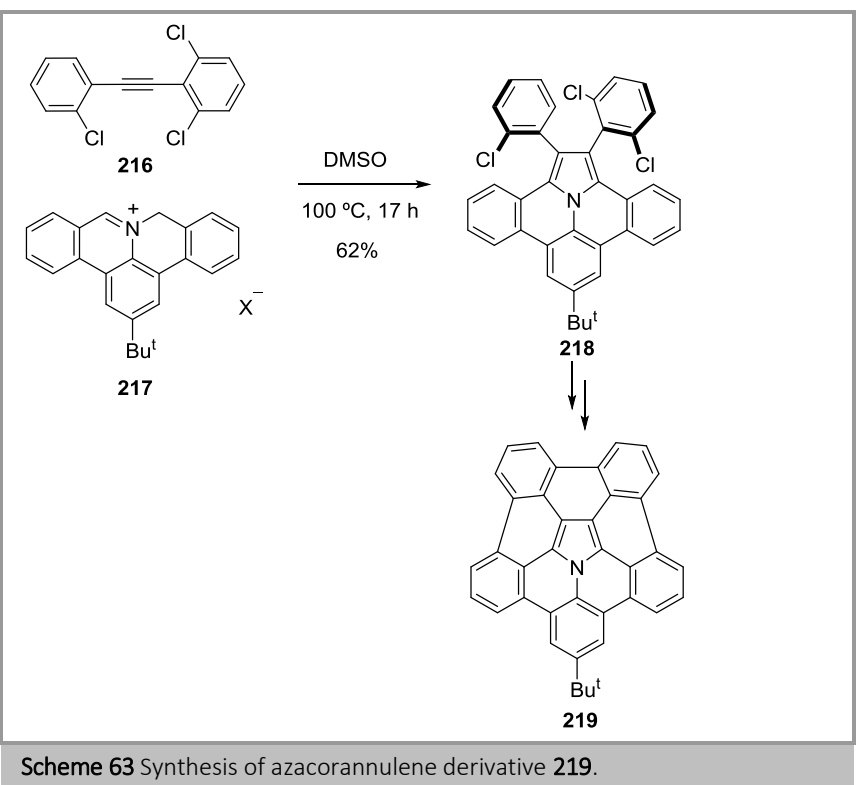

Amine $\mathbf{2 2 1}$ has been widely used for the generation of nonstabilized azomethine ylides under very mild conditions. In other side, the reaction of an azomethine ylide with a carbonyl group of an anhydride is not common. However, isobenzofuranone heterocycles $\mathbf{2 2 2}$ were obtained by the in situ generation of a dipole from $N$-silylatedbenzylamine $\mathbf{2 2 1}$ and phthalic anhydrides $\mathbf{2 2 0}$ affording spirooxazolidines $\mathbf{2 2 2}$ in very good yields and elevated regiocontrol (Scheme 64). ${ }^{95}$

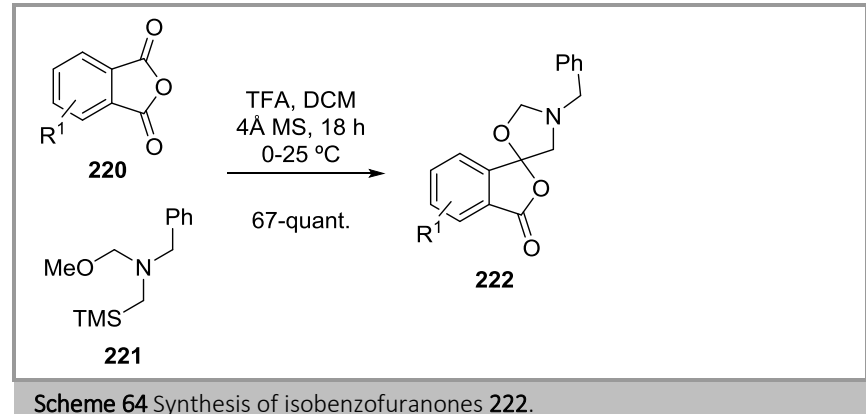

Pentafluorosulfanyl $\left(\mathrm{SF}_{5}\right)$ group is not very common in nature, so the biological study of compounds incorporating it is very attractive. Bouillon and co-workers published a 1,3-DC between $N$-(methoxymethyl)- $N$-[(trimethylsilyl)methyl]benzylamine 221 and $\mathrm{SF}_{5}$-substituted acrylic ester $\mathbf{2 2 3}$ or its corresponding amide as dipolarophiles afforded trisubstituted pyrrolidines 224 in good yields. In the case of using benzylideneglycine methyl ester 107, the 1,3-DC was produced in the presence of $\mathrm{AgOAc} / \mathrm{PPh}_{3}$ as catalyst furnishing almost equimolar mixtures of cycloadducts $\mathbf{2 2 5}$ and 226 (Scheme 65). ${ }^{96}$

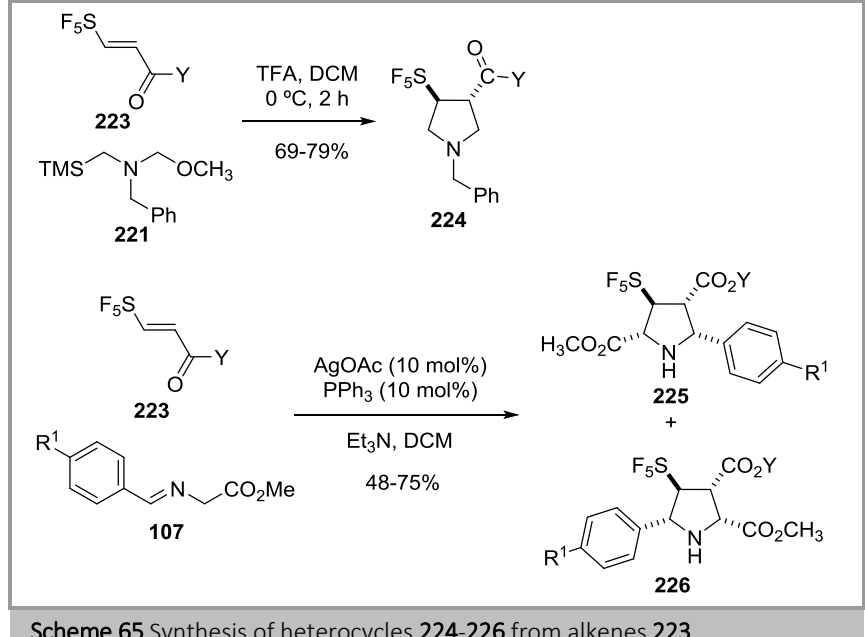

Scheme 65 Synthesis of heterocycles 224-226 from alkenes 223.

In this context, very interesting imidazolidines $\mathbf{2 2 8}$ were obtained during the employment of $N$-sulfinylketimines 227 as dipolarophiles in 1,3-DC with non-stabilized azomethine ylide precursor 221. In the presence of substoichiometric amounts of diphenyl phosphate the reaction proceeded in good yields and high diastereoselections (Scheme 66). ${ }^{97}$

An identical mode of generating the azomethine ylide from the $N$ (trimethylsilylmethyl)benzylamine 221 derivative was employed in the reaction with electrophilic alkenes incorporating a trifluoromethyl group, fluorinated acrylates or 3fluoromaleimides. The resulting $N$-benzylpyrrolidines were obtained in very high yields. ${ }^{98,99}$

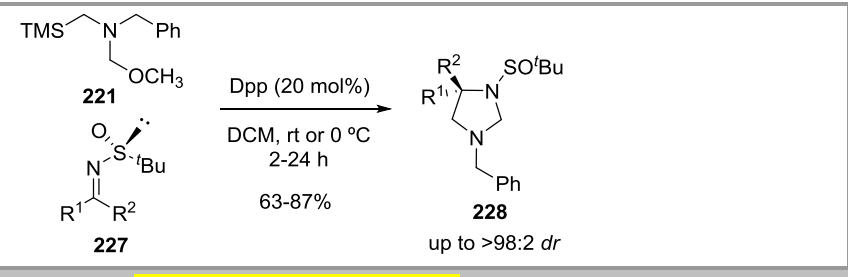

Scheme 66 Synthesis of imidazolidines 228 .

The silver-catalyzed multicomponent reaction between ethyl glyoxylate, 2,2-dimethoxyacetaldehyde, or phenylglyoxal as aldehyde components (in general 229) with $\alpha$-amino ester hydrochlorides $\mathbf{2 3 0}$ and a dipolarophile (for example, maleimides 94) in the presence of trimethylamine, was described. This domino process took place at room temperature by in situ liberation of the $\alpha$-amino ester followed by the formation of the imino ester, which is the precursor of a metalloazomethine ylide. The cycloaddition of this species and the corresponding dipolarophile afforded polysubstituted proline derivatives. Ethyl glyoxylate (229, $\mathrm{X}=\mathrm{CO}_{2} \mathrm{Et}$ ) reacted with glycinate, alaninate, phenylalaninate and phenylglycinate at room temperature in the presence of representative dipolarophiles affording endo-2,5-cis-cycloadducts 231 in good yields and high diastereoselection. In addition, 2,2dimethoxyacetaldehyde [229, $\left.\mathrm{X}=\mathrm{CH}(\mathrm{OMe})_{2}\right]$ was evaluated with the same amino esters and dipolarophiles, under the same mild conditions, generating the corresponding endo-2,5-cis- 
cycloadducts with higher diastereoselections than the obtained in the same reactions using ethyl glyoxylate. In the case of phenylglyoxal $(\mathbf{2 2 9}, \mathrm{X}=\mathrm{Ph})$ the corresponding 5-benzoyl-endo2,5-cis cycloadducts 231 were obtained in short reaction times and similar diasteroselections (Scheme 67). ${ }^{100}$ In these examples, a new functional group, different from alkyl or aryl substituents, was introduced.

Scheme 67 Synthesis of pyrrolidine cycloadducts 231.

The enantioselective version of these transformations was also separately reported for reactions run with ethyl glyoxylate and 2,2-dimethoxyacetaldehyde. Enantiomerically enriched substituted fused bicyclic pyrrolidine derivatives (231, $\mathrm{X}=$ $\mathrm{CO}_{2} \mathrm{Et}$ ) were obtained in a multicomponent 1,3-DC from ethyl glyoxylate $\left(\mathbf{2 2 9}, \mathrm{X}=\mathrm{CO}_{2} \mathrm{Et}\right)$ and phenylalanine $\left(\mathbf{2 3 0}, \mathrm{R}^{1}=\mathrm{Bn}\right)$ in the presence of $\mathrm{Ag}_{2} \mathrm{CO}_{3} \cdot(S)$-Binap 233 catalytic complex. 101 However, Taniaphos 234-silver fluoride complex was the appropriate catalyst to produce an enantioselective 1,3-dipolar cycloaddition using 2,2-dimethoxyacetaldehyde derived imino esters 232 and maleimides 94 (Scheme 68). ${ }^{102}$ The employment of both complexes in their respective transformations allowed the reaction in the absence of an extra base giving high yields and $e e$ of the corresponding endo-cycloadducts, so they acted as bifunctional catalysts.

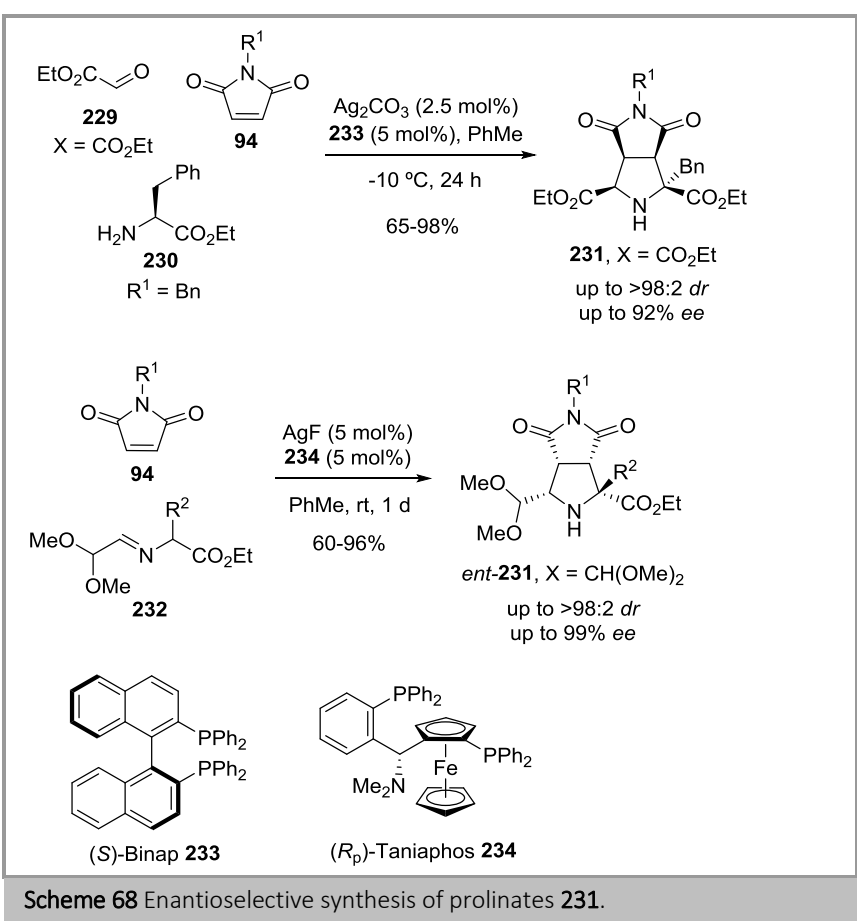

Scheme 68 Enantioselective synthesis of prolinates 231.
Enantiomerically enriched substituted bicyclic pyrrolidines fused to cyclopentanediones $\mathbf{2 3 7}$ were described by Wang et al. in the presence of $\mathrm{AgOAc}$ and (S)-TF-BiphamPhos 236 as catalytic system. The reaction was performed at $-20 \stackrel{\circ}{\circ}$ affording products 237 in good yield and high optical purity (up to $>99 e e$ ) (Scheme 69). ${ }^{103}$ Bicyclic heterocycles fused by pyrrolidine and cyclopentane moieties play a unique role in numerous bioactive naturally occurring compounds and pharmaceutical ingredients. This chiral catalytic complex was also employed for atroposelective desymmetrization of $\mathrm{N}$-(2-tbutylphenyl)maleimides during the enantioselective 1,3-DC affording enantiomerically pure cycloadducts 239 , which could be transformed into pyrrolines ( $\mathrm{eg} \mathrm{240}$ ) and pyrroles (eg 241) in good yields (Scheme 69). ${ }^{104} \mathrm{~A}$ similar approach was reported by Singh et al. with excellent enantioselections but employing PriPhosferrox $238(\mathrm{R}=\mathrm{Pr}){ }^{105}$

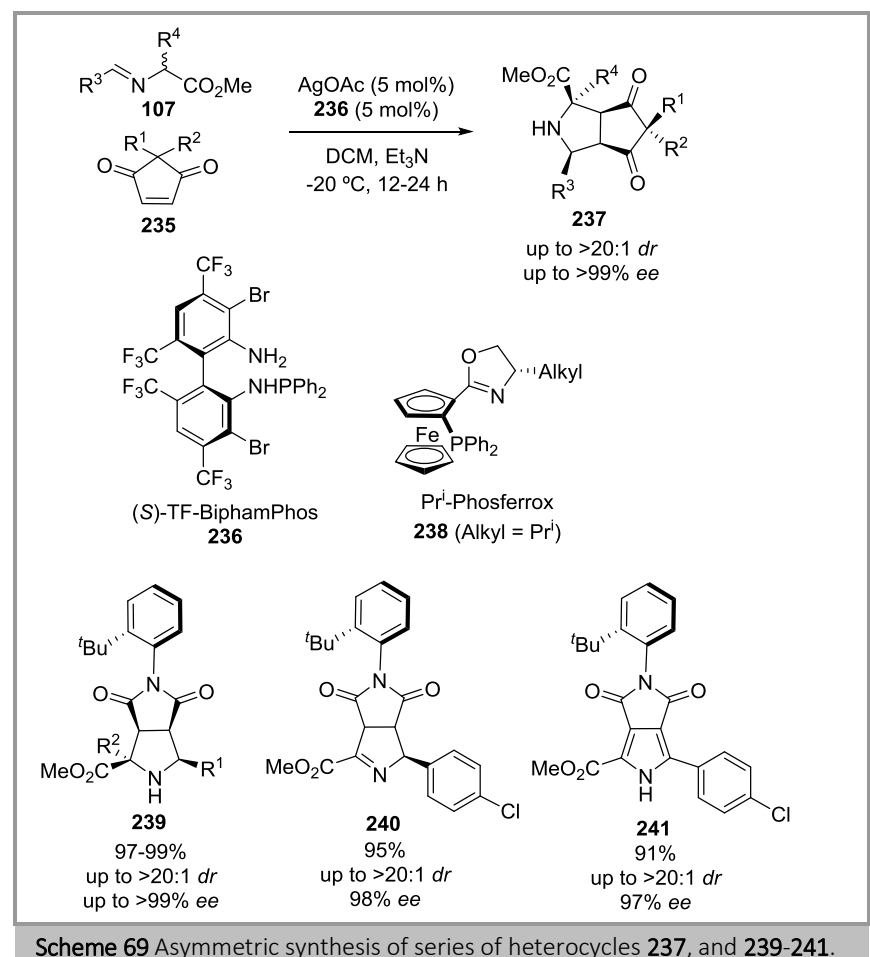

Biologically active isoxazolylpyrrolidines $\mathbf{2 4 4}$ were stereodivergently constructed by Wang and co-workers in the presence of AgOAc and various chiral ligands. The 1,3-DC with imino esters $\mathbf{1 0 7}$, alkene 242, using the catalyst system formed with But-Phosferrox 238 (Alkyl $=\mathrm{Bu}^{\mathrm{t}}$ ) gave diastereo- and enantioselectively endo-cycloadducts 244 in good yields. In contrast, the exo-cycloadducts were formed in the presence of chiral phosphoramidite ligand 243 (Scheme 70). ${ }^{106}$ 


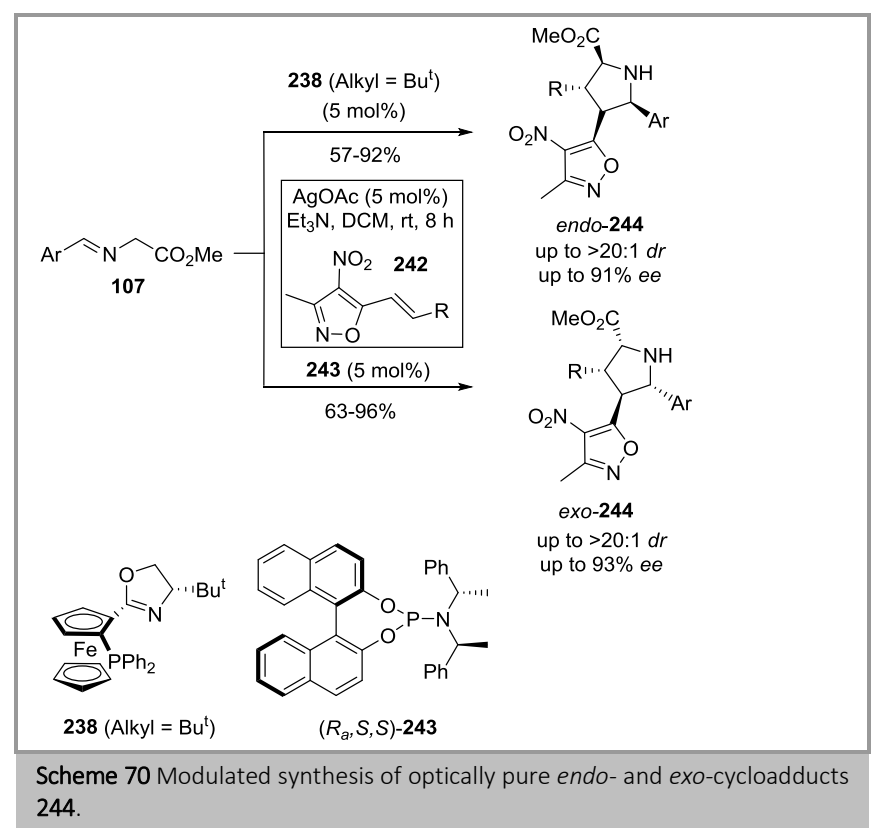

Attractive nitroprolinates $\mathbf{2 4 7}$ incorporating a trifluoromethyl group were employed in several biological tests. They were enantioselectively prepared from imino esters 107 and $\beta$ (trifluoromethyl)nitroalkenes $\mathbf{2 4 5}$ by intermediacy of a chiral copper(I).246 complex under mild conditions. In general enantio- and diastereoselections were excellent and chemical yields were good (Scheme 71).107

Scheme 71 Enantioselective preparation of nitroprolinates 247.

Diamino substituted pyrrolidine derivatives $\mathbf{2 5 2}$ are very attractive compounds in many scientific areas. Their synthesis was accomplished in a $\mathrm{Cu}(\mathrm{MeCN})_{4} \mathrm{BF}_{4} \cdot$ chiral bidentate ligand 249 catalyst system from iminoesters 107 and $\beta$ phthalimidonitroethylene 248. The endo-cycloadducts 251 were obtained as unique diastereoisomers and immediately underwent reduction with $\mathrm{Ni}$-Raney followed by generation of the second free amino group (Scheme 72). ${ }^{108}$ An analogous process, in which a modulation of the ligand was attempted, was reported during the enantioselective 1,3-DC of imino esters 107 and 2-phthalimidoylacrylates $\mathbf{2 5 3}$, mediated by chiral ligand 250, in very good yields and both excellent diastereo- and enantioselectivities. ${ }^{109}$ In general, prolinates and nitroprolinates exhibit many useful properties in sciece.

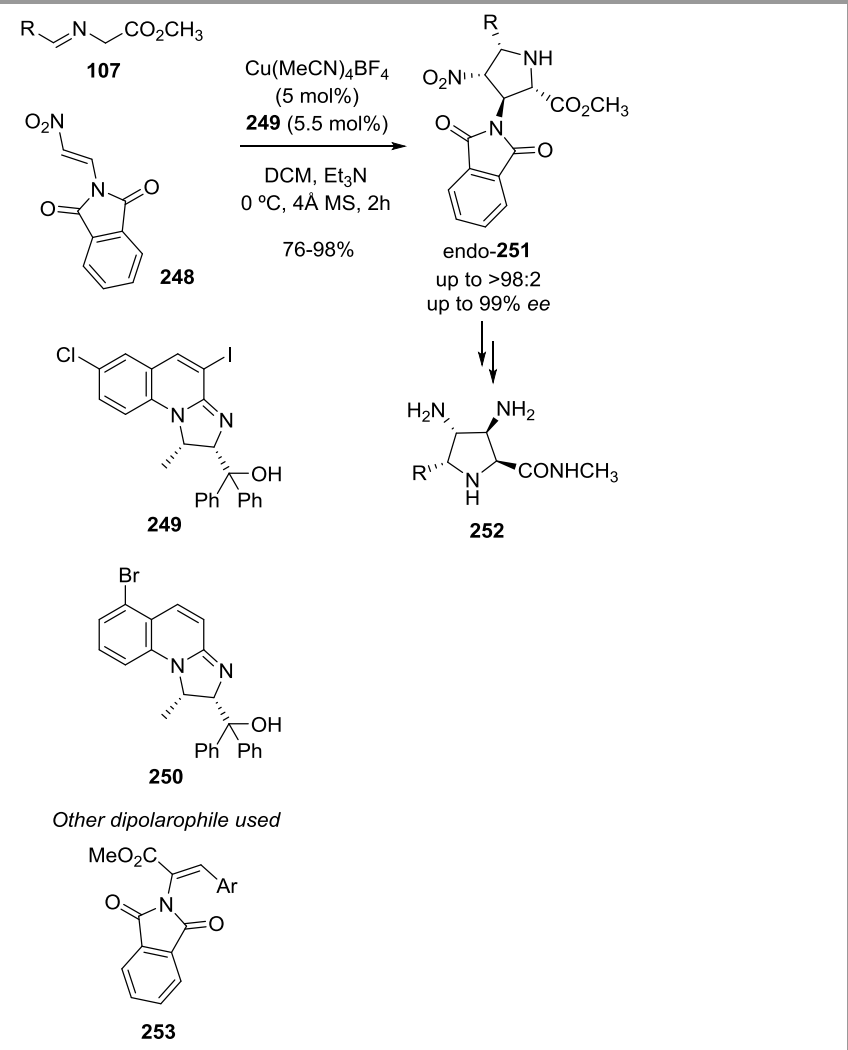

Scheme 72 Synthesis of enantiomerically enriched diamino substituted pyrrolidines 253

These imino esters also were allowed to react with nitrostyrene derivatives 129 through an enantioselective 1,3-DC reported by Fukuzawa et al.. AgOAc.ThioClickFerrophos (TCF) 254 complex, acting in a bifunctional mode, was the best catalyst to yield the corresponding endo-cycloadducts 255 (Scheme 73).110,111

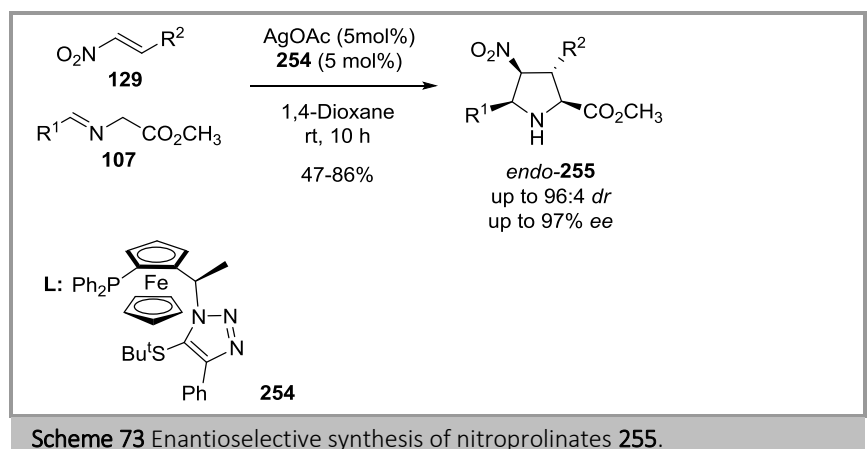

Enantioenriched exo'-pyrroloindolines $\mathbf{2 5 8}$ possesing four stereogenic centers were reported in the presence of an in situ generated catalyst system obtained from $\mathrm{Cu}(\mathrm{OTf})_{2}$ and $(R)$ Difluorphos 257, from alanine imino esters 107 and 3nitroindole surrogates $\mathbf{2 5 8}$. The dearomative 1,3-DC occurred in high diastereoselections and with notable enantioselectivities (Scheme 74).112 These tricyclic entities are present in many natural products and is a straightforward and simple manner to access them. 


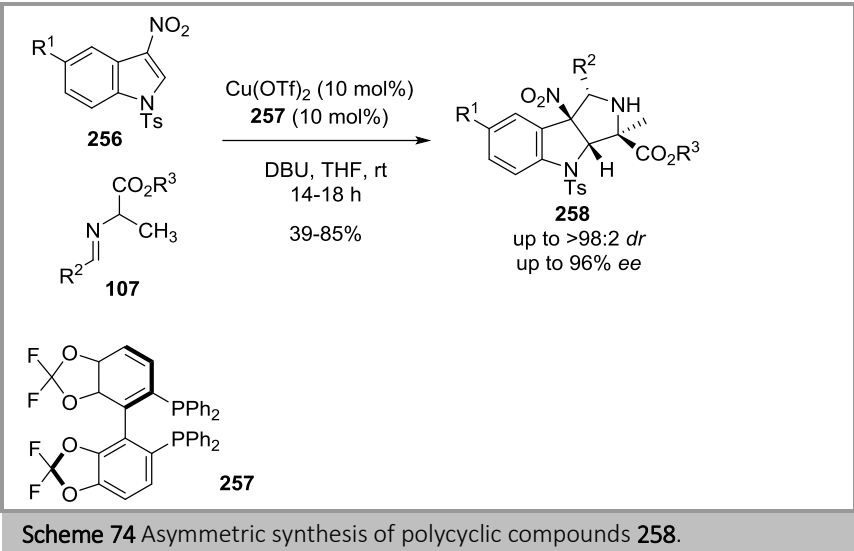

The synthesis of trifluoromethylated pyrrolidine derivatives $\mathbf{2 6 0}$ and $\mathbf{2 6 2}$ was reported by Carretero and co-workers. The hetereocycles were obtained from a series of trifluoromethylsubstituted iminoesters $\mathbf{2 5 9}$ or trifluoroethyl imines possessing a 2-pyridyl unit 261. The 1,3-DC proceeded in tert-butyl methyl ether (TBME) in very good yields and excellent endodiastereoselections with a variety of dipolarophiles $\mathbf{1 2 4}$ in the presence of $\mathrm{AgOAc} / \mathrm{PPh}_{3}$ and $\mathrm{Cs}_{2} \mathrm{CO}_{3}$ as base (Scheme 75). ${ }^{113}$ The enantioselective transformation using the chiral complex formed by AgOAc/Taniaphos 234 afforded endo-diastereoselection with high enantioselectivities of $\mathbf{2 6 2}$ (up to $92 \% e e$ ) under the same conditions.

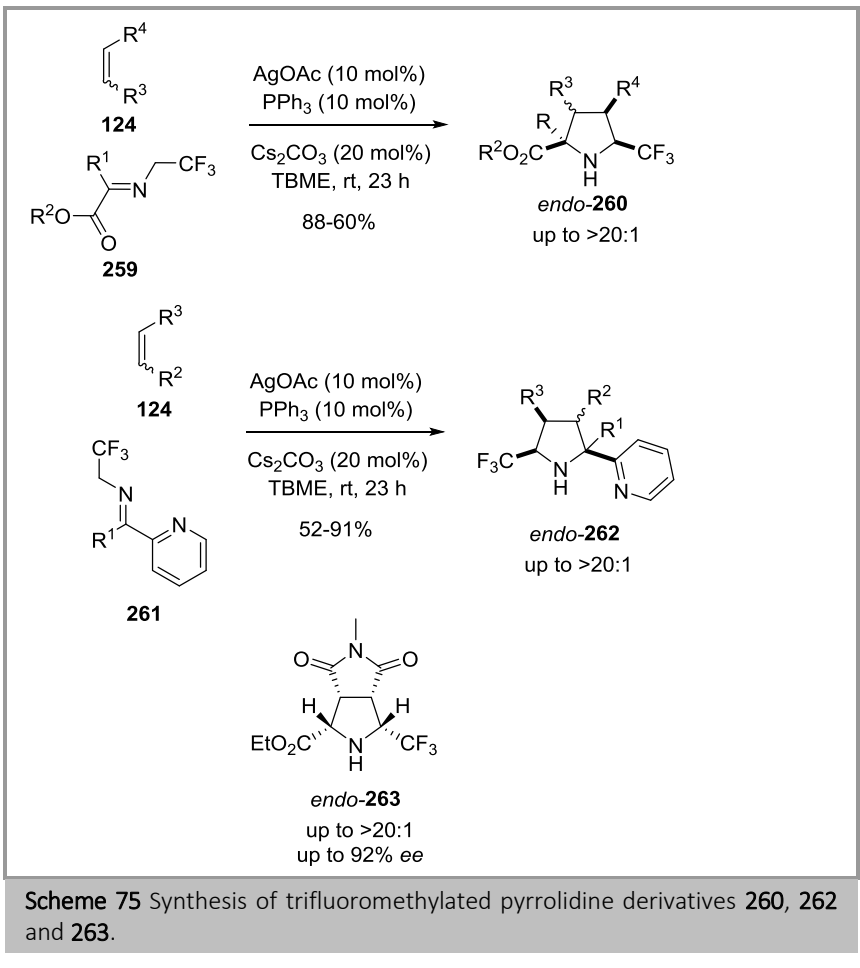

Some fused tricyclic heterocycles $\mathbf{2 6 6}$ were enantioselectively constructed by Waldmann and co-workers in the presence of $\mathrm{Cu}(\mathrm{MeCN})_{4} \mathrm{BF}_{4} \cdot \mathrm{Fesulphos}$ ligand $\mathbf{2 6 5}$ catalyst. Iminoesters $\mathbf{1 0 7}$ (2 equiv), cyclopentadiene $\mathbf{2 6 4}$ and the catalyst, under the optimized conditions, developed a multicomponent cascade reaction which allows the highly diastereo- and enantioselective synthesis of complex natural product cores 266 with eight stereocenters in moderate to good yields (Scheme 76). ${ }^{114} \mathrm{~A}$ notable feature of the process was the aerobic copper-catalyzed oxidation of cyclopentadiene to cyclopentadienone previous to the 1,3-DC.

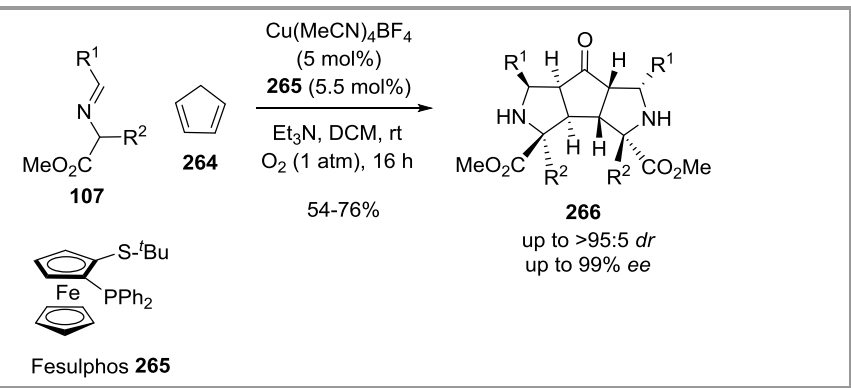

Scheme 76 Natural product frameworks 266 obtained via double 1,3-DC of azomethine ylides.

Carretero and co-workers have designed a very interesting stereodivergent methodology based in a 1,3-DC of azomethine ylides and an activated 1,3-diene 268. The cycloaddition occurred selectively at the terminal $\mathrm{C}=\mathrm{C}$ bond of the diene and, in basis of the chiral ligand employed, the diastereoselection can be controlled. Thus, DTBM-Segphos 269 and BTFM-Garphos 271 favored the formation of the exo- and endo-cycloadducts 272, respectively, in good yields, high diastereocontrol and excellent enantioselectivities (Scheme 77). ${ }^{115}$ This process had potential versatility to access to chromeno[4,3- $b$ ]pyrrole structures $\mathbf{2 7 3}$ and the tetracyclic skeleton core of the alkaloid gracilamine $\mathbf{2 7 4}$. The same research group reported a diastereoselective one-pot synthesis of hexahydrocyclopenta[ $b]$ pyrrole derivatives using a similar catalytic system with (E)-tert-butyl 6-bromo-2hexenoate and $\alpha$-imino esters. This enantioselective 1,3-DC was followed by an intramolecular alkylation. ${ }^{116}$ 


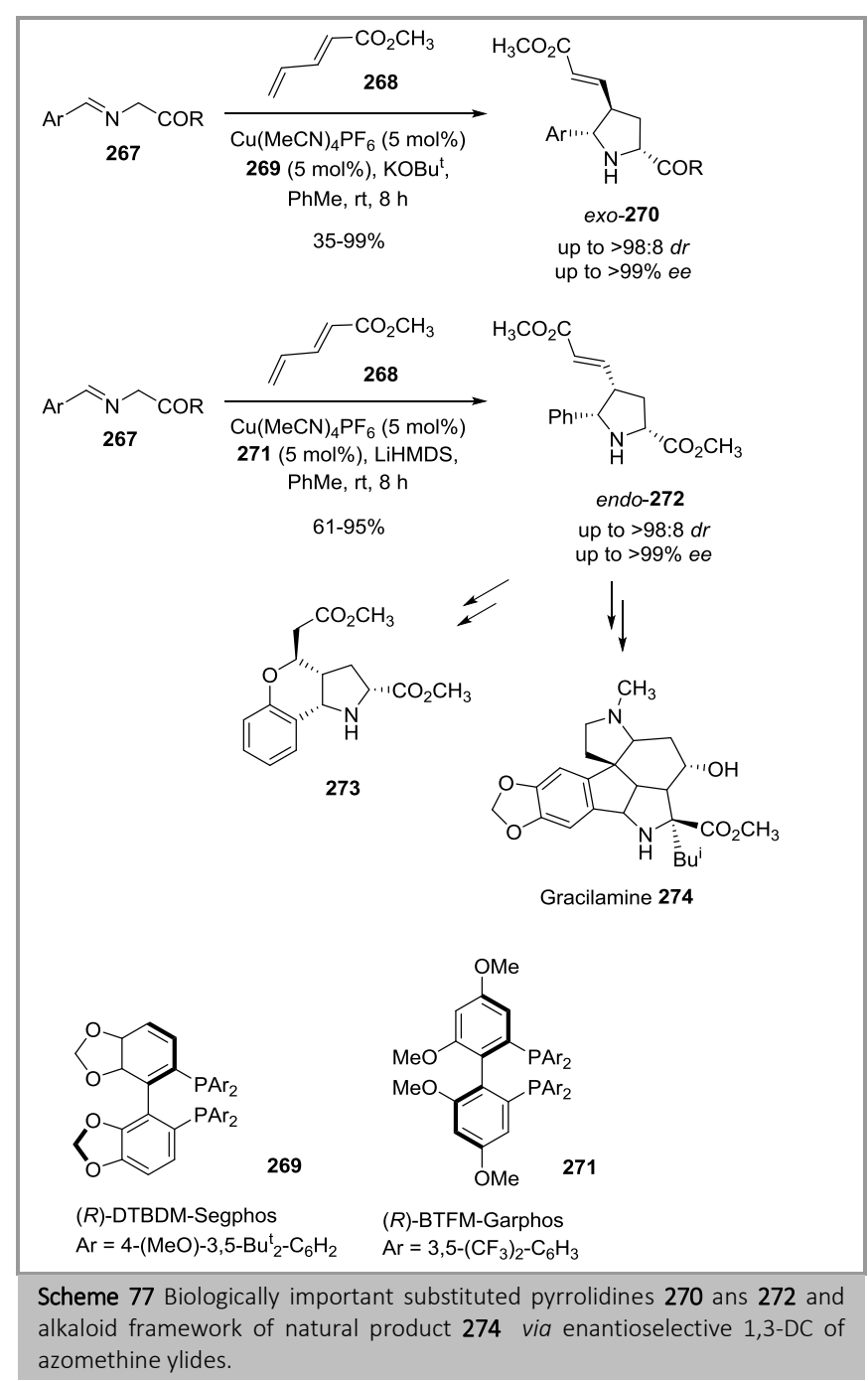

Tetrasubstituted endo-pyrrolidines $\mathbf{2 7 7}$ were prepared in the presence of a metal catalyzed system $\left(\mathrm{Ag}_{2} \mathrm{CO}_{3} /\right.$ chiral amidphos ligand 276). Imino esters 107 and dialkyl maleates 275 reacted at room temperature in good yields. This multifunctional catalyst was able to act in particular reactions with a Brönsted acid domain (Scheme 78).117,118
Chiral C-3 unsubstituted pyrrolidine cycloadducts 279 were reported by Vicario and co-workers in the presence of L-proline 1 as catalyst with the idea of preparing deoxyazasugar surrogates. The 1,3-DC was set up from diethyl arylideneaminomalonates $\mathbf{1 7 1}$ and with acrolein $\mathbf{2 7 8}$ as dipolarophile affording chiral cycloadducts, which were reduced to the corresponding primary alcohols $\mathbf{2 7 9}$ in good yields and high diastereo- and enantioselections (Scheme 79).119

These imino esters 171, derived from aminomalonates, and ethynyl ketones were also employed by Deng and co-workers in the enantioselective synthesis of chiral functionalised 2,5dihydropyrrole framework. In this example, the complex formed by $\mathrm{Cu}(\mathrm{OAc})_{2} \cdot \mathrm{Ph}$-PhosFerrox 146 was the selected catalyst affording cycloadducts in both high diastereoselectivities (98:2$>99: 1)$ and enantioselectivities (89-92\% ee).120

Scheme 79 Organocatalyzed 1,3-DC affording adducts 279.

Chiral organocatalysts were also very effective in enantioselective 1,3-DC of azomethine ylides generated from imino esters 107 and alkenes 137. Bioactive substituted pyrrolidines $\mathbf{2 8 1}$ fused to a cycloheptatriene unit were reported by Jørgensen et al. in the presence of chiral cyclopropenediamines $\mathbf{2 8 0}$ as chiral base catalyst. The reaction proceeded stereoselectively and produced one diastereoisomer in high enantioselections (Scheme 80). ${ }^{121}$ The transformations done in the diene part of cycloadduct gave access to new potentially bioactive heterocycles.

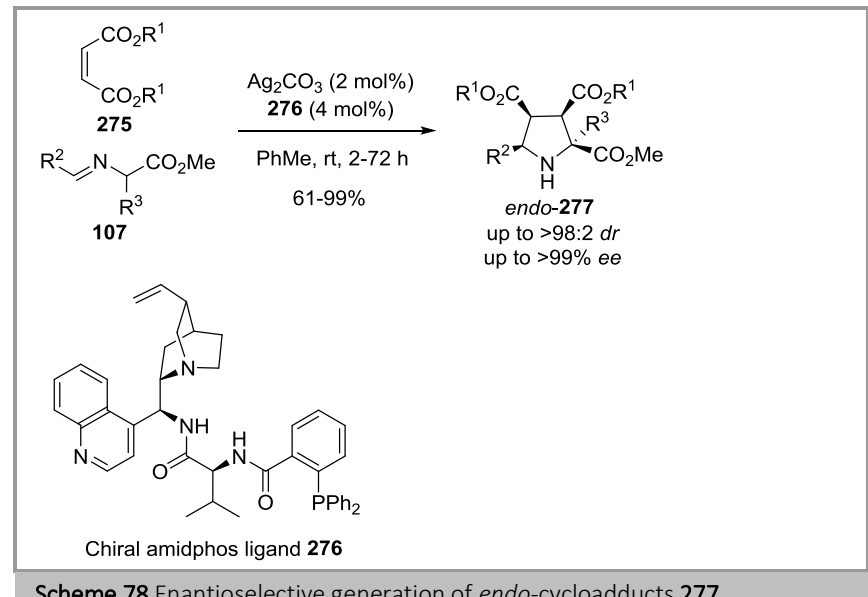

Scheme 78 Enantioselective generation of endo-cycloadducts 277 .

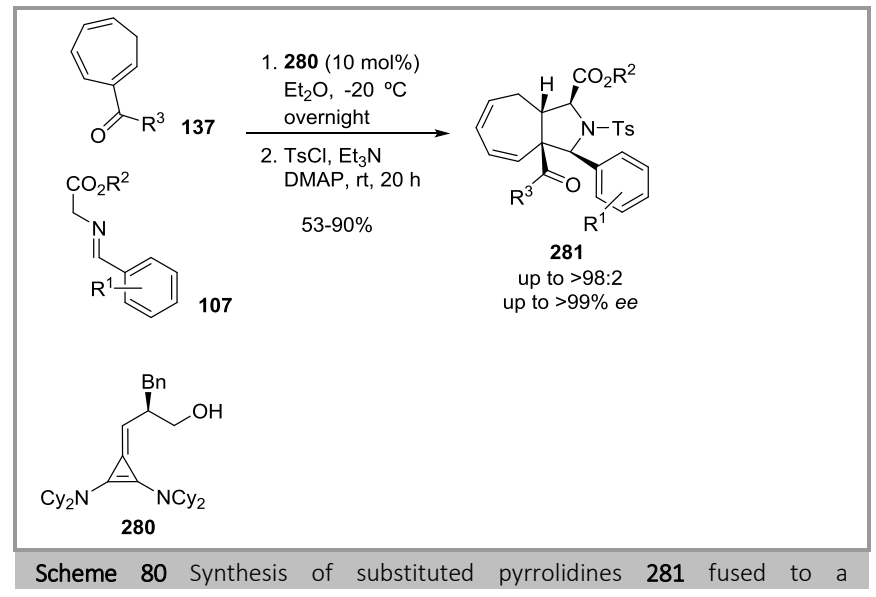

Scheme 80 Synthesis of substituted pyrrolidines 281 fused to a 
one-pot three-component reaction manner obtaining the desired compounds $\mathbf{2 9 0}$ together with an oxapyrrolizidine derivative in variable proportions. These substituted oxazolidines $\mathbf{2 9 1}$ arose when an excess of arylaldehyde $\mathbf{2 0}$ was employed, which acted

\section{Synthesis of pyrrolizidines and indolizidines}

as dipolarophile as well (Scheme 83). ${ }^{124}$

Pyrrolizidine nucleus is a very attractive skeleton due to the biological importance of molecules containing it. In this line, a range of biologically important spiropyrrolizidines $\mathbf{2 8 3}$ and $\mathbf{2 8 4}$ and pyrrolizinones $\mathbf{2 8 6}$ were reported by Yang et al. The threecomponent 1,3-DC of the corresponding 1,3-diketones $\mathbf{2 8 2}$ or hydoxycoumarins 285, aromatic aldehyde $\mathbf{2 0}$ and proline $\mathbf{1}$ took place in short reaction times assisted by microwave irradiation (Scheme 81).122

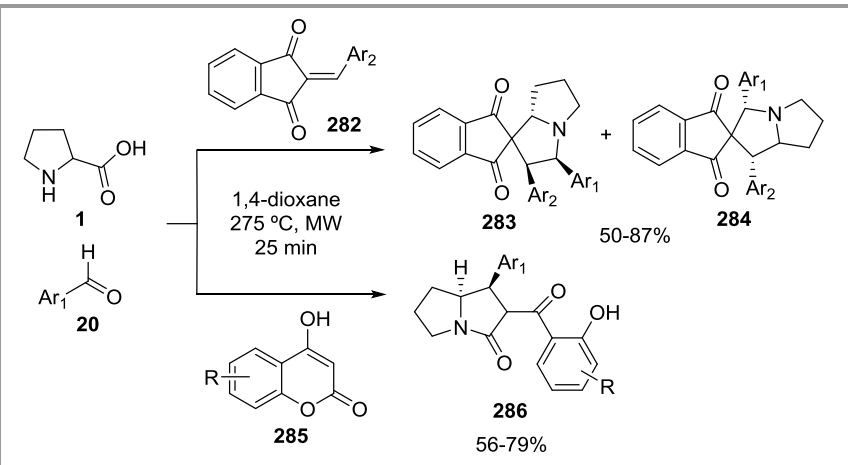

Scheme 81 Synthesis of functionalized pyrrolizidines 283 and 284 and pyrrolizinones 286 .

Highly substituted pyrrolizidines 288, bearing multiple functionality moieties, were prepared in a multicomponent 1,3dipolar cycloaddition. This simple process involved prolinate hydrochlorides 287, aldehydes $\mathbf{2 0}$ and the corresponding dipolarophiles 124. The reaction proceeded with both high regioand diastereoselectively to yield heterocycles in the presence or in the absence of AgOAc as catalyst depending on the aldehyde employed (Scheme 82). ${ }^{123}$ This cascade allowed the access to diverse molecular complexity, multiplication of stereocenters and access to potential bioactive pyrrolizidine alkaloids.

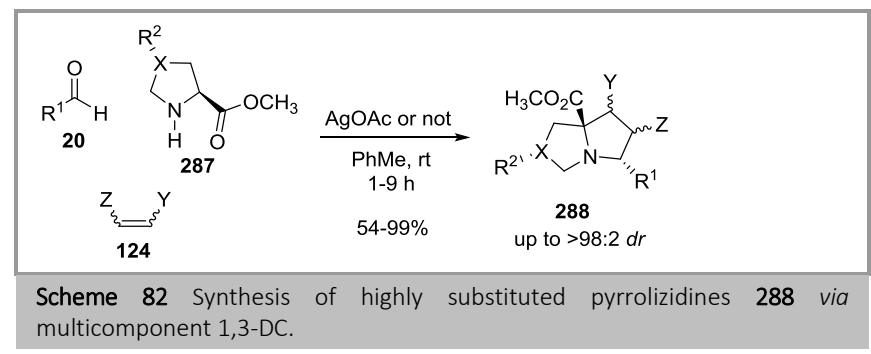

A novel one-pot three component iridium catalyzed dehydrogenation/1,3-dipolar cycloaddition cascade utilizing benzylic alcohols 292 was published. Benzylic alcohols 292, Lproline 1, and maleimides 94 as dipolarophiles reacted in refluxing toluene for $24 \mathrm{~h}$ furnishing antimicrobial surrogates 293 as mixtures of endo/exo-diastereoisomers in good yield (Scheme 84). ${ }^{125}$

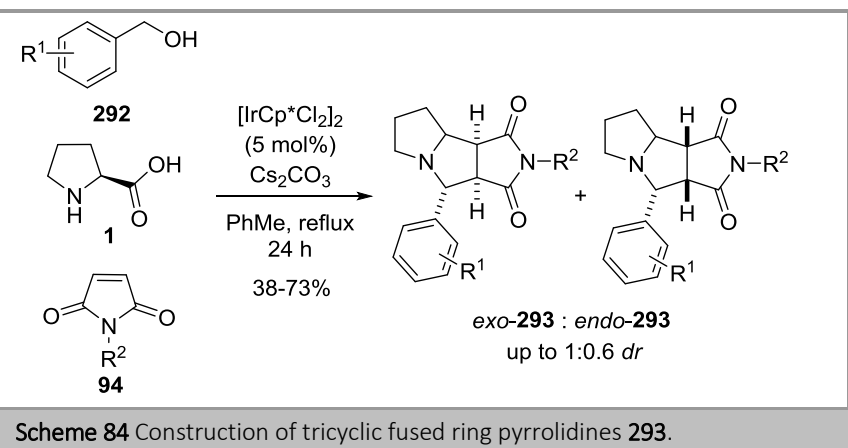

The total synthesis of the proposed structure of yuremamine $\mathbf{2 9 6}$ was achieved from a [3+2]-cycloaddition of the platinumcontaining azomethine ylide (XIV $\rightarrow$ XIV'). The spectral data of the synthetic sample along with its diastereomers were different from the reported one. Lavonoidal skeleton, based on a funcionalized pyrrolo[1,2- $a$ ] indole core, was achieved with $\mathrm{PtCl}_{2}$ (5 mol\%) and 4A MS from the corresponding imine 294 derived from ortho-alkynylanilines. The intermediate platinumcontaining azomethine ylide XIV' underwent and intermolecular 1,3-DC with vinyl ether 295. The intermediate platinum carbine suffered a 1,2-migration of the substituent $\left(\mathrm{CH}_{2}\right)_{2} \mathrm{OTIPS}$ with regeneration of the platinum catalyst to afford the already mentioned pyrroloindole skeleton 296 (Scheme 85). ${ }^{126}$

Another example of the synthesis of trisubstituted pyrrolizidines was recently reported via 1,3-DC of nonstabilized azomethine ylides and chalcones $\mathbf{2 8 9}$ as electron-deficient dipolarophiles in DMF. The reaction proceed regio- and diastereoselectively in a 


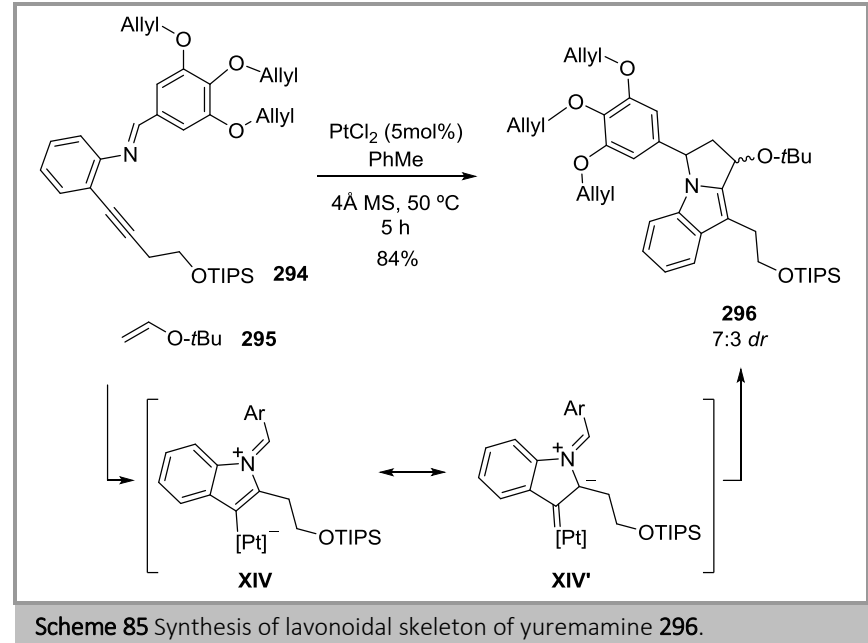

Pandey et al. have recently developed a route to total synthesis of both enantiomers of the biologically active (+)-aspidospermidine 299, whose key step was the preparation of a fused indolizidine core through 1,3-DC using a non-stabilized azomethine ylide XV from precursor 297. The enantiomerically pure starting material afforded only one diastereoisomer possessing the precise absolute configuration in all stereogenic centers (Scheme 86). ${ }^{127}$

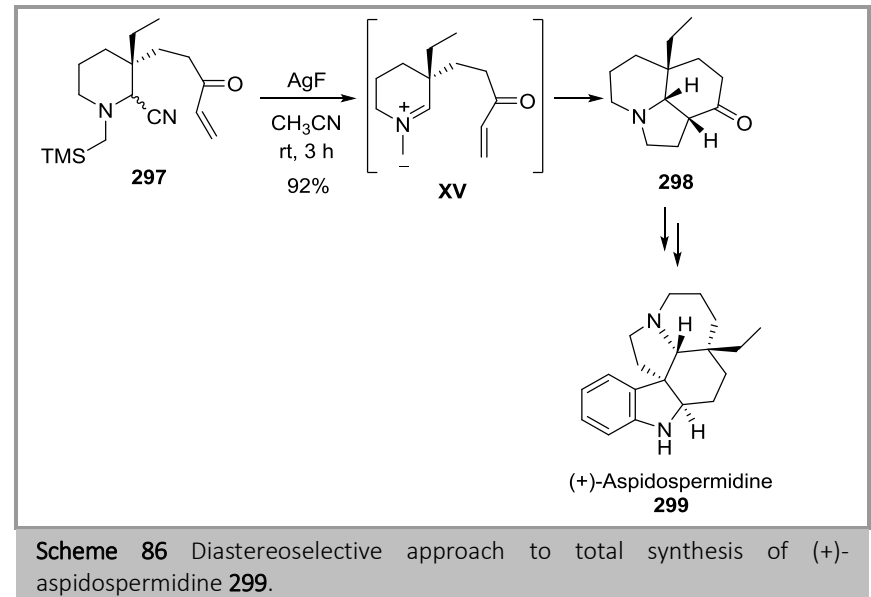

Following an intramolecular key 1,3-DC pattern, Fukuyama and co-workers accomplished the total synthesis of (-)-daphenylline 302. The completion of the synthesis of core $A B C$ tricyclic ring 301 occurred stereospecifically in moderate yield under very harsh reaction conditions due to the low activation of the dipolarophile present in structure 300. In this example, a stabilized azomethine ylide was generated in situ by the iminium route (Scheme 87). ${ }^{128}$
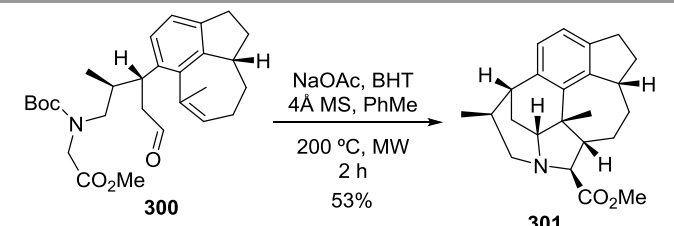

$\mathrm{BHT}=$ 2,6-di-tert-butyl-4-hydroxytoluene

301

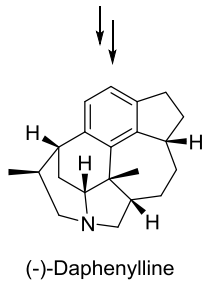

302

Scheme 87 Intramolecular 1,3-DC of cyclic azomethine ylide employed in the synthesis of (+)-daphenylline 302 .

Biologically important core intermediates 304 permitted the access to extremely complex $( \pm)$-caldaphnidine $C$ type alkaloids. Bélanger et al. designed a sequential Vilsmeier-Haack (V-H) cyclization and intramolecular 1,3-DC of an azomethine ylide with an electrophilic alkene as one of the key step of the total synthesis. The V-H cyclization occurred rapidly generating an iminium salt XVI, which was deprotonated and allowed to react with the activated olefin at room temperature in high yields (Scheme 88).129

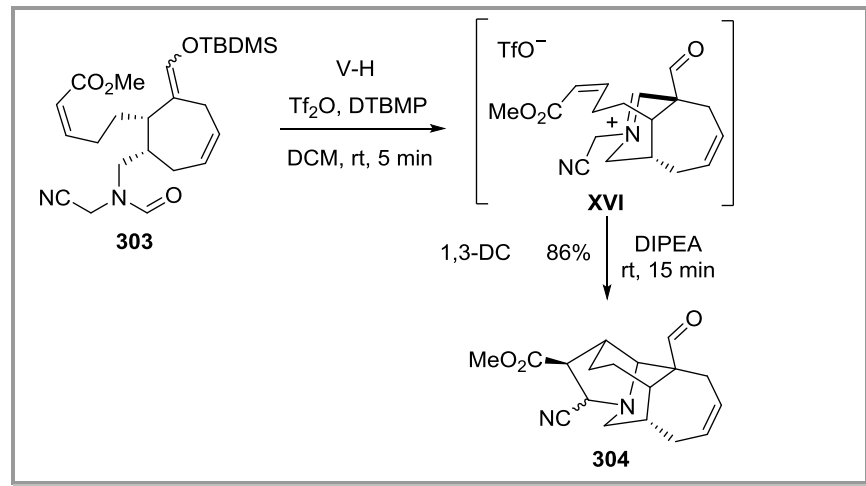

Scheme 88 Synthesis of core intermediate to access $( \pm)$-caldaphnidine $C$ type alkaloid 304.

Recently Brewer et al. have reported an approach to the synthesis of the biologically active tricycle, which is the core CDE-ring system of the aspidosperma alkaloid family 308. Initially, the fragmentation of diazo ester $\mathbf{3 0 5}$ took place using In(OTf $)_{3}$ under mild conditions affording an intermediate stable iminium salt. After treatment of $\mathbf{3 0 6}$ with $\mathrm{CsF}$ in acetonitrile the tricyclic cycloadduct $\mathbf{3 0 7}$ was isolated in good yields as a single diastereomer (Scheme 89). ${ }^{130}$ 


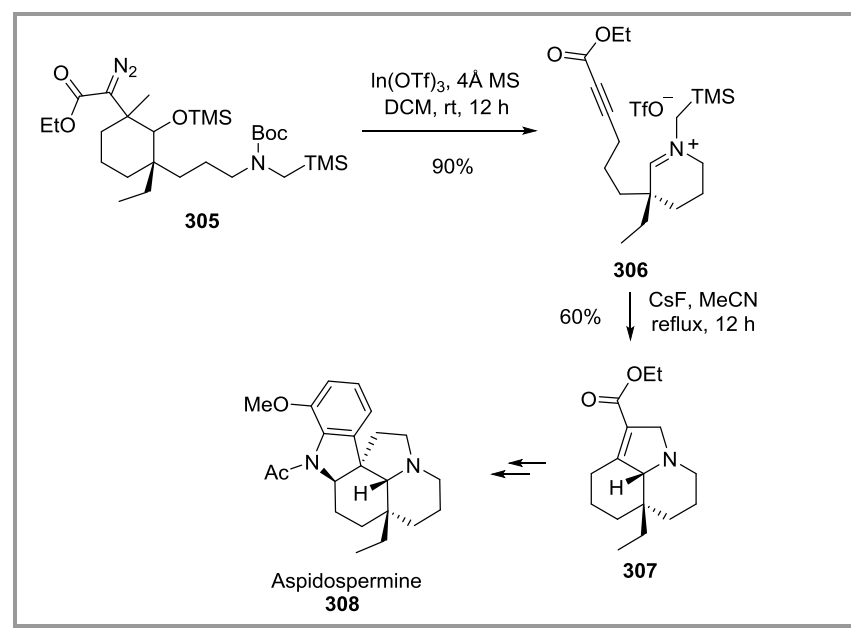

Scheme 89 Ring Fragmentation/Intramolecular Azomethine Ylide 1,3-DC for the synthesis of the aspidosperma tricyclic core 308

Ellman and co-workers described the synthesis of potentially bioactive tropanes 310 and 311, and indolizidines 313 and 314 skeletons through intramolecular 1,3-DC. Non-stabilized azomethine ylides, generated from readily prepared 2trimethylsilyl-substituted 1,2-dihydropyridines 309 or from $N$ (trimethylsilylmethyl)-1,2-dihydropyridines

$312 \quad$ via protonation or alkylation followed by desilylation, were selected to react with alkenes or alkynes. In the first example, densely substituted tropanes $\mathbf{3 1 0}$ and $\mathbf{3 1 1}$, incorporating quaternary carbons, were obtained in good yields and with high regio- and stereoselectivities. However, $N$-trimethylsilylmethyl derivatives $\mathbf{3 1 2}$ furnished regio- and diastereoselectively indolizidines $\mathbf{3 1 3}$ or fused oxazolidine heterocycles $\mathbf{3 1 4}$ depending on the dipolarophile employed (Scheme 90).131 These cascades represented a powerful approach for the rapid assembly of biologically and pharmaceutically relevant nitrogen heterocycle scaffolds. Additionally, all these heterocycles reported in this work are difficult to synthesize by other methods. The implementation of this sequence into the synthesis of natural products are underway.

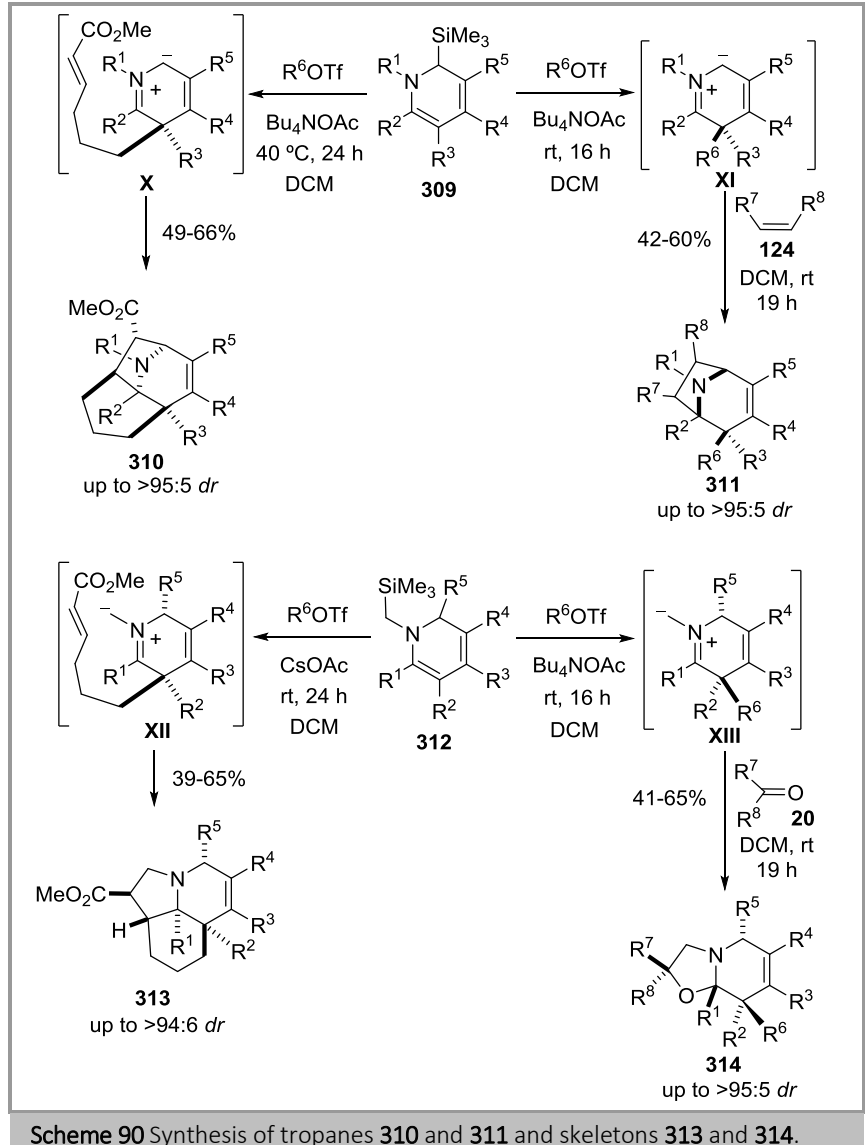

\section{Synthesis of quinolines and isoquinolines}

Tri- and tetra-cyclic pyrrolo/pyrrolizinoquinoline $\mathbf{3 1 6}$ and $\mathbf{3 1 8}$ were prepared. $N$-allylated aldehyde $\mathbf{3 1 5}$ and sarcosine $\mathbf{1 3}$ produced tricyclic pyrrolo[3,2-c]quinolines 316 in good yields. The analogous reactions were surveyed with proline $\mathbf{1}$ instead of sarcosine 13 and aldehyde $\mathbf{3 1 7}$ giving attractive fused tetracyclic pyrrolizinoquinolines $\mathbf{3 1 8}$ with a promising biological potential. The reaction afforded the best yields in refluxing acetonitrile with a total diastereoselection (Scheme 91). ${ }^{132}$

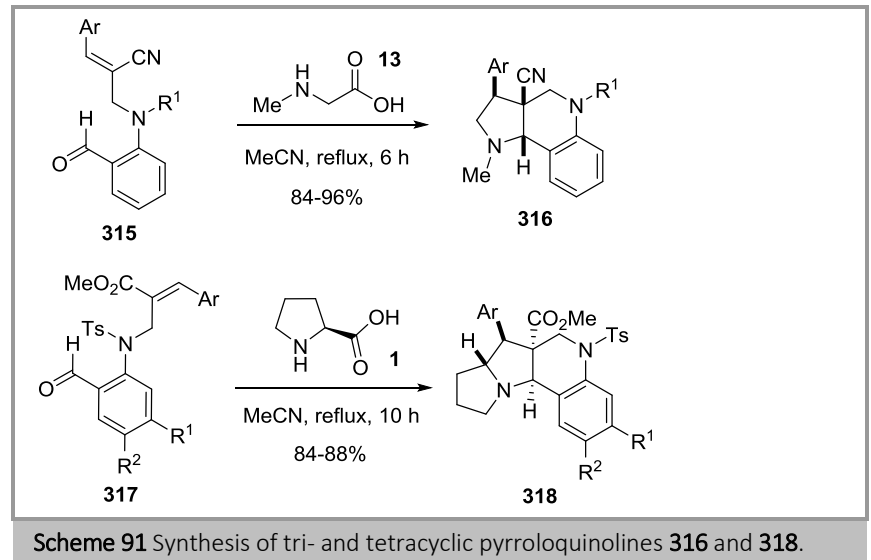

Scheme 91 Synthesis of tri- and tetracyclic pyrroloquinolines 316 and 318 . 
Biologically important substituted pyrrolo[2,1-a]isoquinolines 321 were described by Matsuya and co-workers in the presence of a [(CyJohnPhos)AuCl/AgOTf] catalytic system in 1,2dichloroethane (DCE). In this stereoselective process, a previous 6-exo-dig-cyclization occurred generating the azomethine ylide XVII, which reacted with several dipolaraophiles $\mathbf{1 2 4}$ affording pyrroloisoquinoline heterocycles $\mathbf{3 2 1}$ (scheme 92).133

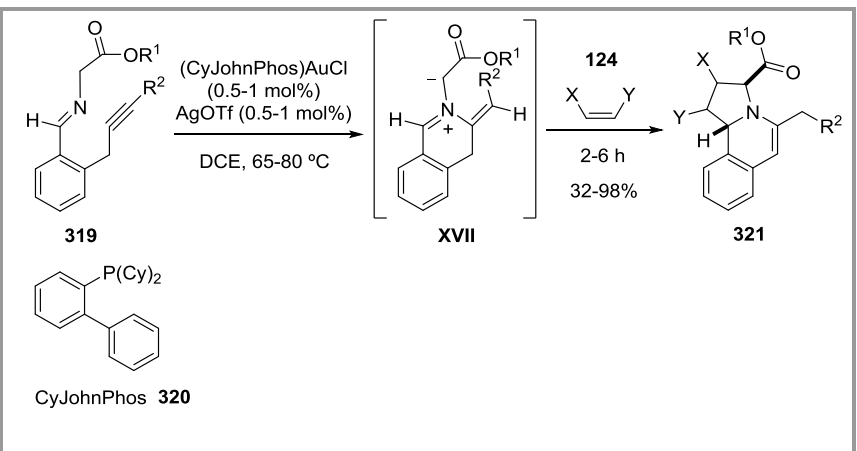

Scheme 92 Stereoselective synthesis of pyrrolo[2,1-a]isoquinolines 321.

Chiral pyrroloisoquinolines $\mathbf{3 2 7}(\mathrm{X}=\mathrm{CH})$ and pyrrolophthalazine $327(X=N)$ were reported employing an asymmetric inverseelectron demand 1,3-dipolar cycloaddition of isoquinolinium methylides 324 with enecarbamates 325 . The catalytic system was formed by $\mathrm{AgBF}_{4}$ and a chiral $N, N^{\prime}$-dioxide 326. Azomethine ylides $\mathbf{3 2 4}$ (isoquinolinium dicyanomethanide or phthalazinium dicyanomethanide) were generated from isoquinolines or phthalazines $\mathbf{3 2 2}$ and tetracyanoethylene oxide (TCNEO) 323. Final fused tricyclic heterocycles $\mathbf{3 2 7}$ were obtained in good to excellent chemical yields, high diastereoselections and very good enantioselectivities (Scheme 93). ${ }^{134,135}$

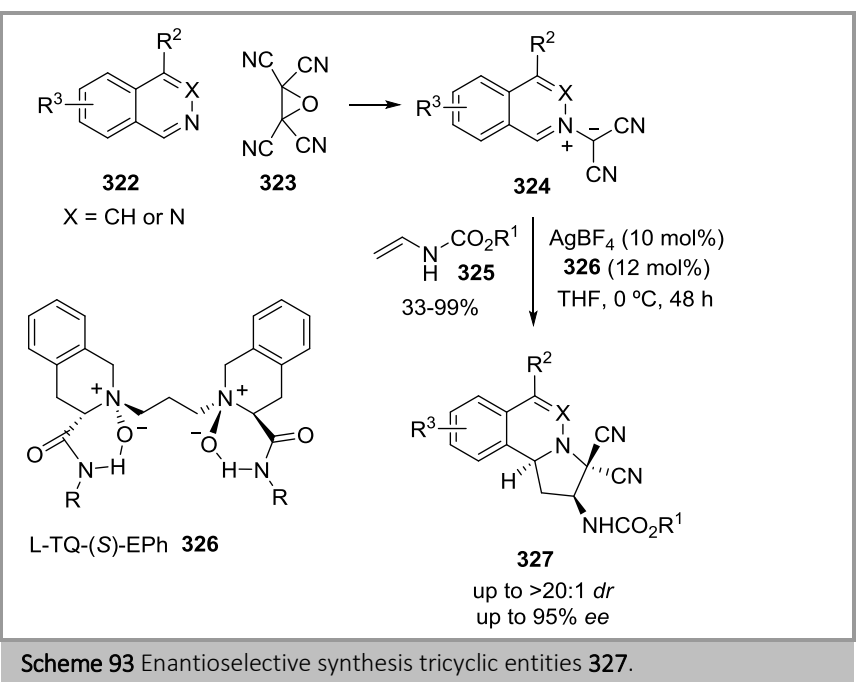

Biologically active heterocycles 331, containing both indolizines and quinoline core structures, were designed by Yavari and coworkers. Pyridinium ylides XVIII, generated by an iodinemediated reaction of 2-methylquinolines $\mathbf{3 2 8}$ and pyridines $\mathbf{3 2 9}$, underwent 1,3-DC with phosphorylated hydroxyketenimines
330. This one pot multicomponent cascade process afforded the desired heterocycles 331 in good yields (Scheme 94). ${ }^{136}$

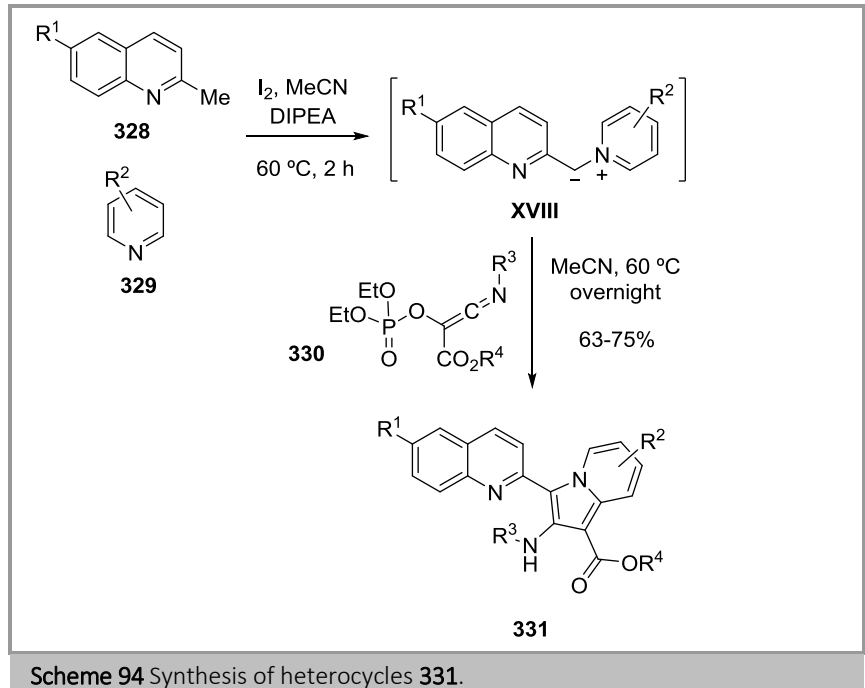

Pyrroloisoquinolines $\mathbf{3 3 4}$ were generated in moderated to high yields via 1,3-DC of azomethine ylide, obtained from isoquinolinium salts $\mathbf{3 3 2}$ with substituted ethyl allenoates $\mathbf{3 3 3}$. The pyrrole structure was achieved after elimination and isomerization occurring during the cycloaddition under basic media (Scheme 95). ${ }^{137}$ The synthetic utility of the cycloaddition products 334 can be demonstrated by simple chemical manipulations permitting the construction of more sophisticated biologically active compounds.

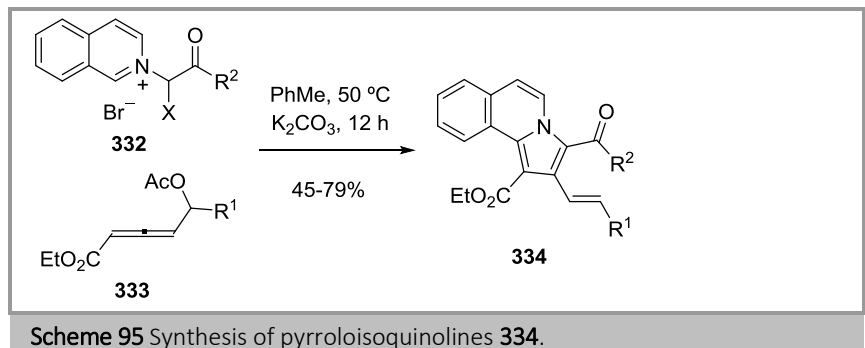

\section{Conclusions}

According to all these sections it is reasonable to conclude that 1,3-DC involving azomethine ylides is a powerful tool in both asymmetric or not asymmetric modalities able to give access to a wide family of skeletons. The exploration and exploitation of their biological activity is preferential for the discovery of new applications of the resulting cycloadducts in many scientific areas. The scope of theses cycloadditions seems to be unlimited and one of main interests of these 1,3-DC is the building of central subunits of complex alkaloids in a reduced number of reaction steps. 


\section{Acknowledgment}

We thank Mersin University (Project no. BAP 2015-AP2-1342), and Universities of Seville and Alicante for their support. We also thank funding by the Spanish Ministerio de Ciencia e Innovación (MICINN) (Consolider INGENIO 2010 CSD2007-00006, CTQ2004-00808/BQU, CTQ2007-62771/BQU, CTQ2010-20387 and the Hispano-Brazilian project PHB2008-0037-PC), the Spanish Ministerio de Economía y Competitividad (MINECO) (projects CTQ2013-43446-P and CTQ201451912-REDC) FEDER, Generalitat Valenciana (PROMETEO/2009/039, and PROMETEOII/2014/017). M.G.R. thanks Junta de Andalucía (Grant 2012/FQM 1078 and a postdoctoral fellowship).

\section{Biosketches}

H.Ali Döndaş received his BSc. in 1990 from Inönü University, He received his MSc. in 1993 from
Çukurova University and received his PhD degree in 1997 under the supervision of Professor Ronald
Grigg (University of Leeds, UK) and received Best Ph.D Thesis award. In 1997 he was appointed
Assistant Professor and become Associate Professor in 2001 at Mersin University. Since March 2007,
he has been promoted to full Professor at Mersin University Faculty of Pharmacy, were he is currently
the head of department at Basic Pharmaceutical Science.
He has been working as Post-Doctoral Research Fellows (2000-2001) at University of Leeds (UK) with
Professor Ronald Grigg and Post-Doctoral Research Fellows (2004) at University of Gent, Faculty of
Bioscience Engineering Gent-Belgium with Professor Norbert De Kimpe.
He has also been working as Visiting Researcher in 1998, Visiting Scholar in 2003 and 2005 at the
University of Leeds, He was invited Visiting Research Scientist at the University of Leeds in 2008, 2015
and 2016.

\begin{tabular}{|l|l|} 
Maria de Gracia Retamosa received her Ph.D. in 2008 at University of Alicante (Spain) under the \\
guidance of Prof. Carmen Nájera and José Miguel Sansano. After that, she did several postdoctoral stays \\
[Prof. Michael Greaneyat at the University of Edimburgh (UK, 2009), Prof. Jesús M. Sanz at the \\
University Miguel Hernández (Elche, Spain, 2009-2011) and Prof. Fernando P. Cossío at the University \\
of the Basque Country and Donostia International Physics Center (Spain, 2012-2016)]. Recently, she \\
has joined to the group of Prof. Rosario Fernández and José M. Lassaletta as a postdoctoral researcher \\
[CSIC (Sevilla, Spain)]. Her current research interests include asymmetric metal and organocatalysis \\
and synthesis of compounds with pharmacological interest.
\end{tabular}

José Miguel Sansano was born in Rojales (Alicante), studied chemistry at the University of Alicante,
where he obtained his B.Sc. and Ph.D. degrees in 1988 and 1994, respectively. His Thesis was
supervised by Prof. C. Nájera and dealt about sulfone chemistry. After spending a two-year
postdoctoral stay at the University of Leeds (U.K.) with Prof. R. Grigg, he joined the University of
Alicante in 1996, where he was appointed Associate Professor in 2001. In 2010 he was promoted to
Full Professor in the same University. He was invited visiting Professor at Chuo University in 2014. He
is coauthor of more than 100 articles and he has supervised 10 PhD students.

\section{References}


(1)

\section{(5)}

(a) Huisgen, R. Angew. Angew. Chem. Int. Ed. Engl. 1963, 2, 565. (b) Huisgen R. Angew. Chem. Int. Ed. Engl. $1963,2,633$.

Baunach, M.; Hertweck, C. Angew. Chem. Int. Ed. 2015, 54, 12550.

(a) Naodovic, M.; Yamamoto, H. Chem. Rev. 2008, 108, 3132. (b) Nájera, C.; Sansano, J. M. Org. Biomol. Chem. 2009, 7, 4567. (c) Nájera, C.; Sansano, J. M.; Yus, M. J. Braz. Chem. Soc. 2010, 21, 377. (d) Kissanea, M.; Maguire A. R. Chem. Soc. Rev. 2010, 39, 845. (e) Adrio, J.; Carretero, J. C. Chem. Commun. 2011, 47, 6784. (f) Nájera, C.; Sansano, J. M. Curr. Topics Medicinal Chem. 2014, 14, 1568. (g) Maroto, E. E.; Izquierdo, M.; Reboredo, S.; Marco-Martínez, J.; Filippone, S.; Martín, N. Acc. Chem. Res. 2014, 47, 2660. (h) Narayan, R.; Potowski, M.; Jia, Z.-J.; Antonchick, A. P.; Waldmann, H. Acc. Chem. Res. 2014, 47, 1296. (i) Nájera, C.; Sansano, J. M. J. Organomet. Chem. 2014, 771, 78. (j) Li, J.; Zhao, H.; Zhang Y. Synlett 2015, $26,2745$. (k) Yoo, E. J. Synlett 2015, 26, 2189. (l) Ryan, J. H. Arkivoc 2015, (i), 160. (m) Hashimoto, T.; Maruoka, K. Chem. Rev. 2015, 115, 5366. (n) Pavlovska, T. L.; Gr. Redkin, R.; Lipson, V. V.; Atamanuk, D. V. Synth. Biol. Activ. Mol. Divers 2016, 20, 299. (o) Meyer, A. G.; Ryan, J. H. Molecules $2016,21,935$. (p) Singh, M.S.; Chowdhury, S.; Koley, S. Tetrahedron 2016, 72, 1603. (q) Nájera, C.; Sansano, J. M. Chem. Record 2016, $16,2430$.

Dispiroindole derivatives are known to have antidiabetic, anticancer, antitubercular, antibacterial as well as antimicrobial activities. (a) Girgis, A. S. Eur. J. Med. Chem. 2009, 44, 91. (b) Ali, M. A.; Ismail, R.; Choon, T. S.; Yoon, Y. K.; Wei, A. C.; Pandian, S.; Kumar, R. S.; Osman, H.; Manogaran, E. Bioorg. Med. Chem. Lett. 2010, 20, 7064. (c) Ivanenkov, Y. A.; Vasilevski, S. V.; Beloglazkina, E. K.; Kukushkin, M. E.; Machulkin, A. E.; Veselov, M. S.; Chufarova, N. V.; Chernyaginab, E. S.; Vanzcool, A. S.; Zyk, N. V.; Skvortsov, D. A.; Khutornenko, A. A.; Rusanov, A. L.; Tonevitsky, A. G.; Dontsova, O. A.; Majouga, A. G. Bioorg. Med. Chem. Lett. 2015, 25, 404. (d) Murugan, R.; Anbazhagan, S.; Sriman-Narayanan, S. Eur. J. Med. Chem. 2009, 44, 3272. (e) Prasanna, P.; Balamurugan, K.; Perumal, S.; Yogeeswari, P.; Sriram, D. Eur. J. Med. Chem. 2010, 45, 5653. (f) Karthikeyan, K.; Sivakumar, P. M.; Doble, M.; Perumal, P. T. Eur. J. Med. Chem. 2010, 45, 3446. (g) Arun, Y.; Bhaskar, G.; Balachandran, C.; Ignacimuthu, S.; Perumal, P. T. Bioorg. Med. Chem. Lett. 2013, 23, 1839.

Pavlovska, T. L.; Redkin, R. G.; Lipson, V. V.; Atamanuk, D. V. Mol. Divers. 2016, 20, 299.

Rouatbi, F.; Askri, M.; Nana, F.; Kirsch, G.; Sriram, D.; Yogeeswari, P. Tetrahedron Lett. 2016, 57, 163.

Isatins and various primary or cyclic secondary amines formed azomethine ylides which underwent self 1,3 dipolar-[3+3]-cyclizations. Xia, P.-J.; Sun, Y.-H.; Xiao, J.-A.; Zhou, Z.-F.; Wen, S.-S.; Xiong, Y.; Ou, G.-C.; Chen, X.-Q.; Yang, H. J. Org. Chem. 2015, 80, 11573.

Tiwari, K. N.; Pandurang, T.P.; Pant, S.; Kumar, R. Tetrahedron Lett. 2016, 57, 2286.

Malini, M.; Periyaraja, S.; Shanmugam, P. Tetrahedron Lett. 2015, 56, 5123.

Taghizadeh, M.-J.; Javidan, A.; Jadidi, K. J. Korean Chem. Soc. 2015, 59, 205.

Li, G.; Wu, M.; Liu, F.; Jiang, J. Synthesis 2015, 47, 3783.

Dong, H.; Song, S.; Li, J.; Xu, C.; Zhang, H.; Ouyang, L. Bioorg. Med. Chem. Lett. 2015, 25, 3585.

Muthusamy, S.; Kumar, S. G. Tetrahedron 2016, 19, 2392.

Nayak, S.; Mishra, S. K.; Bhakta, S.; Panda, P.; Baral, N.; Mohapatra, S.; Purohit, C. S.; Satha, P. Lett. Org. Chem. 2016, $13,11-21$.

Dhanalakshmi, P.; Babu, S. S.; Thimmarayaperumal, S.; Shanmugam, S. RSC Adv. 2015, 5, 33705.

Chornous, V. A.; Mel'nik, O. Y.; Mel'nik, D. A. E. B.; Rusanov, E. B.; Vovk, M. V. Russ. J. Org. Chem. 2015, 51, 1423.

Barkov, A. Y.; Zimnitskiy, N. S.; Korotaev, V.-Y.; Kutyashev, I. B.; Moshkin, V. S.; Sosnovskikh, V.-Y. Tetrahedron 2016, $72,6825$.

Rao, J. N. S.; Raghunathan, R. Tetrahedron Lett. 2015, 56, 2276.

Sumesh, R. V.; Muthu, M.; Almansour, A. I.; Kumar, R. S.; Arumugam, S.; Athimoolam, S.; Prabha, E. A. J.; Kumar, R. R. ACS Comb. Sci. $2016,18,262$. Girgis, A. S.; Panda, S.S.; Aziz, M. N.; Steel, P. J.; Hall, C. D.; Katritzky, A. R. RSC Adv. 2015, 5, 28554.

Girgis, A. S.; Mabied, A. F.; Stawinski, J.; Hegazy, L.; George, R. F.; Farag, H.; Shalaby, E.; Farag, S. A. New J. Chem. 2015, $39,8017$.

George, R. F.; Panda, S. S.; El-Shalaby, A. M.; Srour, A. M.; Farag, I. S. A.; Girgis, A. S. RSC Adv. 2016, 6, 45434.

Girgis, A. S.; Panda, S. S.; Farag, I. S. A.; El-Shabiny A. M.; Moustafa, A. M.; Ismail, N. S. M.; Pillai, G. G.; Panda, C. S.; Hall, C. D.; Katritzky, A. R. Org. Biomol. Chem. 2015, 13, 1741.

Rao, J. N. S.; Raghunathan, R. Tetrahedron Lett. 2015, 56, 1539

Anis'kovl, A. A.; Kamneva, Y. I.; Zheleznova, M. A.; Yegorova, A. Y. Chem. Heterocyclic Comp. 2015, $51,709$.

Feng, G.-L.; Li, Y.; Geng, L.-J.; Zhang, H.-L.; Shi, Y.-J.; Wang, K.-F. Synth. Commun. 2015, 45, 1259.

Chakraborty, D.; Maity, A.; Jain, C. K.; Hazra, A.; Bharitkar, Y. P.; Jha, T.; Majumder, H. K.; Roychoudhury, S.; Mondal, N. B. Med. Chem. Commun. 2015, $6,702$.

Hazra, A.; Mondal, C.; Chakraborty, D.; Halder, A. K.; Bharitkar, Y. P.; Mondal S. K.; Banerjee, S.; Jha, T.; Mondal, N. B. Curr. Topics Med. Chem. 2015, $15,1013$.

Arumugam, N.; Almansour, A.; Kumar, R. S.; Menéndez, J. C.; Sultan, M. A.; Karama, U.; Ghabbour, H. A.; Fun, H. K. Molecules 2015, $20,16142$.

Kumar, R. S.; Almansour, A. A.; Arumugam, N.; Basiri, A.; Kia, Y.; Kumar, R. R. Aust. J. Chem. 2015, $68,863$.

Almansour, A. I.-; Arumugam, N.; Kumar, R. S.; Periyasami, G.; Ghabbour, H. A.; Fun, H. K. Molecules 2015, $20,780$.

Rajkumar, V.; Babu, S. A.; Padmavathi, R. Tetrahedron 2016, 72, 5578.

Poomathi, N.; Mayakrishnan, S.; Muralidharan, D.; Perumal, P. T. Tetrahedron Lett. 2015, 56, 721.

Kathirvelan, D.; Haribabu, J.; Reddy, B. S. R.; Balachandran, C.; Duraipandiyan, V. Bioorg. Med. Chem. Lett. 2015, $25,389$.

Bharitkar, Y. P.; Das, M.; Kumari, N.; Kumari, M. P.; Hazra, A.; Bhayye, S. S.; Natarajan, R.; Shah, S.; Chatterjee, S.; Mondal, N. B. Org. Lett. 2015, 17, 4440 .

Rajeswari, M.; Kumari, S.; Khurana, J. M. RSC Adv. 2016, 6, 9297.

Kaur, A.; Kaur, M.; Singh, B. J. Heterocyclic Chem. 2015, 52, 827.

Haddad, S.; Boudriga, S.; Akhaja, T. N.; Raval, N. P.; Porzio, F.; Soldera, A.; Askri, M.; Knorr, M.; Rousselin, Y. E.; Kubicki, M. M.; Rajani, D. New J. Chem. 2015, 39, 520.

Haddad, S.; Boudriga, S.; Porzio, F.; Soldera, A.; Askri, M.; Knorr, M.; Rousselin, Y.; Kubicki, M. M.; Golz C.; Strohmann, C. J. Org. Chem. 2015, 80, 9064.

Bharitkar, Y. P.; Kanhar, S.; Suneel, N.; Mondal, S. K.; Hazra, A.; Mondal, N. B. Mol. Divers. 2015, 19, 251.

Sun, J.; Chen, L.; Gong, H.; Yan, C.-G. Org. Biomol. Chem. 2015, 13, 5905.

Ponnuchamy, S; Sumesh, R. V.; Kumar, R. R. Tetrahedron Lett. 2015, 56, 4374

Dandia, A.; Singh, R.; Khan, S.; Kumari, S.; Soni, P. Tetrahedron Lett. 2015, 56, 4438.

Taghizadeh, M. J.; Javidan, A.; Keshipour, S. Chem. Heterocycl. Comp. 2015, 51, 467.

Mathusalini, S.; Arasakumar, T.; Lakshmi, K.; Lin, C.-H.; Mohan, P. S.; Ramnath, M. G.; Thirugnanasampandan, R. New J. Chem. 2016, $40,5164$.

Yu, B.; Sun, X.-N.; Shi, X.-J.; Qi, P.-P.; Zheng, Y.-C.; Yu, D.-Q.; Liu, H.-M. Steroids 2015, 102, 92.

Wang, Y.-M.; Zhang, H.-H.; Li, C.; Fan, T.; Shi, F. Chem. Commun. 2016, 52, 1804.

Al-As'ad, R. M.; El-Abadelah, M. M.; Sabri, S. S.; Zahra, J. A.; Awwadi, F. F.; Voelter, W. Monatsh Chem. 2015, $146,621$.

Dai, W.; Jiang, X.-L.; Wu, Q.; Shi, F.; Tu, S.-J. J. Org. Chem. 2015, 80, 5737.

Wang, C. S.; Zhu, R. Y.; Zheng, J.; Shi, F.; Tu, S. J. J. Org. Chem. 2015, 80, 512.

Yang, F.; Sun, Z.; Gao, H.; Yan, C. G. RSC Adv. 2015, 5, 32786.

Thirumala, P. P.; Krishnan, R.; Emanathan, G.; Doraiswamy, M. J. Chem. Sci. 2015, 127, 7.

Hu, W.-Q.; Cui, Y.-S.; Wu, Z.-J.; Zhang, C.-B.; Dou, P.-H.; Niu, S.-Y.; Fu, J.-Y.; Liu, Y. RSC Adv. 2015, 5, 70910.

Liu, F.-H.; Song, Y.-B.; Zhai, L.-J.; Lia, M. J. Heterocyclic Chem. 2015, 52, 322.

Hamzehloueian, M.; Yaghoub-Sarrafi, Y.; Aghaeib, Z. RSC Adv. 2015, 5, 76368.

Malathi, K.; Jeyachandran, V.; Kalaiselvan, K.; Kumar, R. R. Synth. Commun. 2015, 45, 503.

Gavaskar, D.; Suresh-Babu, A. R.; Raghunathan, R.; Dharani, M.; Balasubramanian, S. Steroids 2016, $109,1$.

Yang, W.-L.; Liu, Y.-Z.; Luo, S.; Yu, X.; Fossey, J. S.; Deng, W.-P. Chem. Commun. 2015, 51, 9212. 
(59) Conde, E.; Rivilla, I.; Larumbe, A.; Cossío, F. P. J. Org. Chem. 2015, 80, 11755

(60) Cayuelas, A.; Ortiz, R.; Nájera, C.; Sansano, J. M.; Larrañaga, O.; de Cózar, A.; Cossío, F. P. Org. Lett. 2016, $18,2926$.

(61) The general trend of 1,3-DC involving nitroalkenes is the formation of the exo-cycloadducts.

(62) Liu, T.; Li, Q.; He, Z.; Zhang, J.; Wang, C. Chin. J. Catal. 2015, 36, 68.

(63) Wu, Y.; Liu, H.; Zhang, L.; Sun, Z.; Xiao, Y.; Huang, J.; Wang, M.; Guo, H. RSC Adv. 2016, 6, 73547

(64) He, Z.-L.; Sheong, F. K.; Li, Q.-H.; Lin, Z.; Wang, C.-J. Org. Lett. 2015, 17, 1365.

(65) Vidadala, S. R.; Golz, C.; Strohmann, C.; Daniliuc, C. G.; Waldmann, H. Angew. Chem. Int. Ed. 2015, $54,651$.

(66) Yang, W.- L.; Li, C.-Y.; Qin, W.-J.; Tang, F.-F.; Yu, X.; Deng, W.-P. ACS Catal. 2016, 6, 5685.

(67) Arasasppan, H.; Thangamuthu, M. D. J. Heterocyclic Chem. 2016, 53, 313.

(68) The methodology consisting in a one-pot copper iodide mediated 1,3-DC of $O$-alkyl azides derived from salicylaldehyde with $O$-propargyl nitroolefin bonded to the glucose unit, followed by the described 1,3-DC of the thermally generated azomethine ylide, gave slightly better yields (74-81\%). Rao, J. N.S.; Raghunathan, R. Tetrahedron Lett. 2016, 56, 2669.

(69) Oliveira-Udry, G. A.; Repetto, E.; Vega, D. R.; Varela, O. J. Org. Chem. 2016, 81, 4179.

(70) Zhang, W. J.; Luo, X.; Meng, X.; Li, Z. Tetrahedron Lett. 2016, 57, 1981.

(71) Kudryavtsev, K. V.; Ivantcova, P. M.; Muhle-Goll, C.; Churakov, A. V.; Sokolov, M. N.; Dyuba, A. V.; Arutyunyan, A. M.; Howard, J. A. K.; Yu, C.-C.; Guh, J.-H.; Zefirov, N. S.; Bräse, S. Org. Lett. 2015, 17, 6178.

(72) Kudryavtsev, K. V.; Mantsyzov, A. B.; Ivantcova, P. M.; Sokolov, M. N.; Churakov, A. V.; Bräse, S.; Zefirov, N. S.; Polshakov, V. I. Org. Lett. 2016, 18, 4698.

(73) Usachev, S. A.; Popova, N. V.; Moshkin, V. S.; Sosnovskikh, V. Y. Chem. Heterocyclic Comp. 2015, $51,913$.

(74) Potowski, M.; Golz, C.; Strohmann, C.; Antonchick, A. P.; Waldmann, H. Bioorg. Med. Chem. 2015, $23,2895$.

(75) Buev, E. M.; Moshkin, A. S.; Sosnovskikh, V. Y. Tetrahedron Lett. 2015, 56, 6590

(76) Yang, W.; Guanyu, Q.; Honglei, L.; Lei, Z.; Zhanhu, S.; Yumei, X.; Hongchao, G. RSC Advances 2015, 5, 84290.

(77) Wang, C.-S.; Zhu, R.-Y.; Zhang, Y.-C.; Shi, F. Chem. Commun. 2015, 51, 11798.

(78) Mantenuto, S.; Cayuelas, A.; Favi, G.; Attanasi, O. A.; Mantellini, F.; Nájera, C.; Sansano, J. M. Eur. J. Org. Chem. 2016, 4144.

(79) Zhang, X.; Zhi, S.; Wang, W.; Liu, S.; Jasinskid, J. P.; Zhang, W. A. Green Chem. 2016, 18, 2642.

(80) Semenyuk, Y. P.; Kochubei, A. S.; Morozov, P. G.; Burov, O. N.; Kletskii, M. E.; Kurbatov, S. V. Chem. Heterocycl. Comp. 2015, $12,1881$.

(81) Swain, S. P.; Shih, Y.-C.; Tsay, S.-C.; Jacob, J.; Lin, C.-C.; Hwang, K. C.; Horng, J.-C.; Hwu, J. R. Angew. Chem. Int. Ed. 2015, 54, 9926.

(82) Ma, D.; Cheng, H.; Huang, C.; Xu, L. Tetrahedron Lett. 2015, 56, 2492.

(83) Costa, P. R. R.; Sansano, J. M.; Cossío, U.; Barcellos, J. C. F.; Dias, A. G.; Nájera, C.; Arrieta, A.; de Cózar, A.; Cossío, F. P. Eur. J. Org. Chem. 2015, 4689.

(84) Craven, P.; Aimon, A.; Dowa, M.; Fleury-Bregeot, N.; Guilleux, R.; Morgentin, R.; Roche, D.; Kalliokoski, T.; Foster, R.; Marsden, S. P.; Nelson, A. Bioorg. Med. Chem. 2015, 23, 2629.

(85) Xie, H.; Gong, B.; Zhong, X.; Cui, H.; Xiang, J. Chem. Heterocycl. Comp. 2016, 52:484

(86) Pavan-Kumar, C. S.; Harsha, K. B.; Sandhya, N. C.; Ramesha, A. B.; Mantelingu, K.; Rangappa, K. S. New J. Chem. 2015, $39,8397$.

(87) Cardoso, A. L.; Henriques, M. S. C.; Paixão, J. A.; Pinho e Melo, T. M. V. D. J. Org. Chem. 2016, 81, 9028.

(88) Laia, F. M. R.; Pinho e Melo, T. M. V. D. Synthesis 2015, 47, 2781.

(89) Vidadala, S. R.; Waldmann, H. Tetrahedron Lett. 2015, 56, 3358.

(90) Pathak, R. B.; Dobson, B. C.; Ghosh, N.; Ageel, K. A.; Alshawish, M.; Saruengkhanphasit, R.; Coldham, I. Org. Biomol. Chem. 2015, $13,3331$.

(91) Huang, P.-Q.; Lang, Q.-W.; Hu, X.-N. J. Org. Chem. 2016, 81, 10227.

(92) Buev, E. M.; Moshkin, V. S.; Sosnovskikh, V.Y. Org. Lett. 2016, 18, 1764

(93) Meng, J.; Wu, D.; Shi, Y.; Yu, X.; Deng, W.-P. Tetrahedron 2015, 71, 1074

(94) Ito, S.; Tokimaru, Y.; Nozaki, K. Angew. Chem. Int. Ed. 2015, 54, 7256

(95) Santos, H.; Distiller, A.; D’Souza, A. M.; Arnoux, Q.; White, J. M.; Meyer, A. G.; Ryan, J. H. Org. Chem. Front. 2015, $2,705$.

(96) Falkowska, E.; Tognetti, V.; Joubert, L.; Jubault, P.; Bouillon, J.-P.; Pannecoucke, X. RSC Adv. 2015, 5, 6864.

(97) Izquierdo, C.; Esteban, F.; García-Ruano, J. L.; Fraile, A.; Alemán, J. Org. Lett. 2016, 18, 92.

(98) Markitanov, Y. N.; Timoshenko, V. M.; Shermolovich, Y. G.; Mykhalchuk, V. L.; Grafova, I. A.; Grafov, A. V. Chem. Heterocycl. Comp. 2016, 52, 503.

(99) McAlpine, I.; Tran-Dube, M.; Wang, F.; Scales, S.; Matthews, J.; Collins, M. R.; Nair, S. K.; Nguyen, M.; Bian, J.; Alsina, L. M.; Sun, J.; Zhong, J.; Warmus, J. S.; O'Neill, B. T. J. Org. Chem. 2015, 80, 7266.

(100) Mancebo-Aracil, J.; Cayuelas, A.; Nájera, C.; Sansano, J. M. Tetrahedron 2015, 71, 8804

(101) Mancebo-Aracil, J.; Nájera, C.; Sansano, J. M. Tetrahedron: Asymmetry 2015, 26, 674

(102) Cayuelas, A.; Larrañaga, O.; Nájera, C.; Sansano, J. M.; de Cózar, A.; Cossío, F. P. Tetrahedron 2016, $72,6043$.

(103) Liu, H. C.; Liu K.; Xue, Z. Y.; He, Z. L.; Wang, C. J. Org. Lett. 2015, 17: 5440

(104) Liu, H.-C.; Tao, H.-Y.; Cong, H.; Wang, C.-J. J. Org. Chem. 2016, 81, 3752.

(105) Das, T.; Saha, P.; Singh, V. K. Org. Lett. 2015, 17, 5088.

(106) Liu, K.; Xiong, Y.; Wang, Z.-F.; Tao, H.-Y.; Wang, C.-J. Chem. Commun. 2016, 52, 9458

(107) Tang, L.-W.; Zhao, B.-J.; Dai, L.; Zhang, M.; Zhou, Z.-M. Chem. Asian J. 2016, 11, 2470.

(108) He, F.-S.; Zhu, H-; Wang, Z.; Gao, M.; Yu, X.; Deng, W.-P. Org. Lett. 2015, 17, 4988.

(109) Wang, Z.; Yu, X.; Tian, B.-X.; Payne, D. T.; Yang, W.-L.; Liu, Y.-Z.; Fossey, J. S.; Deng, W.-P. Chem. Eur. J. 2015, 21,10457

(110) Kimura, M.; Matsuda, Y.; Koizumi, A.; Tokumitsu, C.; Tokoro, Y.; Fukuzawa, S.-I. Tetrahedron 2016, $72,2666$.

(111) Very similar work using a chiral ferrocenyl-oxazoline-phosphine ligand with an imidazolium unit was reported. On it the study of its recyclability was an interesting task. Dai, L.; Xu, D.; Dong, X.; Zhou, Z. Tetrahedron: Asymmetry 2015, 26, 350. For enantioselective 1,3-DC with alkylidenemalonates with these copper(II)-ligand catalysts: Dai, L.; Xu, D.; Tang, L.-W.; Zhou, Z.-M. ChemCatChem $2015,7,1078$.

(112) Gerten, A. L.; Stanley, L. M. Org. Chem. Front. 2016, 339.

(113) Ponce, A.; Alonso, I.; Adrio, J.; Carretero, J. C. Chem. Eur. J. 2016, 22, 4952.

(114) Potowski, M.; Merten, C.; Antonchick, A. P.; Waldmann, H. Chem. Eur. J. 2015, 21, 4913.

(115) González-Esguevillas, M.; Pascual-Escudero, A.; Adrio, J.; Carretero, J. C. Chem. Eur. J. 2015, 21, 4561.

(116) Arpa, E. M.; González-Esguevillas, M.; Pascual-Escudero, A.; Adrio, J.; Carretero, J. C. J. Org. Chem. 2016, 81, 6128.

(117) Wang, H.; Deng, Q.; Zhou, Z.; Hu, S.; Liu, Z.; Zhou, L.-Y. Org. Lett. 2016, 18, 404.

(118) Chiral ferrocenyl-P,S-ligands was studied in these 1,3-DC: Han, F.-Z.; Yu, S.-B.; Zhang, C.; Hu, X.-P. Tetrahedron 2016, $72,2616$.

(119) Ugarriza, I.; Uria, U.; Reyes, E.; Carrillo, M. L.; Vicario, J. L. Asymmetric Catal. 2015, 2, 26.

(120) Tang, F.-F.; Yang, W.-L.; Yu, X.; Deng, W.-P. Catal. Sci. Technol. 2015, 5, 3568.

(121) Lauridsen, V. H.; Ibsen, L.; Blom, J.; Jørgensen, K. A. Chem. Eur. J. 2016, 22, 3259.

(122) Manjappa, K. B.; Peng, Y.-T.; Jhang, W.-F.; Yang D.-Y. Tetrahedron 2016, 72, 853.

(123) Mancebo-Aracil, J.; Nájera, C.; Castelló, L. M.; Sansano, J. M.; Larrañaga, O.; de Cózar, A.; Cossío, F. P. Tetrahedron 2015, $71,9645$.

(124) Gayen, B.; Banerji, A.; Dhara, K. Synth. Commun. 2016, 46, 293.

(125) Hunter, J.; Pask, C. M.; Sridharan, V. Tetrahedron Lett. 2016, 57, 2774

(126) Ohyama, T.; Uchida, M.; Kusama, H.; Iwasawa, N. Chem. Asian J. 2015, 10, 1850.

(127) Pandey, G.; Burugu, S. K.; Singh, P. Org. Lett. 2016, 18, 1558.

(128) Yamada, R.; Adachi, Y.; Yokoshima, S.; Fukuyama, T. Angew. Chem. Int. Ed. 2016, 55, 6067.

(129) Boudreault, J.; Lévesque, F.; Bélanger, G. J. Org. Chem. 2016, 81, 9247.

(130) Giampa, G. M.; Fang F. Brewer, M. Org. Lett. 2016, 18, 3952.

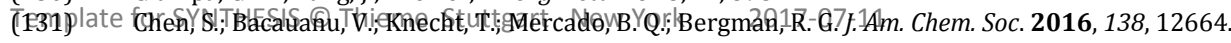


(132) Bakthadoss, M.; Srinivasan, J.; Vinayagam, V. Org. Biomol. Chem. 2015, 13, 2870

(133) Sugimoto, K.; Hoshiba, Y.; Tsuge, K.; Matsuya, Y. Synthesis 2016, 48, 1855.

(134) Xu, Y.; Liao, Y.; Lin, L.; Zhou, Y.; Li, J.; Liu, X.; Feng, X. ACS Catal. 2016, 6, 589.

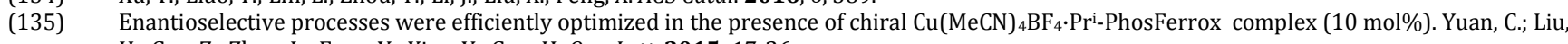
H.; Gao, Z.; Zhou, L.; Feng, Y.; Xiao, Y.; Guo, H. Org. Lett. 2015, 17, 26.

(136) Yavari, I.; Naeimabadi, M.; Hosseinpour, R.; Halvagar, M. R. A. Synlett 2016, 27, 2601.

(137) Li, F.; Chen, J.; Hou, Y.; Li, Y.; Wu, X. Y.; Tong, X. Org. Lett. 2015, 17, 5376. 